\title{
The TRIPS Article 31 Tug of War: Developing Country Compulsory Licensing of Pharmaceutical Patents and Developed Country Retaliation
}

\author{
Lucas Volman \\ Supervised by Professor Eoin O’Dell
}

This thesis was submitted in partial fulfilment of the requirement for the degree of the LL.M. Intellectual Property and Information Technology Law at the School of Law, The University of Dublin, Trinity College. 


\section{Declaration}

1) I declare that this thesis has not been submitted as an exercise for a degree at this or any other university and it is entirely my own work

2) I agree to deposit this thesis in the University's open access institutional repository and/or the LL.M Course Office or allow the library to do so on my behalf, subject to Irish Copyright Legislation and Trinity College Library conditions of use and acknowledgement.

3) I have read and I understand the plagiarism provisions in the General Regulations of the University Calendar for the current year, found at http://www.tcd.ie/calendar

4) I have also completed the Online Tutorial on avoiding plagiarism "Ready, Steady, Write", located at http://tcd-ie.libguides.com/plagiarism/ready-steady-write"

Signed: Lucas Volman

Date: 28 June 2018, Dublin 


\section{Acknowledgments}

First, I want to thank my dissertation supervisor, Eoin O'Dell, for the advice, support and pleasant exchanges over the course of writing my dissertation. Without his expert guidance the final product would have taken a different, much worse shape.

Second, I will never be able to thank my parents enough for being so wonderful and for giving me all the means to be where I am today. I am eternally grateful to them for instilling in me the values and ideals that helped shape my self and, by extension, my work. On that note, I want to also thank the rest of my family for the role they each played in making me who I am today.

Finally, I want to thank - in purely alphabetical order - some of my amazing friends, whose company I cherish and who have added to my life each in their own way. I truly hope each of them knows how much I appreciate them. In particular, I want to thank Anastasia, Manisha, Lauren, Lizzy and Shuhan for relentlessly supporting me ever since I have known each of them. I also want to thank Cedric, Joachim and Niels, for being with me since childhood and for the now decades of good times we have now shared. 


\section{Contents}

1. Introduction

2. Access to Medicines, the Patent System and Drug Prices: Issues of Global Concern

2.1 The human right to health: sources and obligations

2.2 Multilateral calls for increased action on health issues

2.3 Drug prices global and local ramifications

2.4 Attempts to address high drug prices

2.5 Justifications for and objections to pharmaceutical patent protection

2.6 The asymmetrical lobby: PhRMA \& the Special 301 Report

3. Compulsory Licensing under TRIPS Article 31

3.1 The TRIPS Agreement

3.2 Controversies in the pre-Doha Period: US, Canada, South Africa, Brazil

3.3 The Doha Declaration on TRIPS and public health

3.4 Compulsory \& government-use licences post-Doha

4. Voluntary and Compulsory Licensing of Pharmaceuticals: The Role of Compulsory Licensing Pressure

4.1 Voluntary licensing of pharmaceutical patents

4.2 Example of voluntary licensing: the Gilead Model

4.3 Discounts and 'voluntary' licences resulting from compulsory licensing pressure

4.4 Viability of compulsory licensing pressure in access to medicines strategies: a collective action alternative?

4.5 Medicine patent pools

5. 'Free' Trade Agreements and the Compulsory Licence: Restrictions to Legitimate Development Space Through TRIPS-plus Provisions

5.1 Free trade agreements as a vehicle for regulatory control

5.2 The Trans-Pacific Partnership

5.3 TRIPS-plus provisions in the ongoing EU-Mercosur FTA negotiations

5.4 Canada in the TPP renegotiation

5.5 FTA conclusions

6. Conclusion 


\section{Summary}

My dissertation places itself at the intersection of public health, intellectual property, and international trade, and in doing so, seeks to contribute to the vast scholarship surrounding an ever-contentious intellectual property mechanism: the compulsory licence over pharmaceutical patents to improve access to medicines. The central theme of the writing is the way in which the TRIPS Article 31 flexibility of compulsory licensing has been utilised by developing countries and resisted by developed countries since TRIPS came into force.

The discussion begins at the contextual level, by considering different contemporary matters in relation to access to medicines. Dual barriers to access - high drug prices and patents over pharmaceuticals - are considered in relation to the human rights obligations of states to attain the highest levels of health possible for their citizens. The justifications for strong patent protection in the pharmaceutical arena are critically evaluated to separate the needs of the pharmaceutical industry from discussions around the extent to which intellectual property flexibilities should be available to countries seeking to improve the health of their citizens.

Subsequently, the discussion turns to the utilisation and legitimacy of compulsory licensing under the TRIPS-Doha regime. Reference is made to several instances of compulsory licences in developing countries, as well retaliatory actions put in place by developed countries, particularly the US. Several case studies showcase the tactics utilised by the pharmaceutical industry and the countries which back it to discourage compulsory licensing in developing countries.

The compulsory licence is then considered in relation to a newer development, the voluntary licensing by the pharmaceutical industry. Despite this welcome development, I argue that compulsory licensing can still retain a place as a vehicle for improved access to medicines until the coverage of voluntary licensing expands to a sufficient degree.

Finally, my dissertation explores the ramifications of provisions commonly found in free trade agreements and smaller investment protection treaties for compulsory licensing and public health. These frequently constitute another layer of substantive and procedural hurdles for the issuance of compulsory licences in developing countries. TRIPS-plus clauses that provide for the evergreening of patents, investor-state dispute resolution, and national exhaustion are among those considered as detrimental to access to medicines and legitimate policy responses thereto. 


\section{Introduction}

Enormous strides have been made in the last hundred years in terms of improving the effectiveness of pharmaceutical products and healthcare services. ${ }^{1}$ Thanks to groundbreaking successes in combating diseases, the past century has seen the near-eradication of previously devastating diseases such as poliomyelitis, ${ }^{2}$ while general improvements in health have driven the average life expectancy throughout the world to previously unthinkable levels. ${ }^{3}$ Innovative, effective drugs have played and continue to play a crucial role in treating patients and preventing the spread of diseases. ${ }^{4}$ However, essential medicines and drugs are not available to all who need them, especially in countries with lower incomes. ${ }^{5}$ In the last few decades, the lack of universal access to medicines has become an urgent issue on a global scale, with up to a third of the world's population lacking access to essential medicines. ${ }^{6}$

Though the importance of improving the health of all people is broadly viewed as a noble goal, differences of opinion emerge when it comes to the approach that ought to be taken to reach it. Such divisions become especially apparent as soon as the relationship between access to medicines and intellectual property rights (IPR) is considered. On the one hand, the pharmaceutical industry and its supporters argue that strong patent protections for pharmaceuticals incentivise innovation and consequently allow new, beneficial products to be developed and brought to market. ${ }^{7}$ On the other hand, many commentators and other

\footnotetext{
${ }^{1}$ Carlos F Gomes, Mahmoud M Yasin, Yousef Yasin, 'Assessing Operational Effectiveness in Healthcare Organizations: A Systematic Approach' (2010) 23(2) International Journal of Health Care Quality Assurance 127, 130.

${ }^{2}$ Global Polio Eradication Initiative, History of Polio, <http://polioeradication.org/polio-today/history-of-polio/> accessed 26/05/2018.

${ }^{3}$ GBD 2013 Mortality and Causes of Death Collaborators, 'Global, regional, and national age-sex specific allcause and cause-specific mortality for 240 causes of death, 1990-2013: a systematic analysis for the Global Burden of Disease Study 2013' (2015) 385 Lancet 117, 117.

4 Bernard Munos, 'Lessons from 60 years of pharmaceutical innovation' (2009) 8 Nature Reviews in Drug Discovery 959, 967.

${ }^{5}$ World Health Organization, Health in 2015: from MDGs, Millennium Development Goals to SDGs, Sustainable Development Goals (2015) [hereinafter "Health in 2015 Report"], 60.

${ }^{6}$ Joint UN Programme on HIV/AIDS, Towards Universal Access: Scaling up priority HIV/AIDS interventions in the health sector (World Health Organisation, 2008), 5.

${ }^{7}$ Access to Medicine Foundation, Methodology for the 2018 Access to Medicine Index (September 22, 2017$), 6$.
} 
stakeholders contend that such protections may in fact constitute a barrier to access for many people if rigidly maintained, and that a more flexible approach is needed. ${ }^{8}$

Since the entry into force of the Agreement on Trade-Related Aspects of Intellectual Property Rights (TRIPS) ${ }^{9}$ - which introduced a global regime for intellectual property protection - issues surrounding access to medicines have become more relevant than ever before. Prior to TRIPS, patenting pharmaceuticals was primarily the preserve of rich, industrialised nations, as few developing countries authorised patents for pharmaceuticals. ${ }^{10}$ By requiring all countries wishing to accede to the World Trade Organization (WTO) to offer patent protection for any inventions and in all fields of technology, ${ }^{11}$ the TRIPS Agreement introduced patent protection for pharmaceuticals in countries that had previously not offered such protection. The expansion of patent protection on a global scale had access ramifications due to the monopoly prices that pharmaceutical companies could now set for patented drugs, but also in terms of limitations to the ability of many countries to produce, distribute, or obtain generic versions of medicines. ${ }^{12}$ As a result, while global health has unequivocally continued to improve since TRIPS, there have been ongoing issues of access to drugs under the TRIPS regime.

The TRIPS Agreement introduced different upward and downward flexibilities - such as the possibility of compulsorily licensing patents - to allow individual states some policy space to mitigate the potentially harmful impact of the new TRIPS rules in various arenas. ${ }^{13}$ Some of these flexibilities proved controversial when used by developing countries. Countries which circumvented patents by using the compulsory licensing regime in TRIPS Article 31 in response

\footnotetext{
${ }^{8}$ Nathan Ford, 'Patents, access to medicines and the role of non-governmental organisations' (2003) 1(2) Journal of Generic Medicines 137, 140; Frederick M Abbott, Jerome H Reichman, 'The Doha Round's Public Health Legacy: Strategies for the Production and Diffusion of Patented Medicines Under the Amended TRIPS Provisions' (2007) 10(4) Journal of International Economic Law 921, 927; Molly Land, 'Rebalancing TRIPS' (2012) 33(3) Michigan Journal of International Law 433.

9 TRIPS: Agreement on Trade-Related Aspects of Intellectual Property Rights, Apr. 15, 1994, Marrakesh Agreement Establishing the World Trade Organization, Annex 1C, 1869 U.N.T.S. 299, 33 I.L.M. 1197 (1994) [hereinafter "TRIPS Agreement or TRIPS"].

${ }^{10}$ Thomas Pogge, 'The Health Impact Fund: Better Pharmaceutical Innovations at Much Lower Prices' in Thomas Pogge, Matt Rimmer, Kim Rubenstein, Incentives for Global Health: Patent Law and Access to Essential Medicines (Cambridge University Press, 2010), 182.

${ }^{11}$ TRIPS Agreement, Art 27.1.

${ }^{12}$ Dianne Nicol, Olasupo Owoeye, 'Using TRIPS flexibilities to facilitate access to medicines' (2013) 91 Bulletin of the World Health Organization 533, 534.

${ }^{13}$ Land (2012), 439-441.
} 
to prohibitive drug prices faced continuous resistance in doing so from developed countries and the pharmaceutical industry. ${ }^{14}$ In recent years, the voluntary licensing of pharmaceuticals by pharmaceutical patent holders has increased in usage, while at the same time regional free trade agreements featuring intellectual property regulations that exceed the TRIPS Agreement have grown in scope and in number, generating novel issues for access to medicines. ${ }^{15}$ Both of these latter developments give rise to questions about the continued value of the compulsory licence as a tool to effect improvements for access to medicines.

This dissertation explores the merits of compulsory licensing and compulsory licensing threats in the face of a tightening regulatory landscape and changing industry practices. Chapter Two explores various themes which emerge in relation to access to medicines to contextualise the discussion that follows. Starting from an examination of the human right to health and resulting obligations for states, the discussion then turns to considering the impact and justifiability of high drug prices and patent monopolies as potential barriers to access, as well as two types of attempts to address drug prices, voluntary differential pricing of pharmaceuticals and price controls. The asymmetry between industry and civil society lobbies is also considered, in order to examine the industry's influence on international rulemaking and the foreign policy of the United States.

In Chapter Three the focus turns to the flexibilities built into TRIPS, particularly the Article 31 flexibility of compulsory licensing pharmaceutical patents. As will be shown, developing countries on occasion considered using this flexibility before 2001, which led to considerable backlash by developed countries. Most infamously, the dual cases of South Africa and Brazil led directly to the adoption in 2001 of a Declaration on TRIPS and Public Health, at the WTO Ministerial Conference in Doha. ${ }^{16}$ The Doha Declaration clarified the status of TRIPS flexibilities, but continued pressure by developed countries has meant that usage of these

\footnotetext{
${ }^{14}$ See Naomi A Bass, 'Implications of the TRIPS agreement for developing countries: pharmaceutical patent laws in Brazil and South Africa in the 21st Century' (2002) 34(1) The George Washington International Law Review 191, 207-215; Donald Harris, 'TRIPs after Fifteen Years: Success or Failure, as Measured by Compulsory Licensing' (2011) 18 Journal of Intellectual Property Law 367, 387-388.

${ }^{15}$ Carlos M Correa, 'Implications of bilateral free trade agreements on access to medicines' (2006) 84 Bulletin of the World Health Organization 399, 399-402.

${ }^{16}$ William W Fisher, Cyrill P Rigamonti, 'The South Africa AIDS Controversy: A Case Study in Patent Law and Policy' (2005) Harvard Law School: The Law and Business of Patents 1, 14-15.
} 
mechanisms has remained inconsistent in many developing countries ever since. ${ }^{17}$ In this document, this will be made evident by reference to Thailand, India, Indonesia and Colombia, where in several instances of compulsory licensing the US and other countries continued to apply pressure through multiple avenues despite the adoption of the Doha Declaration.

Chapter Four examines the relationship between compulsory licensing and the voluntary licensing that some pharmaceutical firms have begun using, in order to determine whether the former still has a role to play despite the existence of the latter. First, the growing phenomenon of voluntary licensing is explored as a strategy against compulsory licensing. The voluntary licence is, for the patent holder, far more appealing than a compulsory licence due various factors such as greater retained control and higher compensation. ${ }^{18}$ Drawing upon case studies from Brazil and Malaysia, in which compulsory licensing threats resulted in significantly discounted prices or voluntary licensing, it will be argued that for some countries the compulsory licensing threat can be an especially effective way of obtaining reduced drug prices. For countries lacking ability to effectively utilise compulsory licensing pressure on their own, it is suggested that coordination of efforts can be a powerful tool, although this is constrained by outside factors. A collective, voluntary alternative, the further development of patent pools for medicinal patents, is then considered.

The final Chapter places compulsory licences in the context of a growing body of international rules on intellectual property contained in bilateral and regional free trade agreements. Through reference to the provisions of two major transoceanic free trade agreements, ${ }^{19}$ it will be shown that developed countries seek to impose intellectual property norms exceeding the TRIPS Agreement through this type of agreement. The added constraints and burdens stemming from these provisions can significantly hamper the capacity of signatory developing countries to provide medicines to their citizens, as well as their ability to use TRIPS flexibilities,

\footnotetext{
17 E.g. Duncan N Matthews, 'TRIPS flexibilities and access to medicines in developing countries: the problem with technical assistance and free trade agreements' (2005) 11 European Intellectual Property Review 420, 420; see, however, more recent scholarship which suggests that TRIPS flexibilities have been used to a greater extent than previously thought: Ellen FM ' $\mathrm{t}$ Hoen et al, 'Medicine procurement and the use of flexibilities in the Agreement on Trade-Related Aspects of Intellectual Property Rights, 2001-2016' (2018) 96 Bull World Health Organ 185.

${ }^{18}$ Daniel D Kim, 'Voluntary Licensing of Pharmaceuticals: The Strategy against Compulsory Licensing' (2016) 8 Intellectual Property Brief 63, 80-82.

${ }^{19}$ The Trans-Pacific Partnership (TPP) prior to US withdrawal, and the EU-Mercosur FTA currently under negotiation.
} 
such as compulsory licensing, credibly and effectively. In so doing, the framework of international free trade agreements can be an effective vehicle for restricting the legitimate development space of lower-income countries wishing to make use of flexibilities recognised by international law to improve public health in their territory. ${ }^{20}$ It is then argued that further alliance building, both within lower-income regions and with congenial higher-income partners, may be required to combat the tightening of development space. Canada is identified as a candidate for alliance building.

${ }^{20}$ Robert $\mathrm{H}$ Wade, 'What strategies are viable for developing countries today? the World Trade Organization and the shrinking of 'Development Space' (2003) 10(4) Review of International Political Economy 621, 621-622. 


\section{Access to Medicines, the Patent System and Drug Prices: Issues of Global Concern}

\subsection{The human right to health: sources and obligations}

The right to health has long been recognised as an independent human right in international human rights law (IHRL), on par with other human rights such as the right to life and the right to freedom. ${ }^{21}$ The right to health appears in multiple international agreements and other international documents. The first reference to a 'right to health' stems from the Preamble to the Constitution of the World Health Organization (WHO), adopted in 1946, which proclaims that:

"[t]he enjoyment of the highest attainable standard of health is one of the fundamental rights of every human being without distinction of race, religion, political belief, economic or social condition."22

The 1948 Universal Declaration of Human Rights (UDHR), which was adopted unanimously by the General Assembly of the United Nations, affirms in Article 25 that:

"[e]veryone has the right to a standard of living adequate for the health and well-being of himself and of his family, including food, clothing, housing and medical care and necessary social services". ${ }^{23}$

The 1966 International Covenant on Economic, Social and Cultural Rights (ICESCR) further refines the UN position on a right to health. Article 12 of the Covenant provides a common formulation of the right to health:

"[t]he States Parties to the present Covenant recognize the right of everyone

to the enjoyment of the highest attainable standard of physical and mental health". ${ }^{24}$

\footnotetext{
${ }^{21}$ Alicia Ely Yamin, 'The Right to Health Under International Law and Its Relevance to the United States' (2005) 95(7) Am J Public Health 1156, 1156.

${ }^{22}$ World Health Organization Constitution 1946, Preamble.

${ }^{23}$ United Nations General Assembly, Universal Declaration of Human Rights, United Nations, 217 (III), 1948 [hereinafter "Universal Declaration of Human Rights"], Article 25.

${ }^{24}$ United Nations General Assembly, International Covenant on Economic, Social and Cultural Rights, International Covenant on Civil and Political Rights and Optional Protocol to the International Covenant on Civil and Political Rights, 16 December 1966, A/RES/2200, Article 12(1).
} 
Through these and subsequent international legal instruments that refer back to these, the right to health has to some degree been codified in international human rights law. ${ }^{25}$ Of course, in international law, customs and adherence play a significant role in dictating the normative value of this right in practice. ${ }^{26}$ Nevertheless, a clear majority of countries have ratified at least one treaty that includes some reference to the key elements of the right to health and can therefore be argued to have agreed to be bound by it. ${ }^{27}$ In light of this, there appears to be sufficient evidence to validate the existence of the right to health as part of the IHRL construct.

However, the human right to health must not solely be contemplated from an international human rights perspective. Some national legal regimes also enshrine the 'right to health' constitutionally. ${ }^{28}$ Additionally, even in the absence of a constitutionally recognised right to health, it may be possible for domestic courts to construe such a right on the basis of international instruments. ${ }^{29}$ The sources underpinning the human right to health can thus be said to stem from the IHRL framework, the work of various international bodies, as well as domestic constitutional documents and judicial interpretations at the national level. ${ }^{30}$

Some positive obligations in relation to the respect of the right to health may arise out of these doctrines for different bodies. In a 2017 report commissioned by the World Bank, Tasioulas explains that such obligations may well bind international, national and regional bodies on the basis that many of the UDHR and ICESCR provisions have become part of the body of universal customary international law or have directly been ratified by states. ${ }^{31}$ Such obligations, derived from interpretations of the international instruments, often include the

\footnotetext{
${ }^{25}$ Paul Hunt, 'The human right to the highest attainable standard of health: new opportunities and challenges' (2006) 100 Transactions of the Royal Society of Tropical Medicine and Hygiene 603, 604.

${ }^{26}$ Christopher C Joyner, International Law in the 21st Century: Rules for Global Governance (Rowman \& Littlefield, 2005), 12.

27 John Tasioulas, The Minimum Core of the Human Right to Health (2017) World Bank, 3-4.

28 S Katrina Perehudoff, Richard O Laing, Hans V Hogerzeil, 'Access to essential medicines in national constitutions' (2010) 88 Bulletin of the World Health Organization 800.

${ }^{29}$ Mary Ann Torres, 'The Human Right to Health, National Courts, and Access to HIV/AIDS Treatment: A Case Study from Venezuela' (2002) 3(1) Chicago Journal of International Law 105, 106; Hans V Hogerzeil et al, 'Is access to essential medicines as part of the fulfilment of the right to health enforceable through the courts?' (2006) 368 Lancet 305.

${ }^{30}$ Steven D Jamar, 'The International Human Right to Health' (1994) 22 SU L Rev 1, 17; Hogerzeil (2006), 305.

${ }^{31}$ Tasioulas (2017), 4.
} 
provision of 'essential primary health care' on a non-discriminatory basis, though the full range of obligations has not been defined. ${ }^{32}$

Access to medicines is one of the areas where the human right to health is engaged quite clearly, since the impossibility of obtaining certain drugs directly affects the health of individuals and populations. ${ }^{33}$ Moreover, the constitutions of some states specifically refer to access to medicines. ${ }^{34}$ It can also fall under definitions of 'minimum core' obligations that governments must respect for all their citizens. ${ }^{35}$ Although it has been argued that some such definitions may be overly broad because they include a plurality of other obligations as part of the minimum core, access to medicines features repeatedly as a crucial requirement for the attainment of the highest standard of attainable health. ${ }^{36}$ Moreover, recognising that governments have a duty to facilitate access to medicines does not require a broad conception of the right to health, since the link between medicines and their impact on ailments is quite clear and far less abstract than other potential obligations may be.

Additionally, questions surrounding a right to health and the obligations that can flow from it are not exclusively linked to access to medicines, which is merely one front in a broader debate on health and health-related policy. In fact, similar arguments have been made in several different contexts, which include tobacco control and packaging, ${ }^{37}$ but also the fight against overnutrition. ${ }^{38}$ The overarching signal, then, is that governments derive from international and national conceptions of a right to health certain obligations to provide for the health of their citizens.

\footnotetext{
32 Office of the High Commissioner for Human Rights, CESCR General comment No. 3: The Nature of States Parties' Obligations, Fifth Session of the Committee on Economic, Social and Cultural Rights (December 14, 1990), Para 10.

${ }^{33}$ Philippe Cullet, 'Patents and Medicines: The Relationship between TRIPS and the Human Right to Health' (2003) 79(1) International Affairs 139, 139.

${ }^{34}$ Perehudoff (2010), 800.

${ }^{35}$ Office of the High Commissioner for Human Rights, CESCR General Comment No. 14: The Right to the Highest Attainable Standard of Health (Art. 12), Twenty-Second Session of the Committee on Economic, Social and Cultural Rights (August 11, 2000).

${ }^{36}$ United Nations General Assembly, Right of everyone to the enjoyment of the highest attainable standard of physical and mental health, A/71/304 (August 5, 2016). For a discussion on the various definitions of 'minimum core obligations', see Tasioulas (2017), 5-10.

${ }^{37}$ Benjamin M Meier, Donna Shelley, 'The Fourth Pillar of the Framework Convention on Tobacco Control: Harm Reduction and the International Human Right to Health' (2006) 121 Public Health Reports 494.

${ }^{38}$ Mickey Chopra, Sarah Galbraith, Ian Darnton-Hill, 'A global response to a global problem: the epidemic of overnutrition' (2002) 80(12) Bulletin of the World Health Organization 952, 956.
} 


\subsection{Multilateral calls for increased action on health issues}

\section{a. 2015 Sustainable Development Goals}

In recent times there has been a renewed surge of pressure on governments and other stakeholders to achieve a high standard of health. In the Sustainable Development Goals (SDGs), which were adopted in 2015 after difficult intergovernmental negotiations, the third goal is dedicated to Health. ${ }^{39}$ The SDGs are an important driver in the discussions at both the international multilateral level and at the national level. SDG targets play an important in shaping policymaking at both levels, and much of discourse relating to Health has focused on achieving these targets ever since the new goals were adopted. ${ }^{40}$

In addition to re-energising the debates on how to achieve the attainment of high standards of health, the goal dedicated to health, SDG 3, sets several concrete health targets that governments must aim to meet by $2030 .{ }^{41}$ Some of these targets are directly relevant to issues of access to medicines. Target 3.8 relates to achieving universal health coverage and access to "safe, effective, quality and affordable essential medicines and vaccines for all". ${ }^{42}$ SDG 3.b sets out goals of supporting research and development of vaccines and medicines for the communicable and non-communicable diseases that primarily affect developing countries and providing access to affordable essential medicines and vaccines. ${ }^{43}$

Another ambitious target, listed under SDG 3.3, is to end the epidemics of AIDS, tuberculosis, malaria and neglected tropical diseases and combat hepatitis, water-borne diseases and other communicable diseases by $2030 .{ }^{44}$ These targets influence policy-making at the national level. For instance, the WHO has set out new ambitious targets for identifying and treating viral cases as part of its actions under SDG 3, which has led some countries and

\footnotetext{
${ }^{39}$ Sustainable Development Goal (SDG) 3, 'Ensure healthy lives and promote wellbeing for all at all ages' [hereinafter "SDG 3"] <https://sustainabledevelopment.un.org/sdg3> accessed 27/06/2018.

${ }^{40}$ See Health in 2015 Report; World Intellectual Property Organization Press Release, 'WIPO, WHO and WTO Directors General Pledge Further Cooperation on Innovation and Public Health' WIPO, February 27, 2018; World Trade Organization 2018, Mainstreaming trade to attain the Sustainable Development Goals (ITC/UNCTAD/WTO, 2018), 40-41.

${ }^{41}$ SDG 3, Targets 3.1-3d.

${ }^{42}$ SDG 3, Target 3.8 .

${ }^{43}$ SDG 3, Target 3b.

${ }^{44}$ SDG 3, Target 3.3.
} 
pharmaceutical companies to seek ways to bring expensive patented medicines to more patients, through various types of measures. ${ }^{45}$

The core obligations under a right to health and their concretisation as part of the SDGs can be financially burdensome for many low-income countries, since by WHO estimates even a basic package of health services for all would implicate significant costs per person. ${ }^{46}$ Due to their lack of financial capabilities, these countries may from a purely practical perspective be unable to adequately discharge minimum core obligations in relation to health. ${ }^{47}$ As a result, initiatives have been directed on the international stage towards identifying the misalignment of different policy areas touching access to medicines, and seeking ways to re-align them. ${ }^{48}$

\section{b. The UN High-Level Panel on Access to Medicines Report}

In November 2015, the Secretary-General of the United Nations, Ban Ki-moon, announced the creation of a High-Level Panel that would examine issues of innovation and access to technologies in the field of Health as part of the mandate set out in the SDGs. ${ }^{49}$ The HighLevel Panel reported on its findings in September 2016, to an overwhelmingly positive reception among developing countries, and a more mixed and at times negative reception by developed countries and representative bodies of the pharmaceutical industry. ${ }^{50}$ The report highlights that access to medicines has remained a major issue throughout the new millennium, thus adding to the renewed pressure that governments face to address barriers that affect access to medicines. ${ }^{51}$

The HLP report identifies several factors that restrict access to healthcare across the globe, some of which constitute barriers to access to medicines. ${ }^{52}$ High and rising prices of drugs

\footnotetext{
${ }^{45}$ Fifa Rahman, Shangeetha Thirumanyi, 'Making sense of the WHO international viral hepatitis targets strategising for concerted action' in Fifa Rahman (ed), At the edge of a miracle: the hepatitis C virus (HCV) in Malaysia (2017) Malaysian AIDS Council [hereinafter “Malaysian AIDS Council Report”], 12.

46 Olubayo Oluduro and Ebenezer Durojaye, 'The Normative Framework on the Right to Health under International Human Rights Law' in Ebenezer Durojaye (ed), Litigating the Right to Health in Africa: Challenges and Prospects (Routledge, 2016), 35.

47 John Tobin, The Right to Health in International Law (OUP, 2012), 240.

${ }^{48}$ United Nations High-Level Panel on Access to Medicines, Report of the United Nations Secretary General's High-Level Panel on Access to Medicines (United Nations, September 2016) [hereinafter "HLP Report"].

49 HLP Report, 3.

${ }^{50}$ See World Trade Organization, Intellectual Property Council debates access to medicines, November 8-9, 2016 $<$ https://www.wto.org/english/news e/news16 e/trip 08nov16 e.htm> accessed 16/06/2018.

51 HLP Report, 3.

52 HLP Report, 15-16.
} 
mean they are unaffordable to many, which causes disparities of access. Intellectual property rules can create further barriers by restricting who can produce and distribute protected drugs. ${ }^{53}$ Both of these factors had long been recognised in the literature as barriers to access, ${ }^{54}$ but the HLP report lends additional weight to these arguments.

\subsection{Drug prices: global and local ramifications}

Prices of medicines have soared in recent years, ${ }^{55}$ with pharmaceutical companies such as Pfizer, ${ }^{56}$ Gilead, ${ }^{57}$ and Teva ${ }^{58}$ announcing or enacting plans to increase prices of their drugs in developed countries. In many cases, rising prices are part of a longer-term upward trend. ${ }^{59}$ These price increases have at times been highly publicised and controversial, but the negative publicity has not deterred pharmaceutical companies from hiking prices of their drugs further, pushing them to levels unsustainable for many patients. Moreover, price increases have been especially marked in some patented medicines, as the exclusive rights offered by the patent system can allow the patent owner to set high prices in order to reap the benefits of their innovation without the fear of competitors producing generic versions of the same drug at much lower prices. ${ }^{60}$ The staggering increases in drug pricing raise concerns of access to medicines, as drugs are unaffordable to large portions of the populations that need them. ${ }^{61}$

\footnotetext{
53 Jillian C Cohen-Kohler, Lisa Forman, Nathaniel Lipkus, 'Addressing legal and political barriers to global pharmaceutical access: Options for remedying the impact of the Agreement on Trade-Related Aspects of Intellectual Property Rights (TRIPS) and the imposition of TRIPS-plus standards' (2008) 3 Health Economics, Policy and Law 229, 231-233.

${ }^{54}$ Ellen FM 't Hoen, 'TRIPS, Pharmaceutical Patents and Access to Essential Medicines: Seattle, Doha and Beyond' (2002) 3(1) Chicago Journal of International Law 39; Robert C Bird, 'Developing Nations and the Compulsory License. Maximizing Access to Essential Medicines While Minimizing Investment Side Effects' (2009) 37 Journal of Law, Medicine \& Ethics 209, 209.

${ }^{55}$ Brady Dennis, 'Prescription drug prices jumped more than 10 percent in 2015, analysis finds' The Washington Post January 11, 2016; Lydia Ramsey, 'We just experienced the largest rise in drug costs in 24 years' Business Insider, October 18, 2016; Truveris Press Release, 'Prescription Drug Prices Continue to Climb, Soaring $8.77 \%$ in Latest Truveris NDI Report' Truveris, May 10, 2017.

${ }^{56}$ Deena Beasley, 'Pfizer hikes U.S. prices for over 100 drugs on January 1', Reuters, January 9, 2016.

${ }^{57}$ Rebecca Robbins, 'Gilead hikes price of HIV therapies, other drugs by up to 10 percent' STAT News, July 1 , 2016.

${ }^{58}$ David Crow, Ilan Ben-Zion, 'Teva plans 'risky' price rise on US medicines' Financial Times, December 17, 2017.

${ }^{59}$ Daniel M Hartung et al, 'The cost of multiple sclerosis drugs in the US and the pharmaceutical industry'. (2015) 84(21) Neurology 2185, 2185.

${ }^{60}$ Kevin Outterson, 'Pharmaceutical Arbitrage: Balancing Access and Innovation in International Prescription Drug Markets' (2005) 5(1) Yale Journal of Health Policy, Law, and Ethics 193, 193-194.

${ }^{61}$ Mohga Kamal-Yanni, 'Hepatitis C drug affordability' (2015) 3(2) Global Health 73; Luis Sagaon-Teyssier et al, 'Affordability of adult HIV/AIDS treatment in developing countries: modelling price determinants for a better insight of the market functioning' (2016) 19 Journal of the International AIDS Society 1, 3.
} 
The barriers to access also disproportionately affect already vulnerable groups such as the less affluent and minorities. ${ }^{62}$

In light of the above, the pricing of pharmaceuticals has been the source of considerable controversy. The media and the public have latched onto some of the most egregious cases of pharmaceutical price gouging and public opinion has at times made those who implement such price increases social pariahs. ${ }^{63}$ Major spikes in the pricing of a single drug can occur for several reasons, including a new company buying the rights over the drug and pharmaceutical executives seeking to deliver quick profits to shareholders. This is coupled with the inaccurate notion that the cost of such increases will often be borne by insurance companies with deep pockets, and not financially affect patients themselves in any major way. ${ }^{64}$

Sudden major price increases certainly make for shocking headlines and are often the source of immediate public backlash against pharmaceutical companies. The trend of steady price inflation across the market for pharmaceuticals is however just as concerning from an access to medicines perspective and can have an insidiously detrimental effect on patients and health systems. The pervasive practice of smaller but consistent price increases means that over time a larger amount of drugs become unavailable to an increased percentage of the public, as the more limited public backlash leaves these price raises unchecked.

The nefarious effects of high drug costs present themselves in multiple ways at individual and institutional levels. Individuals faced with unaffordable drug prices will take measures to reduce the costs such as not completing courses of treatment. ${ }^{65}$ This is detrimental to the effectiveness of the drug and can lead to further deterioration of the individual's health, which adds to the burden faced by the health system. Even where such drastic steps are not taken, the individual and their family may undergo undue financial strain due to the high costs

\footnotetext{
${ }^{62}$ Angus Reid Report, Prescription drug access and affordability an issue for nearly a quarter of all Canadian households (Angus Reid Institute, July 2015), 2 [hereinafter "Angus Reid Report"].

${ }^{63}$ Zoe Thomas, Tim Swift, 'Who is Martin Shkreli - 'the most hated man in America'?' BBC News, August 4, 2017.

${ }^{64}$ See Cathy Schoen et al, 'How Health Insurance Design Affects Access To Care And Costs, By Income, In Eleven Countries' (2010) 29(12) Health Affairs 2323; Karen L Tang, William A Ghali, Braden J Manns, 'Addressing costrelated barriers to prescription drug use in Canada' (2014) 186(4) Canadian Medical Association Journal 276, 276.

${ }^{65}$ Aidan Hollis, Thomas Pogge, 'The Health Impact Fund: Making new medicines accessible for all' in Aidan Hollis, Thomas Pogge, The Health Impact Fund: Making New Medicines Accessible for All (Incentives for Global Health, 2008), 73.
} 
of drugs. ${ }^{66}$ The impact of this is not spread evenly across society, as vulnerable groups such as the elderly, minorities and the young face disproportionate financial burdens stemming from drug prices due to limited means or other discriminatory factors. ${ }^{67}$

In cases where the government institutions of a country are responsible for the procurement of drugs, high medicine prices will bring about heavier institutional burdens. Where the government oversees procurement of drugs, high prices for drugs may result in services of lesser quality being offered in other areas impacting access to medicines or health in general. ${ }^{68}$ Eventually, the increased public spending by the government as a result of high prices is shifted to the citizens through higher taxation or increases to public debt, which become necessary to support the higher public spending on drug procurement. ${ }^{69}$ Alternatively, in situations where healthcare costs are borne by insurance companies, the consumers themselves may eventually face higher insurance premiums as a result of costshifting on the part of the insurer, thus bringing the cost of high drug prices back to the consumers themselves. ${ }^{70}$

All these circumstances paint a similar picture wherein the costs of high drug prices eventually return to individuals in some form or another, whether as taxpayers or as customers of insurance companies. This has destructive effects on the individual health of patients, which can be enormous. Strained public budgets for health can become unsustainable if further stretched by rising drug prices. ${ }^{71}$ The repercussions of high drug prices on access are clear and operate both directly, in terms of access becoming unaffordable to many, and indirectly, by reducing the capacity of institutions to achieve access.

Price increases for pharmaceuticals are however not limited to the developed countries where drugs are often originally elaborated, as similar patterns of high priced drugs become

\footnotetext{
${ }^{66}$ Angus Reid Report, 8.

${ }^{67}$ Fabrizio Tediosi et al, 'Access to medicines and out of pocket payments for primary care: Evidence from family medicine users in rural Tajikistan' (2008) 8 BMC Health Services Research, 2.

${ }^{68}$ See Aaron Berman et al, 'Curbing Unfair Drug Prices: A Primer for States by the Global Health Justice Partnership' (2017) Global Health Justice Partnership Policy Paper, 9. The findings of this paper relate to the US, in countries with smaller health budgets the strain will be more severe.

69 Jon Sussex, Adrian Towse, Nancy Devlin, 'Operationalizing Value-Based Pricing of Medicines' (2013) PharmacoEconomics 1, 4.

70 lbid.

${ }^{71}$ Berman (2017), 9.
} 
apparent in low- and middle-income countries. ${ }^{72}$ In the face of the overwhelming portion of patients in lower income countries, the issues highlighted above become even more pronounced there. ${ }^{73}$ Therefore, although some generalities exist in terms of the drug pricing practices carried out by pharmaceutical companies in developing and developed countries, the situations of different countries can therefore not be considered equal.

Several factors can be drawn upon to explain the different impact of pharmaceutical price increases developed and developing countries. When it comes to access to medicines, part of the difference stems from the disparity in average income and spending power of person in each of these cases. The concepts of availability and affordability of medicines take up an entirely different meaning depending on the level of income of a person. For a person living on wages close to or below the poverty line, a drug might be entirely unaffordable at a much lower price if purchasing it will require them to make considerable sacrifices in other areas such as nutrition or shelter, which can also have further repercussions on health. ${ }^{74} \mathrm{~A}$ large majority of persons living below or slightly above the poverty line live in developing countries. ${ }^{75}$ These countries are therefore disproportionately affected by increases in the price of medicines, whether these are effected quickly or more slowly. A second factor that serves to further hinder access to medicines in developing countries is infrastructure. Several aspects of infrastructure influence access to medicines, such as the capacity to manufacture drugs in the country itself and having sufficiently developed physical and medical infrastructures for the drugs to easily reach those who need them. ${ }^{76}$

Moreover, a developing country's government will, in comparison to developed country counterparts, often lack bargaining power when negotiating with pharmaceutical

\footnotetext{
72 Marcela Fogaça Vieira, Gabriela Costa Chaves, The Patent Paradox in Brazil - implications for purchases of medicines by the public health system, Access IBSA (March 2018), 8.

${ }^{73}$ Bryan Mercurio, 'Resolving the Public Health Crisis in the Developing World: Problems and Barriers of Access to Essential Medicines' (2006) 5(1) Northwestern Journal of International Human Rights 1, 1.

${ }^{74}$ The World Bank currently sets the International Poverty Line at \$1.90. See World Bank, 'FAQs: Global Poverty Line Update' September 30, 2015 <http://www.worldbank.org/en/topic/poverty/brief/global-poverty-line-faq> accessed 27/06/2018; International Federation of Pharmaceutical Manufacturers \& Associations, The Pharmaceutical Industry and Global Health: Facts and Figures 2017 (February 2017), 32.

${ }^{75}$ World Bank, 'WDI 2017 Maps' <https://data.worldbank.org/products/wdi-maps> accessed 19/06/2018.

${ }^{76}$ Joia S Mukherjee et al, 'Antiretroviral Therapy in Resource-Poor Settings: Decreasing Barriers to Access and Promoting Adherence' (2006) 43(1) Journal of Acquired Immune Deficiency Syndromes 123, 123.
} 
companies. ${ }^{77}$ Major pharmaceutical companies have enormous financial capabilities, with turnovers that exceed the Gross National Product of many developing countries. ${ }^{78}$ This financial strength places the pharmaceutical companies in a strong negotiating position from the outset. In addition to this, a government with a population more gravely affected by a health crisis will have an acute need to engage with the manufacturer of a pharmaceutical product that can benefit its population. This is more commonly the case in developing countries, where the ability to provide adequate healthcare is often already limited by financial and infrastructural factors. Strictly speaking, the pharmaceutical manufacturer has no such need to engage in negotiations, as buyers for pharmaceutical products could be found elsewhere. These bargaining considerations play a part in shaping the relations between the pharmaceutical industry and developing country governments.

Due to the belief that market entry in a developing country will be unprofitable, the pharmaceutical company may at times prefer to entirely avoid bringing its drugs onto the market there, which restricts access. ${ }^{79}$ This does not occur to the same extent in developed country markets, where it is assumed that there is potential for profit. ${ }^{80}$ Additionally, in many cases diseases that are considered unprofitable due to the poverty of the majority of patients may receive insufficient investment, thus further limiting access. ${ }^{81}$

\subsection{Attempts to address high drug prices}

To address the disparity of pharmaceutical profitability in different countries, while simultaneously seeking to improve access to medicines in unfavoured countries by entering the market, industry actors at times operated differential pricing schemes. ${ }^{82}$ In other cases,

\footnotetext{
77 Patricia M Danzon, Adrian Towse, 'Differential Pricing for Pharmaceuticals: Reconciling Access, R\&D and Patents' (2003) 3(3) International Journal of Health Care Finance and Economics 183, 195.

${ }^{78}$ Angathevar Baskaran, Rebecca Boden, 'Globalization and the commodification of science' 42-72 in Mammo Muchie (ed), Globalization, Inequality and the Commodification of Life and Well-Being (Adonis \& Abbey, 2006), 58-59.

${ }^{79}$ Gavin Yamey, 'The world's most neglected diseases: Ignored by the pharmaceutical industry and by publicprivate partnerships' (2002) 325 BMJ 176, 176-177; Stefano Villa, Amelia Compagni, Michael R Reich, 'Orphan drug legislation: lessons for neglected tropical diseases' (2009) 24 International Journal of Health Planning and Management 27, 27.

${ }^{80}$ Donald W Light, 'Foreign free riders and the high price of US medicines' (2005) 331 BMJ 958, 958.

${ }^{81}$ Dieter Vanderelst, Niko Speybroek, 'Quantifying the Lack of Scientific Interest in Neglected Tropical Diseases' (2010) 4(1) PLoS Neglected Tropical Diseases, 1; HLP Report, 16.

82 David Henry, Joel Lexchin, 'The pharmaceutical industry as a medicines provider' (2002) 360 The Lancet 1590, 1594.
} 
governments have sought to control prices through price ceilings. ${ }^{83}$ Both differential pricing and price controls are discussed below, where it is argued that neither is, on its own, adequate to produce adequate access-related outcomes, although price controls may usefully support other types of measures.

\section{a. Differential Pricing}

Pharmaceutical companies have at times voluntarily put into effect differential pricing schemes for developing and developed markets. Such schemes aim to recoup the losses from low prices in developing countries through higher prices in developed country markets. ${ }^{84}$ The underlying rationales for this lie in the extraction of rent from low-income populations being morally unjustifiable and unnecessary, as these populations would generally not be able contribute much to recovering R\&D costs. ${ }^{85}$

Although some commentators have suggested that this practice should become more widespread to increase access to medicines, ${ }^{86}$ differential pricing can bring about several access issues of its own. Indeed, other commentators argue that pricing gaps of this type may cause parallel trade of pharmaceuticals to flourish between jurisdictions where the drugs are offered at different prices and that this could impact the profitability of the drug in the markets where the pharmaceutical company is looking to recoup the profits that it stands to lose by offering lower-priced drugs in developing country markets. ${ }^{87}$ If such parallel trade is left untouched, it is argued that it would threaten to not only undercut the effectiveness of voluntary differential pricing schemes that are already in place, but would also reduce the willingness of pharmaceutical companies to continue such schemes. ${ }^{88}$ However, Outterson's comprehensive analysis of pharmaceutical arbitrage, as this phenomenon is otherwise

\footnotetext{
${ }^{83}$ Margaret K Kyle, 'Pharmaceutical Price Controls and Entry Strategies' (2007) 89 Review of Economics and Statistics 88, 90.

${ }^{84}$ Outterson (2005), 195.

${ }^{85}$ Kevin Outterson, Nonrival access to pharmaceutical knowledge, January $3^{\text {rd }}, 2005$, Submission to the WHO Commission on Intellectual Property Rights, Innovation \& Public Health [hereinafter “Outterson WHO"], 1-2.

${ }^{86}$ Danzon (2003).

${ }^{87}$ Tommaso M Valletti, Stefan Szymanski, 'Parallel Trade, International Exhaustion and Intellectual Property Rights: A Welfare Analysis' (2006) 54(4) Journal of Industrial Economics 499, 499.

${ }^{88}$ See Harvey E Bale, 'The Conflicts between Parallel Trade and Product Access and Innovation: The Case of Pharmaceuticals' (1998) 1 Journal of International Economic Law 637.
} 
known, suggested that such fears are often overstated and can only rarely be observed empirically. ${ }^{89}$

Outterson's work in this area further suggests that the effectiveness of voluntary differential pricing schemes to provide drugs at the lowest marginal cost is limited and that other measures are therefore required to increase access to a sufficient degree. ${ }^{90}$ In some cases, the prices voluntarily offered by the pharmaceutical company under such schemes will continue to be well beyond the financial capabilities of the citizens in developing countries to whom they are offered. ${ }^{91} \mathrm{~A}$ further argument against differential pricing is that because only certain diseases and drugs are targeted, and since the schemes are limited to certain countries, they may not do enough to improve access to medicines. ${ }^{92}$ Additionally, differential pricing does not address capacity building for local production, which is an essential component of any long-term access strategy. ${ }^{93}$

\section{b. Price Controls}

In some cases, notably in India, the government in a country affected by price increases has responded by setting price controls. These aim to prevent pharmaceutical companies from setting high initial prices or increasing the prices beyond a certain level. ${ }^{94}$ Price controls can be effective in containing price increases in the short-term. ${ }^{95}$ In terms of access, however, ceiling price controls are flawed due to the detrimental effect they have on market entry. ${ }^{96}$

Price controls will in many cases discourage pharmaceutical companies from marketing their drugs in countries that operate them. ${ }^{97}$ This discouraging effect of price controls becomes more pronounced where the price controls are extensive, but it is also present for moderate

\footnotetext{
${ }^{89}$ Outterson (2005), 198.

90 Ibid, 197.

${ }^{91}$ Brenda Waning et al, 'Global strategies to reduce the price of antiretroviral medicines: evidence from transactional databases' (2009) 87 Bulletin of the World Health Organization 520, 525.

92 Outterson WHO, 4.

${ }^{93}$ Abbott (2007), 977-979.

94 Kyle (2007), 89.

95 John E Calfee, 'Pharmaceutical Price Controls and Patient Welfare' (2001) 134 Ann Intern Med 1060, 1063.

${ }^{96}$ Giuliano Russo, Barbara McPake, 'Medicine prices in urban Mozambique: a public health and economic study of pharmaceutical markets and price determinants in low-income settings' (2010) 25 Health Policy and Planning $70,80$.

97 Jean O Lanjouw, 'Patents, Price Controls and Access to New Drugs: How Policy Affects Global Market Entry' (2005) National Bureau of Economic Research Working Paper No. 11321, 1; Kyle (2007), 89.
} 
regulation of prices. ${ }^{98}$ Both the timing and the extent of new drug launches are negatively affected by the presence of price controls in a country, as research appears to indicate that pharmaceutical companies will strategically avoid or delay entering markets where pharmaceutical price controls are operated. ${ }^{99}$ However, recent economic research suggests that price controls can be useful to support other measures geared towards improving access, such as the compulsory licensing of pharmaceutical patents. ${ }^{100}$

In addition to being to the detriment of access through decreased market entry, some types of price controls may also face issues of legitimacy within the global trade framework contained in the General Agreement on Tariffs and Trade of the WTO. ${ }^{101}$ Under the principle of national treatment, goods that are imported by WTO members from other WTO member states must be afforded treatment no less favourable than their own goods receive. ${ }^{102}$ Price control lists frequently operate based on treating scheduled and unscheduled drugs differently - often including drugs or drug combinations that are patented elsewhere among the scheduled drugs, which could undermine arguments that rely on treatment being no less favourable than that afforded to national products. India, for example, uses different schedules for pricing under the Drug (Prices Control) Order 2013. ${ }^{103}$ In the current climate, where debates around trade protectionism are being bitterly waged on the international stage, ${ }^{104}$ these types of measures are liable to being viewed negatively and could further sour trade relations.

\subsection{Justifications for and objections to pharmaceutical patent protection}

Intellectual property protections are identified by the UN HLP report and NGOs as one of the factors that could prevent access to medicines. ${ }^{105}$ Governments have clear human rights

\footnotetext{
98 Lanjouw (2005), 17.

99 Kyle (2007), 95-97.

${ }^{100}$ Eric Bond, Kamal Saggi, 'Compulsory licensing, price controls, and access to patented foreign products' (2014) 109 Journal of Development Economics 217, 223.

${ }^{101}$ General Agreement on Tariffs and Trade, Annex 1A to the Final Act Embodying the Results of the Uruguay Round of Multilateral Trade Negotiations, Marrakesh, 15 April 1994 [hereinafter "GATT"].

102 Ibid, Art III.2

103 National Pharmaceutical Pricing Authority, Order S.O. 1039(E) (April 1, 2017).

${ }^{104}$ Roberta Rampton, Jean-Baptiste Vey, 'G7 agrees to fight protectionism as Trump threatens allies on trade' Reuters, June 9, 2018.

${ }^{105}$ HLP Report, 15-16. For NGO views see: Médecins sans Frontières, Oxfam Canada, Canadian HIV-AIDS Legal Network, Interagency Coalition on AIDS and Development, Canadian Council for International Cooperation, and Canadian Treatment Action Council, An Open Letter to All Members of Parliament (25 October 2001).
} 
obligations derived from the international agreements to which they are signatories. As shown, these obligations include the duty to preserve and improve the health of their citizens through their actions and policies and can include access to medicines more specifically. ${ }^{106}$ Pharmaceutical companies, on the other hand, derive self-centred concerns from their corporate nature. Although humanitarian motivations such as contributing to the improvement of health can certainly play a role in guiding their actions, the pursuit of profit for shareholders is often a primary driver for the actions of private pharmaceutical firms. ${ }^{107}$ As a result, the interests of governments and the pharmaceutical industry may in some cases clash. ${ }^{108}$ In circumstances of excessive drug prices, this can lead to conflict between the profitseeking pharmaceutical industry and governments which are taking action to ameliorate the health of their citizens.

Under the intellectual property regime introduced at the entry into being of the World Trade Organization in 1995, all countries wishing to join the WTO are required to provide protection for a range of intellectual property rights, and patent protection was extended to all forms of technology, including pharmaceuticals. ${ }^{109}$ Patents represent at their essence a monopolistic protection of inventions and incentivise innovation by delaying competitive imitation. ${ }^{110}$ Economically, their function is to allow technically useful, innovative products to be commercially successful by making profits above normal competitive rates possible under the monopoly conditions that are created. ${ }^{111}$ Patent owners are thus, under TRIPS, able to set monopoly prices over drugs due to the rights of exclusion that they are granted over the innovation claimed in their patent. This is based on the argument that this will spur further innovation. ${ }^{112}$ By giving owners of pharmaceutical patents the right to exclude others from developing medications covered by their patent, patent systems can add to the issue of

\footnotetext{
106 Tasioulas (2017), 5.

${ }^{107}$ Fred J Cohen, 'Macro trends in pharmaceutical innovation' (2005) 4 Discovery Medicine 78, 79.

${ }^{108}$ Christopher Gibson, 'A Look at the Compulsory License in Investment Arbitration: The Case of Indirect Expropriation' (2010) 25 American University Law Review 357, 419.

109 TRIPS Article 1.

${ }^{110}$ Frederic M Scherer, Industrial Market Structure and Economic Performance ( ${ }^{\text {nd }}$ edn, Rand McNally, 1980) cited in Ronald J Vogel, 'Pharmaceutical Patents and Price Controls' (2002) 24(7) Clinical Therapeutics 1204, 1205.

111 Vogel (2002), 1205.

112 Richard A Epstein and F Scott Kieff, 'Questioning the Frequency and Wisdom of Compulsory Licensing for Pharmaceutical Patents' (2011) 78(1) The University of Chicago Law Review 1, 2.
} 
highly-priced drugs. ${ }^{113}$ Competition from others, including manufacturers of generic versions of pharmaceuticals is in normal circumstances prevented for the period of patent protection, since this would constitute a patent infringement unless the patent owner grants permission. ${ }^{114}$

Pharmaceutical companies and their supporters frequently argue that strong patent protection is needed for pharmaceutical products. ${ }^{115}$ Though other arguments exist, their arguments are most frequently based on economic and legal premises. ${ }^{116} \mathrm{It}$ is argued that a pharmaceutical company which successfully produces a new drug will spend considerable resources on research and development (R\&D) for each of the drugs it produces. ${ }^{117}$ It must also take into account the financial costs for drugs which fail at either the R\&D stage or in later stages. ${ }^{118}$ These costs of drug development must be recovered somehow for the company to remain profitable. This, it is argued, is only possible by setting high prices which the patent protection enables. Moreover, it is argued that patent regimes give pharmaceutical investors the certainty that they need to invest significant resources into the processes of developing, manufacturing, and distributing drugs. ${ }^{119}$ If pharmaceutical companies will no longer be incentivised to innovate and invest its resources into the research and development of new drugs if this is not a profitable activity, this will have detrimental consequences for patients, as they will no longer be able to benefit from improved treatment. ${ }^{120}$

Despite these arguments, countervailing objections exist to challenge the arguments commonly brought forward by pharmaceutical companies and their supporters. Firstly, a distinction must be drawn between pharmaceutical goods and pharmaceutical knowledge.

\footnotetext{
113 Henry G Grabowski, 'Patents, Innovation and Access to New Pharmaceuticals' (2002) 5(4) Journal of International Economic Law 849, 856

114 Pogge (2010), 181.

115 Susan K Sell, 'The Quest for Global Governance in Intellectual Property and Public Health: Structural, Discursive, and Institutional Dimensions' (2004) 77 Temp L Rev 363, 373.

${ }^{116}$ Roberto Mazzoleni, Richard R Nelson, 'The benefits and costs of strong patent protection: a contribution to the current debate' (1998) 27 Research Policy 273, 275-279.

117 Epstein (2011), 5.

118 Joseph A DiMasi, Ronald W Hansen, Henry G Grabowski, 'The price of innovation: new estimates of drug development costs' (2003) 22 Journal of Health Economics 151, 158.

${ }^{119}$ International Federation of Pharmaceutical Manufacturers \& Associations, Export Manufacturing Exemption During SPC/PTR Extended Patent Term: Global Position, Policy Position (September 19, 2016).

${ }^{120}$ Iain Cockburn, Genia Long, 'The importance of patents to innovation: updated cross-industry comparisons with biopharmaceuticals' (2015) 25(7) Expert Opinion on Therapeutic Patents 739, 739-741.
} 
Pharmaceutical goods are rival, in that two people cannot take the same pill. On the other hand, pharmaceutical knowledge is non-rival, as sharing knowledge does not diminish the knowledge of others. ${ }^{121}$ Once R\&D costs are covered, non-rival use does not cause anything other than monopolistic profits to be lost for the company engaged in pharmaceutical research. ${ }^{122}$ It is therefore possible for pharmaceutical producers to license their intellectual property without it being to their detriment, whereas this could not be the case if their goods were being counterfeited.

A counterargument to the industry's ostensible reliance on high prices to recoup R\&D costs is that large parts of the costs of pharmaceutical companies are derived from marketing and other types of costs, rather than just R\&D. ${ }^{123}$ While exact percentages are not always disclosed, it is certain that in no cases the pharmaceutical company's full investment is in R\&D. ${ }^{124}$ Furthermore, there have been suggestions that strong patent IPRs for pharmaceuticals do not lead to increases in discovery of compounds that would justify the additional burdens that are brought about. ${ }^{125}$

Some have also argued that appropriation through intellectual property law is not the most efficient way to support pharmaceutical R\&D. ${ }^{126}$ Baker, Jayadev, and Stiglitz contend that markets consistently undersupply public goods such as pharmaceutical knowledge. ${ }^{127}$ They suggest that a variety of alternative ways exist for financing innovation and that providing the right incentives to it does not require a patent system of the current type. Centralised direct financing and de-centralised direct financing (i.e. through tax credits) are both possibilities that do not require the existence of patent monopolies but can still provide the necessary incentives and exist today in various contexts. ${ }^{128}$

\footnotetext{
121 Outterson WHO, 2.

122 Outterson (2005), 217.

${ }^{123}$ Marcia Angell, The Truth About Drug Companies: How They Deceive Us And What To Do About It (Random House, 2005), 51.

124 Joseph A Golec, John A Vernon, 'New Estimates of Pharmaceutical Research and Development Spending by US-based Firms from 1984 to 2003' (2007) 28 Managerial and Decision Economics 481.

${ }^{125}$ See Giovanni Dosi, Joseph E Stiglitz, 'The Role of Intellectual Property Rights in the Development Process, with Some Lessons from Developed Countries: An Introduction' (2013) LEM Working Paper Series, No. 2013/23. ${ }^{126}$ Outterson WHO, 1.

127 Dean Baker, Arjun Jayadev, Joseph E Stiglitz, 'Innovation, Intellectual Property, and Development: A better set of approaches for the 21st century.' AccessIBSA (July 2017), 11.

${ }^{128}$ Ibid, 11-12.
} 
It must also be noted that pharmaceutical innovators are frequently supported by public funding in performing their innovations. ${ }^{129}$ Where this is the case, strong IP protections are much more problematic if they restrict access to drugs for individuals. In such cases the public pays to help fund the company's research, effectively reducing the risk of undertaking that the company would otherwise face through public subsidy. This weakens arguments that rely on pharmaceutical companies' financial investment being the driver for innovation since the innovation is in part driven by public financing. Additionally, such use of public money may raise questions of accountability of the pharmaceutical producers to the public. ${ }^{130}$ The protestations of pharmaceutical companies against measures taken by governments in performance of their human rights duties in respect to health also become less justified. While it could be argued that only taxpayers in countries funding R\&D of drugs should be deriving the benefits from the innovations their money has funded, this would be inconsistent with the universality of health as a human right. ${ }^{131}$

Some commentators have suggested that since many essential medicines are not patented in developing countries, the lack of access to medicines stems not from patent systems but is rather a product of the poverty of the population of these countries. ${ }^{132}$ This view appears to be overly reductive for several reasons. While it is of course true that conditions of poverty play a key role in preventing access to medicines in developing countries, the monopolistic prices that result from the granting of patents over pharmaceuticals are a factor that compounds the general issues. ${ }^{133}$ Additionally, improving conditions of poverty to a sufficient degree takes decades, while many of the patients afflicted by serious diseases do not have that kind of time - if they cannot access medicines in the immediate future they will quite

\footnotetext{
${ }^{129}$ Donald W Light, 'Basic research funds to discover important new drugs: Who contributes how much?' in Mary Anne Burke (ed), Monitoring the Financial Flows for Health Research 2005: Behind the Global Numbers (Global Forum for Health Research, 2006), 35; Paolo Piergentili, 'Monopoly and public health in the medication market: The case of sofosbuvir' (2017) 13(3) Journal of Generic Medicines 131, 134.

130 MN Graham Dukes, 'Accountability of the pharmaceutical industry' (2002) 360 The Lancet 1682.

131 United Nations Committee on Economic, Social and Cultural Rights, Substantive issues arising in the implementation of the International Covenant on Economic, Social and Cultural Rights, E/C.12/2000/4 (11 August 2000), [1].

${ }^{132}$ Amir Attaran, 'How Do Patents And Economic Policies Affect Access To Essential Medicines In Developing Countries?' (2004) 23(3) Health Affairs 155, 155-156.

133 Jonathan Quick et al, 'Twenty-five years of essential medicines' (2002) 80(11) Bulletin of the World Health Organization 913, 914.
} 
simply die. ${ }^{134}$ Moreover, if developing countries were to show unwillingness to grant a patent for a certain pharmaceutical compound, the patent owner may refuse to enter the markets in those countries, which further harms access. Finally, some of the states which do not offer patent protection in their jurisdiction may not have the manufacturing capabilities of their own to produce the pharmaceuticals they need and therefore rely on importation from other states which do offer patent protection for those same drugs, thus returning to patentmonopoly issues. ${ }^{135}$

\subsection{The asymmetrical lobby: PhRMA \& the Special 301 Report}

The pharmaceutical industry dedicates a substantial amount of effort to ensuring that its interests are protected and that its voice is heard in various political arenas. ${ }^{136}$ Industry representatives, as obvious stakeholders in matters of access to medicines, have a considerable input in matters related to this topic. At both the national and international levels there are important lobbying activities by the pharmaceutical industry which influence policies and shape the discourse in this area. Through multiple channels, the pharmaceutical industry ensures that its economic and legal interests feature prominently in the discourse relating to health and access to medicines where global, regional and national rules and policies are being developed. ${ }^{137}$

Lobbying activities of the pharmaceutical industry manifest themselves in several ways in different arenas with influence over access to medicines policy. In multilateral organisations such as the WHO, representative bodies speak in favour of strong intellectual property protections on behalf of pharmaceutical companies, as well as conducting various lobbying activities in favour of stronger rights for pharmaceutical manufacturers. ${ }^{138}$

\footnotetext{
${ }^{134}$ Susan K Sell, 'Trips-plus free trade agreements and access to medicines' (2007) 28 Liverpool Law Review 41, 47.

135 Thomas A Haag, 'TRIPS Since Doha: How Far Will the WTO Go Toward Modifying the Terms for Compulsory Licensing?' (2002) $84 \mathrm{~J}$ Pat \& Trademark Off Soc'y 945, 947.

${ }^{136}$ Ken J Harvey et al, 'Will the Australia-United States free trade agreement undermine the pharmaceutical benefits scheme?' (2004) 181(5) MJA 256, 256.

${ }^{137}$ Patrick Bond, 'Globalization, pharmaceutical pricing, and South African health policy: managing confrontation with US firms and politicians' (1999) 29(4) International Journal of Health Services 765, 769; Mohamad Omar Gad, 'Impact of Multinational Enterprises on Multilateral Rule Making: The Pharmaceutical Industry and the TRIPS Uruguay Round Negotiations' (2003) 9 Law and Business Review of the Americas 667.

${ }^{138}$ International Federation of Pharmaceutical Manufacturers and Associations, IFPMA Statement at WHA 71 on agenda item 11.5 Addressing the global shortage of, and access to, medicines and vaccines (May 23, 2018).
} 
The authoritative role of the Association of Pharmaceutical Research and Manufacturers of America (PhRMA) in the process of drafting the annual US review of the state of IPR protection by US trading partners, which the Office of the United States Trade Representative (USTR) conducts in its Special 301 Report, is exemplary of the influence enjoyed by the pharmaceutical industry. ${ }^{139}$

The Special 301 is a unilateral process whereby the US identifies among its trading partners countries that deny "adequate and effective protection of intellectual property rights," 140 or deny "fair and equitable market access to United States persons who rely upon intellectual property protection", ${ }^{141}$ and places them on watch lists of differing degrees until their practices are satisfactorily reformed. ${ }^{142}$ The Special 301 provisions further require the USTR to place countries on a 'priority watch list' if their IP-related acts, practices, or policies are sufficiently onerous or egregious and have potential for a greatly adverse economic impact on the US. ${ }^{143}$ Of course, such a process is toothless unless accompanied by sanctioning powers. These are provided in 19 U.S. Code $\S 2411 .{ }^{144}$ The US Trade Representative is thereby provided with the authority to impose duties, import restrictions, or other measures for such time as are deemed appropriate. ${ }^{145}$

Interested parties are encouraged to make submissions on the fields in which they trade. The submissions of PhRMA carry considerable weight in deciding which countries are identified in these reports, with watch list and priority watch list recommendations from PhRMA frequently being included almost verbatim in Special 301 Reports. ${ }^{146}$ Civil society members also participate in the Special 301 process through their own submissions, but they face difficulties in competing with the organised, well-funded pharmaceutical lobby. ${ }^{147}$ The

\footnotetext{
139 Office of the United States Trade Representative, 2017 Special 301 Report (April 2017), 1.

14019 U.S.C. § 2242(a)(1)(A) (1988).

14119 U.S.C. $\S 2242(a)(1)(B)$.

142 Judith H Bello, Alan F Holmer, “'Special 301”: Its Requirements, Implementation, and Significance' (1989) 13(3) Fordham International Law Journal 259, 259.

14319 U.S.C. § 2242 (b)(1)(A)-(B).

14419 U.S.C. § 2411.

14519 U.S.C. § 2411 , (c)(1).

146 This is highlighted by a comparison of the submissions made by PhRMA in PhRMA, 'Pharmaceutical Research and Manufacturers of America (PhRMA) Special 301 Submission 2017', and the final report: Office of the United States Trade Representative, 2017 Special 301 Report (April 2017), 20-21.

147 Paul CB Liu, 'U.S. Industry's Influence on Intellectual Property Negotiations and Special 301 Actions' (1994) 13 UCLA Pac Basin LJ 87, 88-89; Peter Drahos, 'Negotiating Intellectual Property Rights: Between Coercion and Dialogue' (2002) 7 International Intellectual Property Law \& Policy 82-1, 82-2.
} 
asymmetry between the lobbying capabilities of industry and civil society with regard to the Special 301 Report has led some to criticise the Special 301 as "a public law devoted to the service of corporate interests" ${ }^{148}$

Unilateralism on trade from a global superpower with important trade links throughout the globe has repercussions on the rest of the world. In subsequent sections, it will be shown through case studies from multiple countries how the Special 301 mechanism is employed by the US as an effective deterrent for IP-related measures initiated by its trading partners. As the Special 301 Report is a review of IPR protection offered by all US trading partners, it will be shown how the US employs this mechanism to achieve its foreign policy goals on intellectual property, as dictated by US-based stakeholders. ${ }^{149}$

\footnotetext{
${ }^{148}$ Peter Drahos, John Braithwaite, Information Feudalism (Earthscan Publications, 2002), 89.

149 John Gero, Kathleen Lanna, 'Trade and Innovation: Unilateralism v. Multilateralism' (1995) 21 Canada-United States Law Journal 81, 94.
} 


\section{Compulsory Licensing under TRIPS Article 31}

\subsection{The TRIPS Agreement}

According to the UN High-Level Panel on Access to Medicines, the adoption in 1994 of the Agreement on Trade-Related Aspects of Intellectual Property Rights (TRIPS) "ushered in a new and unprecedented era of global intellectual property norms". ${ }^{150}$ As part of the body of Treaties negotiated at the time of the creation of the WTO, TRIPS sets out minimum IP protection standards that countries wishing to accede to the WTO must include in their national laws and to which they must adhere. ${ }^{151}$ Different IPRs are covered by the Agreement. Articles 27 to 38 are dedicated to patents and deal with topics including patentable subject matter, minimum terms of protection and rights conferred upon the patent holder. ${ }^{152} \mathrm{~A}$ full exploration of the many implications of TRIPS, political, economic, socio-economic and others, falls outside of the scope of this document. Nevertheless, a few points must be made concerning the impact of legal regime introduced by TRIPS to better understand its troublesome relationship with access to medicines.

In addition to introducing substantive provisions on intellectual property protection, the new regime under TRIPS significantly affected other areas. ${ }^{153}$ Indeed, the significance of the TRIPS Agreement also brought matters of intellectual property into the global framework for trade. ${ }^{154}$ Prior to the entry into force of TRIPS and the consequent expansion of intellectual property protections worldwide, many of the issues around expensive patented drugs were almost exclusively relevant to the most affluent regions of the world, as patent protections for pharmaceuticals were not offered in many countries. ${ }^{155}$ Due to the inclusion of intellectual property into the global trade framework, these issues came to bear relevance for all countries participating in global trade.

\footnotetext{
150 HLP Report, 7.

${ }^{151}$ Pascal Lamy, 'The Place of the WTO and its Law in the International Legal Order' (2007) 17(5) European Journal of International Law 969, 971-972.

152 TRIPS, Part II - Standards concerning the availability, scope and use of Intellectual Property Rights, Section 5: Patents.

153 Joseph S Papovich, 'NAFTA's Provisions Regarding Intellectual Property--Are They Working as Intended--A U.S. Perspective' (1997) 23(32) Canada-United States Law Journal 253, 254-255.

154 Joel R Reidenberg, 'Trade, TRIPS and NAFTA' (1993) 4(1) Fordham Intellectual Property, Media and Entertainment Law Journal 283, 283.

155 Pogge (2010), 182.
} 
Discussions around the TRIPS Agreement's overall impact on access to medicines have divided developed and developing countries. A body of literature which argues that the provisions of the TRIPS Agreement have had a detrimental impact on public health and development has been developed by commentators. ${ }^{156}$ In this body of work driven by developing country commentators, the stronger IP protections contained in TRIPS are regularly identified as generating additional barriers to access to medicines. ${ }^{157}$

It must also be emphasised that TRIPS arose out of the global power structures of the late $20^{\text {th }}$ century and embodies the dominant conception of intellectual property and knowledge of that time. ${ }^{158}$ This period saw Western industrialised nations in a dominant position, with a vacuum left elsewhere by the Soviet Union's dissolution. In recent decades, there has been rapid economic growth in other regions of the world, including Asia, South America and Africa. ${ }^{159}$ Countries within those regions - led by regionally influential players such as India, Brazil and South Africa - have increasingly sought to challenge the TRIPS status quo with their own conceptions of intellectual property in various fora as their influence grows. ${ }^{160}$ The ability of developing countries to project power has grown tremendously as a result of their economic growth, and was not at the same level when the WTO treaties were being negotiated. Thus, the regime that emerged from the negotiations was largely oriented towards the protection of developed country intellectual property interests. ${ }^{161}$

In the negotiations for the WTO, the US made an agreement containing strong intellectual property rights protections one of its top offensive priorities. ${ }^{162}$ Accordingly, the text of the TRIPS agreement draws heavily on the North American intellectual property context, with

\footnotetext{
156 See Nicol (2013), 533.

${ }^{157}$ Maria A Oliveira et al, 'Has the implementation of the TRIPS Agreement in Latin America and the Caribbean produced intellectual property legislation that favours public health?' (2004) 82(11) Bulletin of the World Health Organization 815; Alejandro Cerón, Angelina S Godoy, 'Intellectual property and access to medicines: an analysis of legislation in Central America' (2009) 87 Bulletin of the World Health Organization 787; Towhidul Islam, 'TRIPS Agreement of the WTO: Implications and Challenges for Bangladesh' (2011) 17 Int Trade Law Reg 10.

${ }^{158}$ Baker (2017), 6.

159 See Anthony P Thirlwall, Economic Growth in an Open Developing Economy: The Role of Structure and Demand (Edward Elgar, 2013), 7-10.

160 Laurence Helfer, 'Regime Shifting: The TRIPs Agreement and New Dynamics of International Intellectual Property Lawmaking' (2004) 29 Yale Journal of International Law 1, 2.

${ }^{161}$ Susan K Sell, 'TRIPS and the Access to Medicines Campaign' (2001) 20(3) Wisconsin International Law Journal 481, 481-482.

162 Catherine Field, 'Negotiating for the United States' in Jayashree Watal, Antony Taubman (eds), The Making of the TRIPS Agreement: Personal Insights from the Uruguay Round Negotiations (WTO, 2015), 132.
} 
numerous provisions similar to those found in the North American Free Trade Agreement, Chapter 17. ${ }^{163}$ However, as part of their acceptance of the TRIPS deal, developing countries were able to retain some flexibility in the implementation of the new comprehensive body of rules. ${ }^{164}$ Some of these flexibilities subsequently became vital to the development of situationally appropriate intellectual property approaches in low- and middle-income countries as part of their strategies for drug procurement. ${ }^{165}$

\section{a. Flexibilities under TRIPS}

The TRIPS Agreement retains some provisions designed to allow governments policy space in implementing the new rules on IPR protection contained in the Agreement. As a general flexibility, Article 1.1 provides that WTO members may implement stronger protections than the minimum standards set out in the Treaty. ${ }^{166}$ Cognizant of the potential barriers to public health that could arise from such a wide-ranging intellectual property agreement, negotiators also introduced some flexibilities with the specific aim of ensuring that governments would be able to respect their duties in relation to the human rights of their citizens, and particularly ensure public health. ${ }^{167}$ One such flexibility is present in Article 31 of TRIPS, where WTO members are given the right to introduce into their legislation measures that allow them to issue compulsory licences that override patents. ${ }^{168}$

In addition, TRIPS negotiators were at the time already aware of specific needs of least developed countries (LDCs) and included provisions to address their needs. LDCs were granted a grace period of 10 years from 1995 before implementation of the TRIPS rules was required. ${ }^{169}$ This grace period was later extended until 1 July 2021, or until countries are no longer considered LDCs. ${ }^{170}$ In granting such a grace period, the aim was to give developing countries time to change their legal systems to be in conformity with the new standard and

\footnotetext{
163 North American Free Trade Agreement, December 22, 1991, Chapter 17; Papovich (1997), 254

${ }^{164}$ Ruth L Gana, 'Prospects for Developing Countries Under the TRIPs Agreement' (1996) 29(4) Vanderbilt Journal of Transnational Law 735, 744; Baker (2017), 61.

165 Nicol (2013), 533.

166 TRIPS Agreement, Art 1.1.

${ }^{167}$ Lawrence Helfer, 'Pharmaceutical Patents and the Human Right to Health: The Contested Evolution of the Transnational Legal Order on Access to Medicines' in Terence Halliday, Gregory Shaffer (eds), Transnational Legal Orders (Cambridge University Press, 2014), 323.

168 Nicol (2013), 533.

${ }^{169}$ World Trade Organization, Responding to least developed countries' special needs in intellectual property, <https://www.wto.org/english/tratop_e/trips_e/ldc e.htm> accessed January 16, 2017.

170 lbid.
} 
develop a solid technological base ${ }^{171}$ It must be noted, however, that many developing and least-developed countries adopted TRIPS-compliant legislation on intellectual property well before the expiration of these deadlines. ${ }^{172}$

Developed countries are also encouraged in TRIPS Article 66.2 to introduce measures that incentivise and facilitate the transfer of technology to least-developed countries. ${ }^{173}$ This is consistent with the stated objectives of TRIPS contained in Article 7, which states that "[t]he protection and enforcement of intellectual property rights should contribute to ... the transfer and dissemination of technology ... in a manner conducive to social and economic welfare, and to a balance of rights and obligations". ${ }^{174}$ The requirement of incentivising and facilitating technology transfer to developing countries supports arguments on their behalf that the TRIPS flexibilities ought to be available to all countries.

\section{b. Compulsory Licences}

Compulsory licences are a legal mechanism whereby a government effectively 'breaks' the monopoly offered by the patent and restores competitive market conditions by giving licence to a specific party to produce the drugs over which the patent is held. ${ }^{175}$ Generally, nonvoluntary approaches to licensing have been used in cases where the patent holder failed to work the patent, or in cases where it was felt that the patent holder was abusing the patent monopoly. ${ }^{176}$ These types of licences have a long history and have been utilised by a number of countries. ${ }^{177}$ Due to their non-voluntary nature, they have been highly divisive, attracting both critics and supporters.

The focus of critics of the compulsory licensing mechanism is generally twofold. The first argument is economic at its base, since it revolves around the same concerns around

\footnotetext{
171 Ibid.

${ }^{172}$ Attaran (2004), 161.

173 TRIPS, Art 66.2.

174 TRIPS, Art 7.

175 Daniel R Cahoy, 'Breaking Patents' (2011) 32(3) Michigan Journal of International Law 461, 478 citing Thomas F Mullin, 'AIDS, Anthrax, and Compulsory Licensing: Has the United States Learned Anything? A Comment on Recent Decisions on the International Intellectual Property Rights of Pharmaceutical Patents' (2002) 9 ILSA J Int'I \& Comp L 185, 192.

176 Jerome H Reichman, Catherine Hasenzahl, 'Non-Voluntary Licensing of Patented Inventions: Historical Perspective, Legal Framework under TRIPS, and an Overview of the Practice in Canada and the U.S.A.,' (2003) UNCTAD-ICTSD Issue Paper No. 5, 10-11.

177 Ibid.
} 
innovation commonly found in debates around patents. ${ }^{178}$ These concerns have been dealt with to some degree above in relation to the patent system as a whole, but also in specific cases of compulsory licensing. Evidence-based studies however suggest that there little to no link between the use of compulsory licensing, and the readiness of pharmaceutical companies to later innovate. ${ }^{179}$ It has been suggested that the link between compulsory licensing and reduced innovation is only present where dual factors of a predictable licence and a significant market are also present. In their absence, only little measurable effect has been observed. ${ }^{180}$ In fact, evidence presented by Chien appears to suggest that innovation continued at the same, or increased pace for most of the pharmaceutical companies which owned the rights over a compulsorily licensed drug. ${ }^{181}$ Based on the evidence, therefore, the widely-held assumption that compulsory licensing will consistently harm innovation does not hold up to closer scrutiny.

A second common argument against compulsory licensing is a legal one, as some critics view the dilution of patent protections as a grave breach of patent law rules, that ought to be limited to cases of 'national emergency'. ${ }^{182} \mathrm{~A}$ precise reading of the relevant provisions of TRIPS, attempted below, should serve to dispel at least the myth that TRIPS compulsory licences will only be valid in health emergencies. The non-consensual nature of the mechanism, however, plays an especially important role in generating the discomfort that is felt by some scholars whenever the topic of compulsory licensing is broached, as it touches upon some of the foundational principles of the legal systems of many countries. ${ }^{183}$ Nevertheless, there are rationales for overriding the normal functioning of the patent.

Recognition that legal policy should be tailored to the public goods that it seeks to effect, and that international law has a role to play in bringing about global public goods is growing. ${ }^{184}$

\footnotetext{
178 Discussed above in Chapter Two.

${ }^{179}$ Frederic M Scherer, 'The Size Distribution of Profits from Innovation' (1998) Annales D'Économie et de Statistique. - No 49/50.

${ }^{180}$ Colleen Chien, 'Cheap Drugs at What Price to Innovation: Does the Compulsory Licensing of Pharmaceuticals Hurt Innovaton?' (2003) 18 Berkeley Tech L J 853, 879.

181 Ibid, 891-892.

182 Epstein (2011), 4.

${ }^{183}$ Robert P Merges, 'Intellectual Property Rights and Bargaining Breakdown: The Case of Blocking Patents', 62 Tennessee Law Review 75, 76-79.

${ }^{184}$ See Gregory Shaffer, 'International Law and Global Public Goods in a Legal Pluralist World' (2012) 23(3) The European Journal of International Law 669.
} 
The role of international law in this regard is apparent from the text of TRIPS Article 7, which, in full, states the following:

"[t]he protection and enforcement of intellectual property rights should contribute to the promotion of technological innovation and to the transfer and dissemination of technology, to the mutual advantage of producers and users of technological knowledge and in a manner conducive to social and economic welfare, and to a balance of rights and obligations." 185

Supporters of compulsory licensing as a way to improve access to medicines therefore take a different approach to the same issues than its critics. They argue that the public good which governments seek to effect through the issuance of compulsory licences is improved health for persons affected by a lack of access to medicines and, in their view, compulsory licensing falls within the sovereignty of all states to apply measures that can help achieve the public good of improved public health. ${ }^{186}$ By restoring competitive conditions upon removal ofn the patentee's right to exclusivity, the party which is licensed to produce and distribute the drugs can do so at a lower price than the monopoly price set by the patent owner, which ought to benefit patients who could otherwise not afford access to the drugs. ${ }^{187}$

While the economic necessities of the pharmaceutical developer are acknowledged, the realities of deficient access to drugs and consequent implications on the health of patients due to patent-enabled monopoly drug prices may supersede these - as allowing free riding in pharmaceutical innovations could bring about increased global welfare. ${ }^{188}$ Furthermore, there is an argument to be made for overriding property rights on a human rights basis. ${ }^{189}$ The right of all persons to the highest attainable standard of health, discussed in Chapter Two above, is central as a moral basis for this configuration, as are the corresponding obligations

\footnotetext{
${ }^{185}$ For an in-depth analysis of the provisions in TRIPS Article 7 and Article 8, see Alison Slade, 'The Objectives and Principles of the WTO TRIPS Agreement: A Detailed Anatomy' (2016) 53(3) Osgoode Hall Law Journal 948.

${ }^{186}$ Robert Weissman, 'Long, Strange Trips: The Pharmaceutical Industry Drive to Harmonize Global Intellectual Property Rules, and the Remaining WTO Legal Alternatives Available to Third World Countries' (1996) 17(4) University of Pennsylvania Journal of International Law 1069, 1075; Subhasis Saha, 'Patent Law and TRIPS: Compulsory Licensing of Patents and Pharmaceuticals' (2009) 91 J Pat \& Trademark Off Soc'y 364, 366. 187 John H Barton, 'TRIPS And The Global Pharmaceutical Market' (2004) 23(3) Health Affairs 146, 151.

${ }^{188}$ Frederick M Scherer, 'A Note on Global Welfare in Pharmaceutical Patenting,' (2002) Federal Reserve Bank of Philadelphia Working Paper No. 03-11.

${ }^{189}$ Michael A Santoro, 'Human Rights and Human Needs: Diverse Moral Principles Justifying Third World Access to Affordable HIV/AIDS Drugs' (2006) 31(4) North Carolina Journal of International Law and Commercial Regulation 923, 939-941. See also HLP Report, 16.
} 
of states to facilitate this for their citizens. In light of these obligations, the matter of compulsory licensing obtains a significant moral dimension, in addition to the justifications which can be derived from TRIPS Articles 7 and $8 .{ }^{190}$

Supporters of compulsory licensing, then, argue that the health interests of many can, in certain circumstances, justify overriding - subject to due limitations and procedures - the economic interests of the few. As will be shown below, compulsory licences under TRIPS are, as a mechanism, designed to effect this in a needs-based fashion, whereby the displacement of the patent holder's property rights is restricted to those situations where a particular precarity of access has been identified and due procedures have been followed. ${ }^{191}$ Overall, the compulsory licence is a legal solution to a legal barrier; it is typically used where the patent holder is refusing to utilise the patent or make the product available at affordable prices. ${ }^{192}$

As such, the limitation of patent rights through compulsory licensing can be an appropriate way to improve access to medicines, because the issues responded to are generated by the existence of the patent itself and the strictness of its enforcement. The common economic argument against compulsory licensing, namely that these licences would hinder innovation, has not been consistently proven. In fact, evidence-backed studies examining different periods of compulsory licensing appear to suggest that innovation is only hindered in a very limited subset of cases. ${ }^{193}$

\section{c. TRIPS Article 31 Provisions}

The TRIPS Agreement provides, in certain circumstances, for compulsory licences and it imposes several restrictions for these licences to be legitimate under WTO rules. Article 31 details the conditions under which WTO members may grant use of the subject matter of a patent without authorization of the rightsholder to government bodies or private third parties, provided their national law allows for compulsory use. ${ }^{194}$ For such use to be permitted under the TRIPS regime, Article $31 \mathrm{~b}$ requires prior negotiations to have been conducted to

\footnotetext{
${ }^{190}$ TRIPS, Article 7 (above), Article 8.1: "Members may ... adopt measures necessary to protect public health ... provided that such measures are consistent with the provisions of this Agreement."

${ }^{191}$ Sara M Ford, 'Compulsory Licensing Provisions Under the TRIPs Agreement: Balancing Pills and Patents' (2000) Volume 15(4) American University International Law Review 941, 959-960.

192 Bird (2009), 209.

${ }^{193}$ Scherer (1998); Chien (2003).

194 TRIPS, Art 31.
} 
obtain authorization from the rightsholder on reasonable commercial terms. ${ }^{195}$ However, it is not clarified in the text of TRIPS what 'reasonable commercial terms' amount to. The requirement of prior negotiations for authorization may be waived in cases of "national emergency and other circumstances of extreme urgency", or where the use is public and noncommercial. ${ }^{196}$ In each of these circumstances the rightsholder is to be informed as soon as reasonably practicable. Article $31 \mathrm{~h}$ provides that the rightsholder is to be paid 'adequate' remuneration, though once again no clarification is given as to what remuneration would be adequate for the purposes of the TRIPS Agreement. ${ }^{197}$

Other subsections of the same Article set out further restrictions to compulsory licences. Article 31c limits the scope and duration of their use to the purpose for which they are used. The use must also be non-exclusive and non-assignable per Article 31d and Article 31e. ${ }^{198}$ Article $31 \mathrm{f}$ limits the use geographically, as the use must be predominantly to supply the domestic market. ${ }^{199}$ The authorization for the use must end when the circumstances that led to it cease to exist and are unlikely to recur. ${ }^{200}$ Any compulsory licence must be subject to judicial review, as must be the decisions in relation to remuneration. ${ }^{201}$

Since it is not clear what would constitute 'reasonable' commercial terms, different countries may develop different conceptions of what is reasonable, which leaves room for interpretation and leads to differing approaches for breaking off negotiations with the rights holder. ${ }^{202}$ Similarly, there is no definition of adequate remuneration, although practice appears to indicate rates of remuneration far lower than market value. ${ }^{203}$

\footnotetext{
195 TRIPS, Art 31b.

196 Ibid. Note that the WTO clarifies that a national emergency is not a requirement for using a compulsory licence, see World Trade Organization, Compulsory licensing of pharmaceuticals and TRIPS <https://www.wto.org/english/tratop e/trips e/public health faq e.htm> accessed 13/06/2018.

197 TRIPS, Art 31h.

198 TRIPS, Art 31(d); TRIPS Art 31(e).

199 TRIPS, Art 31f. It was subsequently clarified by WTO Members that States without pharmaceutical capacity could be supplied through TRIPS flexibilities. See World Trade Organization, Amendment of the TRIPS Agreement, WT/L/641 8 December 2005, Decision of December 6, 2005.

200 TRIPS, Art 31g.

201 TRIPS, Art 31i; Art 31j.

202 Land (2012), 441.

203 World Health Organization, Remuneration Guidelines for Non-Voluntary Use of a Patent on Medical Technologies, (2005) Health Economics and Drugs TCM Series No 18, 19.
} 
Despite their existence as part of TRIPS, some have contended that compulsory licences have to date not been used to their fullest extent under the new regime, even though recent studies suggest that they appear to have been more common than was previously thought. ${ }^{204}$ Regardless, the extension in TRIPS of compulsory licensing to developing countries has been highly contentious throughout. ${ }^{205}$ In light of this, the following part is dedicated to identifying and examining two distinct post-TRIPS periods, separated by the Doha Declaration on TRIPS and Public Health. The period preceding the adoption in 2001 of the Doha Declaration is examined through the compulsory licensing-related controversies that arose and brought about that same Declaration. After inspection of the elements of the Doha Declaration, the period that followed its adoption is considered through reference to instances of continued interference by developed countries in spite of this document, and the implications that this has on compulsory licensing.

\subsection{Controversies in the pre-Doha Period: US, Canada, South Africa, Brazil}

\section{a. Anthrax Responses in the US \& Canada}

In the period immediately following the entry into force of the TRIPS Agreement several controversies and disputes related to intellectual property in the new TRIPS context were brought before the WTO Dispute Settlement Bodies. ${ }^{206}$ Some of these included developing countries which issued or planned to issue compulsory licences for pharmaceutical patents, and which faced substantial backlash from countries which were home to the patent-owning companies in question. The repercussions that were threatened by developed governments for such issuing included far-reaching threats of unilateral trade retaliation and the actuation of legal challenges. ${ }^{207}$ South Africa and Brazil were at the centre of two major disputes which pitted the developing country governments against the pharmaceutical industry and its developed-country backers. In the same period, the Canadian and US governments made use of compulsory licensing options to address public health concerns in their own countries. ${ }^{208}$

\footnotetext{
204 't Hoen (2018), 185.

205 Helfer (2014), 323-324.

206 Ford (2000), 949.

207 Amy Kapczynski, 'Harmonization and Its Discontents: A Case Study of TRIPS Implementation in India 's Pharmaceutical Sector' (2009) 97(6) California Law Review 1571, 1627.

208 The Economist, 'Patent problems pending' The Economist, October 25 $5^{\text {th }}, 2001$.
} 
This section first examines the situation that arose in the period between the entry into force of the TRIPS Agreement in 1994 and the adoption by WTO members of the Doha Declaration on TRIPS and Public Health in 2004. The South African and Brazilian IP-related disputes that arose in this period gained considerable amounts of publicity and serve as useful case studies to showcase the issues and agendas of different parties involved in these disputes. At the same time, these cases highlight the deep divides that exist between developing countries and developed countries on the topic of compulsory licensing of pharmaceuticals, in terms of both ideology and practices.

In October 2001, Canada signed a contract for the production of the drug ciprofloxacin - a treatment for serious forms of Anthrax - with companies other than the patent holder in response to public health threats caused by Anthrax outbreaks in the US which occurred in the same year. ${ }^{209}$ The patent belonging to the German pharmaceutical company Bayer was thus expropriated on tenuous grounds of public health interest - only a few dozen cases of Anthrax infection had appeared - with the Canadian government arguing that Bayer could not adequately supply the drug. ${ }^{210}$ The US government similarly threatened to issue compulsory licences to ensure a steady supply of drugs to combat Anthrax in $2001 .^{211}$

Beyond the protests of pharmaceutical companies directly involved, neither Canada nor the US faced backlash by the pharmaceutical industry or other governments to the same extent as will be described in the South African and Brazilian cases. ${ }^{212}$ A US Senator, Charles E Schumer, who was cited in newspapers at the time, summed up the situation for the US quite succinctly:

"I know there's concern about what the pharmaceutical industry thinks but we're in an emergency situation and everybody has to give."213

b. South Africa

\footnotetext{
209 Thomas F Mullin, 'AIDS, Anthrax, and Compulsory Licensing: Has the United States Learned Anything? A Comment on Recent Decisions on the International Intellectual Property Rights of Pharmaceutical Patents' (2002) 9 ILSA J Int'I \& Comp L 185, 201-202.

210 lbid.

211 Baskaran (2006), 55.

${ }^{212}$ Amy Harmon, Robert Pear, 'A nation challenged: the treatment; Canada overrides patent for Cipro to treat Anthrax' New York Times, October 19, 2001.

213 Ibid.
} 
The South African case arose as the African continent battled against the global HIV/AIDS pandemic. About two-thirds of the 36,2 million cases of HIV infection that had been identified at the time occurred in Sub-Saharan Africa. ${ }^{214}$ South Africa was hit especially hard by the pandemic, with over 4 million people there being infected by 2001 - the highest rate of infection in the world. The crisis directly affected almost 20 percent of the South African adult population, with devastating socioeconomic impact on those infected, their families, and their future children. ${ }^{215}$

Drugs that could significantly delay the onset of AIDS in HIV positive people were at the time being developed and patented by pharmaceutical companies. The high cost of these drugs according to some estimates the annual cost of the patented HIV/AIDS drugs in this period was $£ 6,700-£ 10,000$ - made these drugs unaffordable for developing country governments and most of their affected populations. ${ }^{216}$ While proposals were tabled to offer the drugs at reduced rates, even these prices were far beyond the financial capabilities of the South African government due to the vast size of its affected population. ${ }^{217}$

In response to the seriousness of the HIV/AIDS problem and the difficulty in procuring the necessary drugs at affordable prices, the South African government turned to the national emergency clause provided for in TRIPS. It made known its intention to introduce legislation that would allow the importation of cheap generic drugs to reduce the financial costs it was facing in combating the HIV/AIDS pandemic. ${ }^{218}$ The backlash from the pharmaceutical industry and its developed country backers was immediate and severe. Pharmaceutical companies reported issues with the South African legislation to the US, which threatened trade reprisals and placed South Africa on the Special 301 watch list as a country that might be close to contravening TRIPS. ${ }^{219}$

The South African government nevertheless decided to proceed with its plan of importing generic drugs and looked to India to provide these. Drugs produced by Indian generic drug manufacturer Cipla were offered at $£ 250$ a year, which was well below even the discounted

\footnotetext{
${ }^{214}$ Baskaran (2006), 55-56.

215 David Barnard, 'In the High Court of South Africa, Case No. 4138/98: The Global Politics of Access to Low-Cost AIDS Drugs in Poor Countries' (2002) 12(2) Kennedy Institute of Ethics Journal 159, 159-160.

216 Ibid, 163.

217 Baskaran (2006), 57.

218 Ford (2000), 950.

219 Office of the United States Trade Secretary, 1999 Special 301 Report (April 1999), 22.
} 
rates voluntarily offered by the pharmaceutical industry. ${ }^{220}$ In response, a consortium of 39 pharmaceutical companies filed a lawsuit against the South African government - with Nelson Mandela, as head of state, named specifically as a respondent - which alleged that South Africa was seeking to circumvent TRIPS rules. ${ }^{221}$ This lawsuit turned out to be a major political and public relations faux-pas by the participating pharmaceutical companies. The decision of these pharmaceutical companies to legally pursue a government embattled with a major health crisis resulted in enormous public outcry, which led to the legal challenge ultimately being withdrawn. ${ }^{222}$ Naming the popular South African President Nelson Mandela as a respondent, only served to augment the bad publicity. ${ }^{223}$ Unfortunately, the South African government failed subsequently to make use of the emergency powers introduced by its statute. $^{224}$

In addition to the pharmaceutical industry's challenge in the South African courts, the US exerted pressure on the South African government to repeal its law on pharmaceutical substances. ${ }^{225}$ It did so by including the following in the Development Assistance section of US Public Law 105-277:

"none of the funds appropriated under this heading may be made available for assistance for the central Government of the Republic of South Africa, until the Secretary of State reports in writing to the appropriate committees of the Congress on the steps being taken by the United States Government to work with the Government of the Republic of South Africa to negotiate the repeal,

\footnotetext{
220 Baskaran (2006), 58.

221 Barnard (2002), 159; 't Hoen (2011), 3.

222 Barnard (2002), 161.

${ }^{223}$ Pharmaceutical Manufacturers' Association of South Africa and others v. The President of the Republic of South Africa the Honourable Mr. N.R. Mandela and Others, Case no. 4183/98, High Court of South Africa (Transvaal Provincial Division).

224 Barnard (2002), 161.

225 Specifically, the US was concerned with South Africa's Medicines and Related Substances Control Amendment Act No. 90 of 1997, s15(c). See Charan Devereux, Robert Z Lawrence, Michael D Watkins, Case Studies in US Trade Negotiation Volume 1: Making the Rules (Columbia University Press, 2006), 83; Carlos M Correa, 'Implications of the Doha Declaration on the TRIPS Agreement and Public Health' (2002) WHO Health and Economics and Drugs EDM 12, 1.
} 
suspension, or termination of section 15(c) of South Africa's Medicines and

Related Substances Control Amendment Act No. 90 of 1997."226

Though the US is free under its national laws to introduce provisions such as the above, the intent is clear; either the South African government amends its national legal framework to comply with the US request, or any funds dispensed by the US for development assistance to developing countries are withheld from it regardless of South Africa's period of health crisis. $^{227}$

\section{c. The Brazil-US 2001 WTO Dispute}

The other major example of the controversies that arose under the new TRIPS regime is the dispute between the US and Brazil concerning Brazil's national law on intellectual property. Here, in slightly different fashion to the South African case, it was the US government, rather than the pharmaceutical industry, which took the lead in bringing its challenge against Brazil's approach to the compulsory licensing of pharmaceutical patents, though it was influenced in doing so by the American pharmaceutical industry. ${ }^{228}$ In this case, the US did not limit itself to bilateral action for bringing Brazil to task, but went as far as to file a complaint against Brazil within the WTO dispute resolution framework. ${ }^{229}$

Brazil had adopted a policy of guaranteeing universal and free access to antiretrovirals (ARVs) to people living with HIV/AIDS in $1996 .{ }^{230}$ Under this policy, the Brazilian Ministry of Health fully subsidised the drugs to be provided to its citizens as part of its HIV/AIDS programmes. It did so in response to rapidly-increasing numbers of people living with HIV/AIDS, and the death rate of around 50\% encountered by these people in Brazil in the period 1980-2001. ${ }^{231}$ The reduction in mortality through this policy was significant, as were the improvements of quality

\footnotetext{
${ }^{226}$ US Public Law 105-277 (105th Congress, 1999), Title II - Bilateral Economic Assistance, Development Assistance.

227 Ibid, referring to a figure of $\$ 1,225,000,000$.

228 Pharmaceutical Research and Manufacturers of America, PhRMA Applauds USTR Action Against Argentina and Brazil, Press Release May 1, 2000; see also Paul Champ, Amir Attaran, 'Patent Rights and Local Working Under the WTO TRIPS Agreement: An Analysis of the U.S.-Brazil Patent Dispute' (2002) 27(2) Yale Journal of International Law 365, 380.

${ }^{229}$ Reed Beall, Randall Kuhn, 'Trends in Compulsory Licensing of Pharmaceuticals Since the Doha Declaration: A Database Analysis' (2012) 9(1) PLoS Med, 2.

230 Paulo R Teixeira, Marco A Vitória, Jhoney Barcarolo, 'The Brazilian Experience in Providing Universal Access to Antiretroviral Therapy' in Jean-Paul Moatti et al (eds), Economics of AIDS and access to HIV-AIDS care in developing countries: issues and challenges (ANRS, 2003), 76.

231 Jane Galvão, 'Access to antiretroviral drugs in Brazil' (2002) 360 The Lancet 1862, 1862.
} 
of life for Brazilian people living with HIV/AIDS. ${ }^{232}$ Just as significant, however, were the increases in government spending on drug procurement and distribution as a result of the policy and the growing population of people living with HIV/AIDS in Brazil. ${ }^{233}$

As part of its WTO obligations, Brazil had introduced laws to make its internal intellectual property regime compliant with TRIPS in May 1996. ${ }^{234}$ Provisions in the new Brazilian law established a 'local working' requirement, which stipulated that patents would be subject to compulsory licensing if the patented subject matter was not 'worked' in Brazil's own territory. ${ }^{235}$ This enabled local firms to challenge patents if evidence was brought forward that these patents were not being employed by the patent holder in Brazil. ${ }^{236}$

In May 2000, the US government brought a complaint against Brazil within the WTO Dispute Settlement framework, alleging that the provisions on local working in the Brazilian law violated the TRIPS Agreement. Specifically, it was alleged that Articles 27 and 28 of TRIPS which deal with patentable subject matter, and rights conferred on the patent owner, respectively - were violated by Brazil's new intellectual property legislation, on the basis that they would allow for discrimination between locally-granted and imported products. ${ }^{237}$

A panel was established to hear the dispute and bring about consultations between the governments of Brazil and the US, but in bilateral consultations with Brazil a settlement was reached to resolve the dispute before the case could be decided. ${ }^{238}$ As part of the settlement, Brazil agreed to first consult with the US where it planned to issue a compulsory licence for a US company's pharmaceutical patent in exchange for the US withdrawing its WTO complaint. $^{239}$

The difference of responses to developed country and developing country compulsory licensing shows the unfairness that was present in the application of TRIPS clauses in this

\footnotetext{
232 Ibid, 1862-3.

${ }^{233}$ Ellen FM 't Hoen et al, 'Driving a decade of change: HIV/AIDS, patents and access to medicines for all' (2011) 14 Journal of the International AIDS society 1, 3-4.

234 Law No. 9.279 of May 14, 1996 (Law on Industrial Property).

235 World Trade Organization, DS199: Brazil - Measures Affecting Patent Protection.

${ }^{236}$ Omar Serrano, Mira Burri, 'Making use of TRIPS flexibilities: Implementation and diffusion of compulsory licensing regimes in Brazil and India' (2016) World Trade Institute, NCCR working paper 2016/1, 8.

${ }^{237}$ Champ (2002), 367.

238 Ibid.

239 Manisha A Desai, 'Compulsory licensing: Procedural requirements under the TRIPS Agreement.' (2016) 18(1-

4) Pharmaceuticals Policy \& Law 31, 37.
} 
period. The South African and Brazilian cases highlight the stark contrast that existed at the time between the Global North and the Global South regarding pharmaceutical compulsory licensing. Northern countries such as the US and Canada were able to issue or threaten to issue compulsory licences for pharmaceuticals while facing few, if any, repercussions. Attempts to do the same in countries from the Global South were met with immediate retaliation. South Africa faced trade reprisals by the US and domestic challenges to its laws by the pharmaceutical industry. In the Brazilian case, actual steps were taken within the WTO framework by the US, which had engaged in the same practices in that same period. The double standard here was both clear and problematic, and an urgent fix was required for the entire TRIPS regime not to appear farcical. ${ }^{240}$

\subsection{The 2001 Doha Declaration on TRIPS and Public Health}

The issues around compulsory licensing of pharmaceutical patents that appeared in the wake of the TRIPS Agreement entering into force threatened to widen existing rifts in the international establishment. ${ }^{241}$ This quickly became a central concern of policymakers on the international stage. ${ }^{242}$ Developing countries were unhappy that their initiatives aiming to improve the health of their citizens were being put in jeopardy by developed countries' economic arguments. Meanwhile, developed countries - particularly the US - were concerned that the proliferation of compulsory licensing in developing countries would harm their pharmaceutical industry and hurt innovation. ${ }^{243}$ The responses to South Africa and Brazil's laws, and the near simultaneous practices of the US and Canada in the Anthrax crisis, meant that there was a perception of systematic unfairness of the application of TRIPS rules. ${ }^{244}$ This state affairs required urgent measures to avoid the worsening of tensions and to prevent a repeat of the US-Brazil debacle. A breakthrough on the matter was made at the WTO Ministerial Conference of 2001 in Doha. At the Conference, parties adopted a Declaration on the TRIPS Agreement and Public Health, wherein the participating

\footnotetext{
240 Beall (2012), 2.

${ }^{241}$ Haochen Sun, 'The Road to Doha and Beyond: Some Reflections on the TRIPS Agreement and Public Health' (2004) 151 European Journal of International Law 123, 131-134.

${ }^{242}$ Cullet (2003), 139.

243 See Office of the United States Trade Representative, 2001 Special 301 Report (May 2001), 19.

${ }^{244}$ Correa (2002), 3.
} 
governments reaffirmed the importance of implementing and interpreting TRIPS in a manner that supports public health. ${ }^{245}$

In the seven paragraphs of the Doha Declaration, the parties to the Conference made several clarifying statements on the relationship between the TRIPS Agreement and public health considerations. The first four paragraphs of the Declaration are preambular in nature and set out the context the Declaration was formed in. ${ }^{246}$ In recognition of the grave public health difficulties affect developing countries in the Declaration, WTO Members stress in Paragraph 2 of the Doha Declaration the need for TRIPS to be part of actions to address these concerns. ${ }^{247}$ Paragraph 4 then states that TRIPS should not prevent members from taking measures to protect public health and that implementation and interpretation of TRIPS should allow WTO members to protect the health of their citizens and promote access to medicines. ${ }^{248}$

The Declaration subsequently reaffirms the right of WTO members to use TRIPS flexibilities. Paragraph 5 clarifies which flexibilities are recognised for the purposes of the declaration. Importantly, the Declaration includes here the granting of compulsory licences, the freedom of each member to determine what is a national emergency, and the freedom of each member to establish its own regime of exhaustion of intellectual property rights as flexibilities available. ${ }^{249}$ Additionally, the flexibilities include customary rules of interpretation of public international law when applied to TRIPS. In Paragraph 6, the Doha Declaration broaches the topic of resolving the problem of countries that lacked manufacturing capacities in the pharmaceutical sector and could therefore face difficulties in making effective use of compulsory licensing under the TRIPS Agreement. ${ }^{250}$

The Doha Declaration primarily represents an affirmation at ministerial level of the principles that are meant to guide the implementation and interpretation of the TRIPS Agreement. ${ }^{251}$ Thus, the Doha Declaration played a role in bringing the status quo under TRIPS to be more

\footnotetext{
245 World Trade Organization, Doha Declaration on the TRIPS Agreement and Public Health, WT/MIN(01)/DEC/W/2, 14 November 2001 [hereinafter "Doha Declaration"].

${ }^{246}$ Correa (2002), 5.

247 Doha Declaration, Para 2.

248 Ibid, Para 4.

${ }^{249}$ Ibid, Para 5.

250 Ibid, Para 6.

${ }^{251}$ Correa (2002), Preface (i).
} 
in line with health issues. In doing so, the Declaration recognised specific flexibilities which had been controversial up until that point. ${ }^{252}$ The Declaration also placed health issues and the related TRIPS flexibilities firmly into the centre of debates surrounding IPRs at international organizations as the benefits of increased Southern cooperation were noticed. ${ }^{253}$ Overall, the Doha Declaration played an important discursive role in shifting the focus of TRIPS-related discussions from purely IP-centric to be more conscious of health. It arose as part of a broader push from developing countries for trade and intellectual property regimes that would be more conscious of development issues in both WTO and WIPO contexts. ${ }^{254}$ In addition, initial fears of the Doha Declaration having a deleterious impact on innovation appear unfounded, as early research would suggest that innovation was not harmed by what was agreed in Doha. 255

The question of how far the Doha Declaration's influence reaches beyond the discursive effect is however more open to debate. Some, such as Pascal Lamy, European Commissioner for Trade at the time of the Declaration and later Director-General of the WTO, have suggested that the Doha Declaration solved very few of the problems of access to medicines in developing countries. ${ }^{256}$ Others argue that the Doha Declaration is nevertheless a crucial step towards clarifying the legality of compulsory licences and other flexibilities, and it should be read primarily in this light. ${ }^{257}$ Issues surrounding compulsory licences for pharmaceutical patents in developing and least-developed country governments had been at the centre of the South African case, the US-Brazil controversy, and had been threatened, without similar repercussions, in both the US and Canada. In addition, compulsory licensing for pharmaceuticals was practised historically by developed countries, which then were putting pressure on developing countries to refrain from doing the same. ${ }^{258}$ This manifest unfairness in the use of compulsory licensing flexibility was mitigated at least ostensibly by the clarification in the Doha Declaration that these flexibilities ought to be available to all WTO

\footnotetext{
252 See World Trade Organization, The Doha Declaration Explained, <https://www.wto.org/english/tratop_e/dda_e/dohaexplained_e.htm> accessed January 16, 2017.

${ }^{253}$ Sisule F Musungu, Susan Villanueva, Roxana Blasetti, 'Utilizing TRIPS Flexibilities for Public Health Protection Through South-South Regional Frameworks' (2004) South Centre, 4

254 Dosi (2014), 3.

255 Outterson (2005), 194.

${ }^{256}$ Tamar Gutner, International organizations in world politics (2nd ed., CQ Press 2016), 199.

257 Correa (2002), 48; 't Hoen (2011), 5.

${ }^{258}$ Reichman (2003), 4-5.
} 
members, which serves as a legal basis for the actions of developing countries, since this declaration was at the time signed by ministers of all WTO Members.

As the next section will show, attempts by developing countries to use compulsory licensing after the Doha Declaration have, on a global scale, increased as a result of the Declaration. ${ }^{259}$ However, the views of the main proponents of strong IP protection in the international arena - the US and the EU - have not softened to a large degree following the Doha Declaration. The US has consistently maintained its position as the foremost antagonist of compulsory licensing in developing countries. Several governments which have explored the issuance of compulsory licences in a bid to alleviate the burden of public health crises and reduce costs of procurement have in several highly-publicised cases drawn the ire of the pharmaceutical industry and faced reprisals from its developed country backers.

\subsection{Compulsory \& government-use licences in the post-Doha period}

Following the Doha Declaration, a number of countries in South-East Asia and South America sought to utilise compulsory licences as an option to face the mounting social and economic costs caused by ongoing health crises and the rising prices of medicines. ${ }^{260} \mathrm{~A} 2012$ study found 24 instances of compulsory licence issuance in 17 countries, though a limited number of compulsory licences have been issued since then. ${ }^{261}$ The most in-depth study to date on instances of use of TRIPS flexibilities, published in February 2018 in the WHO bulletin, shows that a far larger number of instances of such use occurred than was previously thought. ${ }^{262}$ The study identifies a total of 176 instances of TRIPS flexibilities being used, of which 100 are either compulsory licences or government use licences and suggests that in a high percentage of these instances the flexibilities were ultimately implemented. ${ }^{263}$

In some cases, such as in Thailand in 2006-2008, governments have chosen to only issue government use licences, thereby allowing agencies appointed by the government to manufacture and distribute the drugs. ${ }^{264}$ Other governments have preferred to grant

\footnotetext{
259 Beall (2012), 2; 't Hoen (2018).

${ }^{260}$ For South-East Asia this trend began in 2003 in Malaysia, see Germán Velásquez, 'Indonesia Government Granted 7 Compulsory Licences to promote Acces to HIV related medicines' (2012) 19(3) Vitae 1, 1.

${ }^{261}$ Beall (2012), Figure 1.

262 't Hoen (2018).

263 Ibid, 185.

${ }^{264}$ Inthira Yamabhai et al, 'Government use licenses in Thailand: an assessment of the health and economic impacts' (2011) 7(28) Globalization and Health, 1.
} 
compulsory licences to private third parties. This section describes several of the most publicised examples of the practice in Asia and South America drawing on cases of compulsory licensing and subsequent retaliation in Thailand, Brazil, India, Indonesia, and Colombia. It also examines the response of the US and other industrialised countries in each case, as well as the mechanisms employed by the US to deter the listed developing countries from issuing compulsory licences. While compulsory licences and other TRIPS flexibilities were used by least-developed and developing countries in multiple other instances in the normal course of their drug procurement, the cases that this section engages with are both those which were most publicised, and those in which the reprisals or threats thereof were the most serious. ${ }^{265}$ Several instances also exist of compulsory licensing, or government use licensing proceedings being initiated by developing country governments, with agreement between the government and the pharmaceutical company being reached on more favourable terms before the final issuing of the licences themselves. ${ }^{266}$ As these primarily bear relevance to the negotiating aspects of compulsory licensing, they will be discussed in Chapter Four, which deals with negotiation through compulsory licensing pressure.

\section{a. Thailand}

In the period of 2006-2008, the government of Thailand issued government use licences for seven drugs. ${ }^{267}$ Initially, these covered the ARV efavirenz; ${ }^{268}$ and the ARV combination lopinavir/ritonavir. ${ }^{269}$ These came as part of the government's commitment, undertaken in 2003, to provide universal access to ARVs. ${ }^{270}$ Licences were subsequently issued for other drugs for treating coronary artery disease and different types of cancer; including for the treatment of leukaemia, gastrointestinal stromal tumour, and breast and lung cancers. ${ }^{271}$

\footnotetext{
265 't Hoen (2018), 189.

${ }^{266}$ Serrano (2016), 4.

${ }^{267}$ Suwit Wibulpolprasert et al, 'Government use licenses in Thailand: The power of evidence, civil movement and political leadership' (2011) 7(32) Globalization and Health, 1-2.

268 Department of Disease Control, The Department of Disease Control Notification, titled 'Compulsory License for Patented Medicines and Medical Devices (November 29, 2006).

269 Department of Disease Control, The Department of Disease Control Notification, titled 'Compulsory License for Patented Medicines and Medical Devices: Lopinavir/Ritonavir (January 24, 2007).

270 Yamabhai (2011), 2.

${ }^{271}$ Wibulpolprasert (2011), 1.
} 
Pressure from the US and patent holders soon followed. ${ }^{272}$ The pharmaceutical company Abbott Laboratories announced its withdrawal from Thailand in 2008, when a compulsory licence was issued over its cancer drug Gleevec. ${ }^{273}$ On the US side, retaliatory actions began in late 2006, the Office of the US Trade Representative contacted Thailand's government to urge it to withdraw the compulsory licence on efavirenz. ${ }^{274}$ In a letter dated March 20, 2007, five US senators expressed their concerns surrounding Thailand's compulsory licensing to the US Trade Secretary, and urged the USTR to respond strongly to the steps taken by Thailand. ${ }^{275}$ In both the 2007 and 2008 editions of the Special 301 Report, Thailand was placed on the priority watch list of the report, where specific reference was made to concerns around patent protection stemming from the issuance of compulsory licences in those years. ${ }^{276}$ Despite acknowledging the ability to issue such licences in accordance with WTO rules and the country's, the reports insisted on the weakening of patent protection as a cause for concern. ${ }^{277}$

In addition to the Special 301 processes, media in Thailand reported that the 2007 decision of the USTR to withdraw US Generalized System of Preferences coverage from three Thai export products was in response to the Thai government's issuing of these licences, though direct links were not confirmed. ${ }^{278}$ US pressure on Thailand to limit policies on access to medicines was at the time not a novel development. ${ }^{279}$ However, such pressures by a global

\footnotetext{
272 Harris (2011), 387.

${ }^{273}$ Charitini Stavropoulou, Tommaso Valletti, 'Compulsory licensing and access to drugs' (2015) 16 European Journal of Health Economics 83, 84.

274 James Love, 'Merck, USTR ask Thailand to Reconsider Compulsory License on AIDS Drug' Huffington Post, December 18, 2006.

275 Joseph I Liebermann et al, Letter to USTR Susan F Schwab, March 20, 2007. Available at: <http://www.keionline.org/misc-docs/liebermanplus4.pdf> accessed 25/02/2018. See also: James Love, 'Senator Lieberman and Four Others Rap Thailand Compulsory Licenses on Non-AIDS Drugs' Huffington Post, April 2, 2007.

276 Office of the United States Trade Representative, 2007 Special 301 Report (April 2007), 27; Office of the United States Trade Representative, 2008 Special 301 Report (April 2008), 36-37.

277 Office of the United States Trade Representative, 2007 Special 301 Report, 27.

278 Woranuj Maneerungsee, Phusadee Arunmas, 'Drug dispute could lead to trade trouble' Bangkok Post, April 30, 2007. The products for which US GSP was removed were gold jewellery, polyethylene terephthalate in primary forms, and flat screen colour television sets. See also: Yamabhai (2011), 4-5; Malaysian AIDS Council Report, 31.

279 Susannah Markandya, 'Timeline of Trade Disputes involving Thailand and access to medicines' KEI Online, July 23, 2001.
} 
superpower can have the effect of deterring not just Thailand itself, but also other developing countries from pursuing compulsory licensing measures authorised by the Doha Declaration.

An assessment of the impact of the government use licences in Thailand was published in 2011. ${ }^{280}$ The study sought to estimate increases in patients gaining access to drugs and health gains in terms of Quality-Adjusted Life Years (QALYS) over a five-year period. In addition, the study examined the health-related economic impact of the licences by weighing the increased procurement expenditure against gains in productivity resulting from increased access. The study found that an estimated 84,158 patients had been added to the number able to access the seven drugs, that health gains amounted to 12,493 QALYs, and that net economic benefits translatable to USD 132.4 million resulted for Thailand from the government use licences. ${ }^{281}$

b. Brazil

Brazil has primarily used the threat of compulsory licensing to obtain discounted prices from the pharmaceutical patent holders. The Brazilian procurement strategy is discussed in detail in the following Chapter. ${ }^{282}$ However, in 2007 Brazil issued a compulsory licence for the ARV efavirenz, for which it had previously obtained price concessions from Merck. ${ }^{283}$ In response, the USTR initiated an out-of-cycle review of Brazil in 2007, and placed Brazil on the Special 301 IP Watch List. ${ }^{284}$

\section{c. India}

Prior to India's accession to the WTO, pharmaceutical companies lacked patent protection there. ${ }^{285}$ This had allowed India to cement its status as one of the principal producers and exporters of generic medicines. Due to India's accession to the WTO regime, and its consequent accession to the TRIPS agreement, India was required to introduce TRIPScompliant national laws by $2005 .{ }^{286}$ In March 2005, India introduced a law on the protection

\footnotetext{
280 Yamabhai (2011).

281 Ibid, 1, 6.

${ }^{282}$ Carolinne Thays Scopel, Gabriela Costa Chaves, 'Initiatives to challenge patent barriers and their relationship with the price of medicines procured by the Brazilian Unified National Health System' (2016) 32(11) Cad Saúde Publica 1, 3-4.

283 Brazilian Ministry of Health Press Release, Brasil decreta licenciamento compulsório do Efavirenz, May 4, 2007.

${ }^{284}$ Office of the United States Trade Representative, 2008 Special 301 Report, 38-39.

${ }^{285}$ Gilberto de Lima Lopes Jr, Jonas A de Souza, Carlos Barrios, 'Access to cancer medications in low and middleincome countries' (2013) 10 Nat. Rev. Clin. Oncol 314, 318.

${ }^{286}$ Serrano (2016), 3.
} 
of pharmaceuticals to meet its WTO obligation for IPR protection. ${ }^{287}$ India retained the ability to issue compulsory licences under its new IP legislation. Although India's size and economic weight gave it a growing ability to operate an active compulsory licensing strategy, the Indian government had shown limited interest in issuing compulsory licences until 2012. ${ }^{288}$

In 2012, India issued its first and only compulsory licence for a patented pharmaceutical. ${ }^{289}$ The licence, granted to local firm Natco Ltd, allowed Natco to sell a generic copy of cancer medicine Nexavar, for which the patent was held by Bayer. ${ }^{290}$ This decision was challenged by Bayer in a case that went all the way to the Supreme Court of India, where the German pharmaceutical company's appeal was eventually dismissed in 2014, allowing the Indian company to continue selling Bayer's drug for a fraction of the price set by Bayer ${ }^{291}$ Despite the uproar created by this decision, ${ }^{292}$ it has to date been the only compulsory licence issued by India, with multiple subsequent applications being rejected. ${ }^{293}$

Notoriously, India has also made use of strict patentability requirements to reject patent protection for some drugs. ${ }^{294}$ Due to this, the single compulsory licence, and India's place as the top developing country producer and exporter of generic pharmaceuticals, it has regularly faced pressure from the US and other countries to halt or alter its practices through various channels. ${ }^{295}$ Since its first compulsory licence was issued in 2012, such efforts have redoubled and have included pressure through business advocacy groups. ${ }^{296}$ The 2012 compulsory licence also prompted an out-of-cycle review of India by the USTR. ${ }^{297}$ The Indian

\footnotetext{
287 Donald G McNeil Jr, 'India Alters Law on Drug Patents' New York Times, March 24, 2005.

288 Serrano (2016), 8.

289 Rahul Chaudry, 'Compulsory licensing of patents in India' (2016) 5(6) Pharmaceutical Patent Analyst 401, 401402.

290 Reuters Staff, 'India defends right to issue drug 'compulsory licenses" Reuters, March 23, 2016.

${ }^{291}$ Samanwaya Rautray, 'Nexavar Licence Case: SC dismisses Bayer's appeal against HC decision' India Times, December 13, 2014; Vikas Bajaj, Andrew Pollack, 'India Orders Bayer to License a Patented Drug' New York Times, March 12, 2012.

${ }^{292}$ For instance, see Kaustubh Kulkarni, Henry Foy, 'Analysis: India cancer ruling opens door for cheaper drugs' Reuters, March 13, 2012, where the decision is characterised as 'a major blow to pharmaceutical firms'.

${ }^{293}$ Sandeep K Rathod, 'Compulsory licences on pharmaceutical patents in India: A short article' (2017) 13(3) Journal of Generic Medicines 108, 109.

${ }^{294}$ Ravinder Gabble, Jillian C Kohler, 'To patent or not to patent? the case of Novartis' cancer drug Glivec in India' (2014) 10(3) Globalization and Health, 2-5.

${ }^{295}$ Susanna Zhou, 'Challenging the Use of Special 301 against Measures Promoting Access to Medicines: Options Under the WTO Agreements' (2016) 19 Journal of International Economic Law 51, 51-52.

${ }^{296}$ Zeba Siddiqui, 'India defends right to issue drug 'compulsory licenses" Reuters, March 23, 2016.

297 ‘t Hoen (2018), 188.
} 
government's response to such pressures has mostly been to reiterate that its regime is TRIPScompliant, and that the Doha Declaration gives WTO members the freedom to determine the terms upon which compulsory licences are granted. ${ }^{298}$ However, this kind of political pressure has the effect of discouraging other, smaller countries from using compulsory licences or other TRIPS flexibilities. ${ }^{299}$

\section{d. Indonesia}

From 2004 to the present day, Indonesia has issued a mixture of several compulsory and government use licences, with a peak of 7 government use licences being issued for HIV/AIDS and Hepatitis C medicines in 2012. ${ }^{300}$ The 2012 licences, which had royalty payment rates of $0,5 \%$ attached to them, were met with apprehension by industry representatives, who argued that a dangerous precedent was being set. ${ }^{301}$ As the Indonesian government argued in issuing the government use licences that these were in response to an 'emergency situation', there was no requirement here to engage in prior negotiations for a voluntary licence. ${ }^{302}$ In addition to this, Indonesia's lawmakers introduced provisions in Indonesian legislation to make it easier to issue compulsory licences. ${ }^{303}$ As a result of this, Indonesia has, together with India, been a fixture on Special 301 Reports. ${ }^{304}$

\section{e. Colombia}

Though Colombia has not gone as far as issuing a compulsory licence yet at the time of writing, it is worth mentioning as an example of the pressures that can come to be exerted even where a government is in the stages of preparation for the issuance of a compulsory licence. In June 2016, Colombia's Minister of Health issued a resolution that declared the public interest for reducing the prices of imatinib, a drug for the treatment of leukaemia for which the patent is

\footnotetext{
298 Department of Industrial Policy and Promotion, Intellectual Property Rights Regime in India - An Overview (January 24, 2018), 9.

299 't Hoen (2018), 188-189.

${ }^{300}$ Sara Germano, 'Compulsory Licensing of Pharmaceuticals in Southeast Asia: Paving the Way for Greater Use of the TRIPS Flexibility in Low-and Middle-Income Countries' (2007) 76 UKMC L Rev 251, 289-290; Velásquez (2012).

301 Velásquez (2012), 1-2.

302 Desai (2016), 39.

${ }^{303}$ Brook K Baker, 'Don't be afraid of compulsory licenses despite US threats: Special 301 Reports 1998-2017 listing concerns but taking little action', InfoJustice February 20, 2018.

${ }^{304}$ See, eg, Office of the United States Trade Representative, 2013 Special 301 Report (May 2013), 40.
} 
held by Swiss pharmaceutical company Novartis. ${ }^{305}$ It had already requested additional information from the WHO before initiating the procedures, and had received a positive response from officials at the international organisation, who had confirmed the legitimacy of compulsory licensing. ${ }^{306}$ Colombia's actions were met with stiff resistance by Switzerland and the US. The measures taken by the latter were particularly serious, as US officials threatened the withdrawal of financial support from Colombia's internal peace process for a conflict which had plagued the country for over half a century. ${ }^{307}$ In addition to this, the USTR commenced an out-of-cycle review of Colombia under the Special 301 rules and placed it on the Watch List for 2016 and 2017. ${ }^{308}$

As shown, since 2001, when the legitimacy of the practice was recognised by the Doha Declaration, several countries have issued compulsory licences and government use licences for the procurement of pharmaceuticals. In many cases, the governments have done so in a routine fashion and without attracting much publicity. ${ }^{309}$ Some instances of compulsory licensing, however, attracted at times repercussions from developed countries - most commonly the US - which exerted political, and at times economic, pressure to deter the developing country governments from issuing further compulsory licences.

While recent studies show that these types of licences have been more commonly used than was previously thought, awareness of routine forms of their usage has remained low. ${ }^{310}$ Additionally, due to the political and economic repercussions that the US and other developed countries have been consistent in highlighting, countries considering such licences have been wary to move too far in this regard, for fear of upsetting important trading partners such as the US. The US has taken up a role as unilateral intellectual property enforcer through its Special 301 Reports.

The deterrence approach did not reduce the willingness of countries such as Thailand, Indonesia, and Malaysia to continue issuing compulsory licences into the second decade of

\footnotetext{
305 Ministry of Health and Social Protection, Resolution 2475/16, June 14, 2016.

${ }^{306}$ Marie-Paule Kieny (Assistant Director-General, Health Systems and Innovation, World Health Organization), Letter to Alejandro Gaviria Uribe (Minister of Health and Social Protection, Colombia), May 25, 2016.

${ }^{307}$ Ed Silverman, 'US pressures Colombia over plan to sidestep patent for a Novartis drug' STAT News, May 11, 2016.

308 Office of the United States Trade Representative, 2017 Special 301 Report, 5-6.

309 't Hoen (2018), 186.

310 Ibid, 185.
} 
the new millennium, the effect of this pressure has been effective in discouraging other countries from doing so. ${ }^{311}$ Even in the countries which did issue, the threat of being reviewed as part of the Special 301 process dominates discussions surrounding compulsory licences, despite the legality of these measures being repeatedly asserted by civil society and scholars. ${ }^{312}$

${ }^{311}$ Harris (2011), 392-393; 't Hoen (2018), 190.

${ }^{312}$ Malaysian AIDS Council Report, 32. 


\section{Voluntary and Compulsory Licensing of Pharmaceuticals: The Role of Compulsory Licensing Pressure}

Voluntary licences, whereby a pharmaceutical company willingly grants a licence to a party to produce the pharmaceutical products on its behalf, have grown in popularity in the last two decades. ${ }^{313}$ Voluntary licences and compulsory licences are both possible outcomes under the TRIPS-Doha regime due to the nature of Article 31b, which requires negotiations for a voluntary approach to precede an eventual compulsory approach, ${ }^{314}$ unless it is issued for public non-commercial use, a health emergency, or other circumstances of extreme urgency, in which cases it can be waived. This procedural layer to issuance of compulsory licences gives rise to several possibilities which are interesting from a negotiating perspective, since the parties have the opportunity - on the government side, this is more akin to a TRIPS-imposed requirement ${ }^{315}$ - to meet face-to-face to discuss a voluntary approach before the idea of a compulsory licence is even mooted.

Therefore, this Chapter focuses on the role of compulsory licensing pressure for achieving outcomes favourable to access such as voluntary licences and price discounts, and explores the possibility of voluntary and compulsory licence co-existence. It will be shown that compulsory licensing threats can form part of effective strategies for the procurement of cheaper pharmaceuticals and that there are several strategic implications stemming from compulsory licences that go beyond the purely legal aspects of the compulsory licensing provisions contained in TRIPS Art 31.

\subsection{Voluntary licensing of pharmaceutical patents}

Since 2008 pharmaceutical companies have begun to opt increasingly for a voluntary licensing approach rather than risking the greater losses that would be incurred with a compulsory

\footnotetext{
313 Tahir Amin, 'Voluntary licensing practices in the pharmaceutical sector: An acceptable solution to improving access to affordable medicines?' (2007) Oxfam, 4.

314 TRIPS, Article 31b, which reads: "[S] uch use may only be permitted if, prior to such use, the proposed user has made efforts to obtain authorization from the right holder on reasonable commercial terms and conditions and that such efforts have not been successful within a reasonable period of time". Emphasis added.

${ }^{315}$ Abbott (2007), 940.
} 
licence issued over their products. ${ }^{316}$ Due to the growth of voluntary licensing, usage of TRIPS flexibilities to procure medicines has decreased in the same timeframe. ${ }^{317}$ However, threats of compulsory licensing also feed back into decisions around voluntary licensing, since they can affect the behaviour of the pharmaceutical company by increasing its willingness to voluntarily licence its patented products, or simply help governments to achieve better voluntary licence terms for their territory. ${ }^{318}$ At the same time, voluntary licensing is by its very nature reliant on the patent holder being willing to grant a license. This willingness is not always present to a sufficient degree, as history shows that much of voluntary licensing has been in response to external pressure stemming either from public opinion and civil society efforts, or from compulsory licensing proceedings. ${ }^{319}$ As a result, the characteristics of and interrelationship between compulsory and voluntary licences must be examined in terms of their implications for each other, and for access to medicines.

In several instances of compulsory licensing procedures identified in 2012 and 2018 studies, the patent holder opted to reduce the prices of its marketed pharmaceuticals, while in other cases the response of patent holders faced with the threat of compulsory licences has been to grant voluntary licences with aim of preventing the issuance of the compulsory licence. 320 The strong statements and actions undertaken by the pharmaceutical industry against compulsory licensing make it clear that these are, in their view, highly undesirable, whereas bargaining responses of this kind highlight that the pharmaceutical industry is willing to go to almost any lengths to avoid issuance of compulsory licences for pharmaceutical patents. Such bargaining also suggests that, in the face of mounting pressures to achieve health targets and ongoing health issues in many countries, the pharmaceutical industry's long-standing fight against compulsory licensing is a losing one. ${ }^{321}$

Perhaps the most significant difference between voluntary and compulsory licences lies in the amount of control that the patent owner has in deciding the terms of the licence. ${ }^{322}$ Under a

\footnotetext{
${ }^{316}$ Peter Beyer, 'Developing socially responsible intellectual property licensing policies: non-exclusive licensing initiatives in the pharmaceutical sector' in Jacques De Werra (ed), Research Handbook on Intellectual Property Licensing (Edward Elgar, 2012), 227.

317 't Hoen (2018), 188-189.

${ }^{318}$ Bond (2014), 217-220.

319 't Hoen (2011), 4.

${ }^{320}$ Beall (2012), 4; 't Hoen (2018).

${ }^{321} \mathrm{Kim}(2016), 63$.

$322 \mathrm{lbid}, 91$.
} 
compulsory licence, the patent owner retains very little control, as it is the issuing government, rather than the patent owner, which chooses which third party will be manufacturing the drugs. ${ }^{323}$ Pharmaceutical companies can at any time proactively grant voluntary licences to generic manufacturers of their choice. ${ }^{324}$ This can be a decisive factor for patent owners, as they can exercise more control over local manufacturers which have some affiliation than over local manufacturers that are chosen by a government, and which may already be distrustful of the pharmaceutical company.

Since voluntary licences have no defined procedure, the licensor has considerable freedom in deciding the terms of the licence. Thus, under a voluntary licence the patent owner retains control over the royalty rate, whereas under a compulsory licence it is once again the government body in charge of issuance which decides the remuneration that is to be paid to the patent owner. ${ }^{325}$ Past voluntary and compulsory licences suggest that the royalty rates set by patent owners under the former are far higher than those chosen by governments for the latter. ${ }^{326}$ In terms of economic considerations, the collaboration with local firms also offers an opportunity for low-risk market entry for the pharmaceutical company. ${ }^{327}$ Indeed, for the firm voluntary licensing may be preferable to direct entry in some cases, as the fixed costs of direct entry are higher. ${ }^{328}$

Additionally, when pharmaceutical company decides to proactively grant a voluntary licence over its patented drugs, this can have a further effect of fostering goodwill and cooperation between the patent holder and other stakeholders, including generics manufacturers and governments. ${ }^{329}$ As relationships between different stakeholders in the pharmaceutical world are developed over many years, and commonly feature repeated engagement between different parties, displays of goodwill through voluntary licensing can have a beneficial impact that lasts beyond the immediate. Moreover, this can be positive for the reputation of the

\footnotetext{
323 TRIPS, Article 31.

${ }^{324} \operatorname{Kim}$ (2016), 68.

${ }^{325}$ KD Raju, 'Compulsory v Voluntary Licensing: A Legitimate way to Enhance Access to Essential Medicines in Developing Countries' (2017) 22 Journal of Intellectual Property Rights 23, 25-28.

326 Ibid, 25.

327 Lanjouw (2005), 17.

328 Bond (2014), 219.

${ }^{329} \operatorname{Kim}$ (2016), 68.
} 
pharmaceutical company, whereas breakdowns in relationships due to a reluctance to engage can have the opposite effect. ${ }^{330}$

On the flipside, not all countries possess the manufacturing capacity or viable local firms that can produce the required pharmaceuticals. ${ }^{331}$ In countries where this is the case, it will be impossible to conclude voluntary licensing contracts. These countries may be better served by utilising the parallel importation clause under TRIPS Article 31 Bis to fulfil their health obligations, ${ }^{332}$ but they would find themselves in the same situation of developed country retaliation as with compulsory licensing.

\subsection{Example of voluntary licensing: the Gilead Model}

The American pharmaceutical company Gilead has in recent years actively used the strategy of voluntarily licensing its anti-Hepatitis C virus (HCV) drugs, with the declared aim of combating a disease which affects an estimated 185 million people worldwide. ${ }^{33}$ The company, which owns patent rights for sofosbuvir, one of the most effective HCV drugs on the market, initially marketed this drug in 2013 as Sovaldi at extremely high prices enabled by the patent monopoly it holds over the compound. ${ }^{334} \mathrm{~A}$ major development in terms of Gilead's voluntary licensing occurred in September 2014, when the pharmaceutical company announced its decision to grant a voluntary licence for sofosbuvir and ledipasvir to eleven Indian pharmaceutical manufacturers. ${ }^{335}$

A comparison of the Gilead Licence and the rules for compulsory licensing under TRIPS Article 31 quickly betrays differences that make voluntary licences far more attractive for pharmaceutical companies. The various conditions that must be respected by the licensees constitute the bulk of the agreement, and by and large set stricter conditions than compulsory

\footnotetext{
${ }^{330}$ Attaran (2004), 162.

${ }^{331}$ Keith E Maskus, 'Ensuring Access to Essential Medicines: Some Economic Considerations' (2001-2002) 20 Wisconsin International Law Journal 563.

332 World Trade Organization, Amendment of the TRIPS Agreement, WT/L/641 8 December 2005, Decision of December 6, 2005.

${ }^{333}$ Catherine Jewell, Gilead Targets Elimination of Hepatitis C, World Intell Prop Org Magazine (February 2015) <http://www.wipo.int/wipo magazine/en/2015/01/article 0001.html> accessed 25/03/2018.

334 Piergentili (2017), 131.

${ }^{335}$ License Agreement between Gilead and Licensee app. 1 (Sept. 15, 2014), 1, available at https://www.gilead.com/ /media/files/pdfs/other/2014_original hcv licensing agreement.pdf?la=en accessed 11/04/2018 [hereinafter "Gilead Licence"].
} 
licensing requirements. ${ }^{336}$ These include higher royalty rates than under most compulsory licences, restrictions for reselling, and territorial restrictions for manufacturing and shipping the drug. ${ }^{337}$

\subsection{Discounts and 'voluntary' licences resulting from compulsory licensing pressure}

Another possibility of a different nature than the voluntary licensing of a pharmaceutical patent is the 'voluntary' licence, where a pharmaceutical company grants a licence as a concession following the threat of compulsory licensing of the patent by a government. Governments have in the past obtained both price discounts and such 'voluntary' licences from patent-holding pharmaceutical companies through compulsory licensing threats. Therefore, these will be taken together as positive outcomes for governments employing compulsory licensing pressure as part of their drug procurement or access strategies.

\section{a. Compulsory licensing pressures in developed countries}

Under the TRIPS regime, high-income countries have at times made use of compulsory licensing threats to procure discounted pharmaceuticals. Indeed, the US and Canada's threats to use such licences in response to the 2001 Anthrax outbreaks in their territories, while at the same time actively fighting against South Africa and Brazil's attempts to do the same, drove WTO members to adopt the Doha Declaration. As described in Chapter Three, both the US and Canada were able to easily obtain discounted Anthrax drugs because of the pressure they exerted. ${ }^{338}$

There have also been recent calls in the United States for compulsory licensing to reduce prices of pharmaceuticals. State health officials from Louisiana proposed in 2017 to use a federal provision for compulsory licensing to procure cheaper drugs used to treat Hepatitis $C$ for which Gilead held the patent rights. ${ }^{339}$ In February 2018, eighteen members of the US House of Representatives petitioned the US Health Secretary to issue a compulsory licence for HCV medications on a federal level in light of exorbitant prices. ${ }^{340}$ In their letter, the

\footnotetext{
336 Ibid, starting at 4.

337 Ibid, § 4.1, §2.3 (d)-(f), and §2.3 (b), respectively.

338 Correa (2002), 3, footnote 20.

${ }^{339}$ Sarah J Tribble Kaiser, 'Louisiana proposes tapping a century-old patent law to cut hepatitis C drug prices' Washington Post, May 2, 2017. The provision in question is 28 U.S.C. $§ 1498$.

${ }^{340}$ Ro Khanna et al, Letter to the Department of Health and Human Services Secretary Alex Azar, February 15, 2018.
} 
representatives recalled that compulsory licensing was explored during the Anthrax outbreak, and that the US government's success in obtaining a discounted price for drugs to combat Anthrax was due to the pressure that was placed on the patent holder. ${ }^{341}$

Much like rich-world countries, some of their lower-income counterparts have had some success in obtaining concessions by way of price reductions or voluntary licences from pharmaceutical companies, by putting pressure on them through the threat of government use or compulsory licences. ${ }^{342}$ Due to the majority of post-TRIPS compulsory licensing uses taking place in low- or middle-income countries, there are more instances of this in these regions than in high-income countries. ${ }^{343}$ In some cases, the threat of a compulsory licence alone has been a sufficiently powerful incentive to drive patent holders to compromise. In others, the developing country government has relied on the actual issuance of TRIPS Article 31 licences to maintain or restore the credibility of its threats. Evidence gathered by Beall and Kuhn in 2012, and ' $\mathrm{t}$ Hoen et al in 2018 suggests that Brazil has been the most systematic user of the Article 31 flexibility mechanism among developing countries, although other countries such as Malaysia and Thailand also made use of the same. ${ }^{344}$ Here, Brazil and Malaysia will be taken as case studies for the effectiveness of strategies involving threats of compulsory licensing in middle-income countries. On the basis of these examples, some factors required for the successful utilisation of such strategies in developing countries will subsequently be speculated.

\section{c. Brazil}

Brazil was one of the first countries to realise and capitalise on the potential of compulsory licences as a negotiating tool for prices of pharmaceuticals, doing so as early as the first years of the new millennium. The Brazilian government historically used compulsory licence threats as an effective negotiating tool to drive down prices of pharmaceuticals as part of its policy of universal access to HIV/AIDS medicines. ${ }^{345} \mathrm{~A}$ timeline of these efforts shows that Brazil was

\footnotetext{
341 Ibid, 2.

342 Beall (2012); 't Hoen (2018).

343 't Hoen (2018), 187.

344 Beall (2012), 4;

${ }^{345}$ Galvão (2002), 3; Amy S Nunn, 'Evolution of Antiretroviral Drug Costs in Brazil in the Context of Free and Universal Access to AIDS Treatment' (2007) 4(11) PLoS Med 1804, 1805.
} 
initially able to persuade pharmaceutical companies to reduce the prices of some of their patented pharmaceutical products through threats of compulsory licensing alone.

In the same period of the WTO dispute with the US, the Brazilian government enjoyed some major negotiating successes in its attempts to drive pharmaceutical prices down as part of its strategy for combating the HIV/AIDS crisis. In February 2001, Brazil's government announced that it was considering compulsory licences for antiretroviral drugs nelfinavir and efavirenz, held by Hoffman-La Roche (Roche) and Merck, respectively. ${ }^{346}$ The Brazilian government successfully negotiated a $70 \%$ decrease for the price of Merck Sharp \& Dohme for Merck's drug Efavirenz. ${ }^{347}$ Later in the same year the Brazilian government announced its intention to issue a compulsory licence for the Nelfinavir patent to Brazilian manufacturer FarManguinhos, citing the high prices of pharmaceuticals set by the patent holder Roche Pharmaceuticals and unsuccessful negotiations with Roche for a similar price reduction. ${ }^{348}$ In these early cases, compulsory licensing threats allowed the government to wrest significant discounts on patented drugs from the patent holders, which facilitated its policy of universal access to antiretrovirals by reducing the costs of procurement. ${ }^{349}$

Brazil made several other compulsory licensing threats in the years that followed. Between 2001 and 2007, Brazil continued to use the negotiating power it derived from compulsory licensing threats to obtain significant discounts for patented pharmaceuticals. ${ }^{350}$ Eventually, however, concessions on the part of the patent holder became more infrequent, as the mere threat of compulsory licensing inevitably became insufficient to convince pharmaceutical companies that an actual follow-up was imminent. Thus, threats had to be backed up by actual compulsory licences to remain credible and ensure that further price reductions could be achieved.

In 2007, renewed negotiations between Brazil's government and Merck for the price of Merck's drug Efavirenz stalled. In this case, rather than merely threatening to issue, Brazil

\footnotetext{
346 James P Love, 'Recent examples of the use of compulsory licenses on patents' (2007) KEI Research Note 2007:2, 15.

${ }^{347}$ Ministry of Health, Ministry of Health announces compulsory licensing of Nelvinavir patent: official note, Ministry of Health, August 22, 2001.

348 Ibid.

${ }^{349}$ Colleen Chien (2003), 856, footnote 7.

${ }^{350}$ Gabriela Costa Chaves et al, 'Strategies for price reduction of HIV medicines under a monopoly situation in Brazil' (2015) 49 Rev Saúde Pública 1, 2.
} 
opted to go through with the issuance of a compulsory licence. ${ }^{351}$ This restored the credibility of Brazil's threats, as they were now backed by a concrete example that the government was, if necessary, willing to deliver on its promise to issue compulsory licences where sufficient discounts for highly priced drugs could not be obtained through the pressure of threats alone.

\section{a. Malaysia}

Brazil's utilisation of compulsory licences as a negotiating tool is certainly the most renowned, as this approach constituted an active part of the Brazilian government's strategy for procuring cheaper drugs in its fight against HIV/AIDS. However, Malaysia has also successfully made use of licensing threats, albeit more recently and to a lesser degree. Prior to 2017, Malaysia had issued a government-use licence in 2003 , when it became the first country to do so after the Doha Declaration was adopted by allowing the importation of ARVs. ${ }^{352}$ At that time, an $81 \%$ reduction of the price of the treatment per patient was achieved by Malaysia. ${ }^{353}$ In 2016, the Malaysian government and the American pharmaceutical company Gilead Sciences began negotiations for the price of sofosbuvir without coming to an agreement on the price of the drug. Gilead's initial offering for the drug in Malaysia was USD $\$ 12,000$ for a 12-week course of the drug. ${ }^{354}$

Price ranges for alternative generic versions of sofosbuvir and sofosbuvir combinations show that the production of an effective drug cocktail can be achieved with production costs far lower than the price touted by Gilead for Malaysia. A sofosbuvir/ravidasvir combination under development by the non-profit organization Drugs for Neglected Diseases initiative (DNDi) and Egyptian pharmaceutical manufacturer Pharco is expected to cost around USD $\$ 300$ for a 12-week treatment with similar rates of effectiveness to Gilead's drug in interim clinical trials, according to announcements by DNDi and Pharco. ${ }^{355}$ The disparity between Gilead's offered price and the generic alternatives proved to be a major point of contention

\footnotetext{
351 Matthew Flynn, 'Public Production of Anti-Retroviral Medicines in Brazil, 1990-2007' (2008) 39(4) Development and Change 513, 526.

352 Mohammed K El Said, Public health related TRIPS-plus provisions in bilateral trade agreements (WHO/ICTSD, 2010), 160.

353 Ibid.

354 Malaysian Aids Council Report (2017), 5.

355 DNDi Press Release, 'New affordable hepatitis C combination treatment shows 97\% cure rate', April 12, 2018.
} 
between the parties; the Malaysian government eventually initiated proceedings for a government-use licence, which were finalised in September 2017. ${ }^{356}$

What makes the 2017 Malaysian government-use licence stand out from other cases is that the pressure of the compulsory licensing threat had already resulted in Gilead issuing a voluntary licence just a month earlier. In August 2017, Malaysia was successful in its efforts to be included in a Gilead voluntary licence for sofosbuvir, when the pharmaceutical company announced its extension of the sofosbuvir licence to Malaysia and three other countries (Belarus, Thailand, Ukraine). ${ }^{357}$ In the days that followed, some commentators suggested that compulsory licensing pressure from Malaysia played a substantial role in securing the country's place in that list. ${ }^{358}$

The coexistence of two licences - one voluntary and the other compulsory - raises immediate questions around whether any conflicts will arise between them, and whether issuing a compulsory licence will be precluded by the prior granting of a voluntary licence over the same drug for the same territory. To date, the limited literature on the relationship between voluntary and compulsory licences has conceived this as an exclusionary one, whereby the presence of a voluntary licence would be used to prevent a compulsory one. ${ }^{359}$ However, this is not fully clear from the text of the TRIPS Agreement itself, nor from interpretative notions that have been developed around the Agreement.

Article $31 \mathrm{~b}$ of TRIPS states that use without authorization of the rightsholder "may be permitted only if, prior to such use, the proposed user has made efforts to obtain authorization from the right holder on reasonable commercial terms and conditions and that such efforts have not been successful within a reasonable period of time". ${ }^{360}$ At first glance, this would appear to exclude the issuance of a compulsory licence where a voluntary licence has already been issued. However, the provision specifies that both the commercial terms

\footnotetext{
${ }^{356}$ Martin Khor, 'Action at last on Hepatitis C?', The Star, September 11, 2017.

357 The decision was first announced by Gilead on Twitter. See: James Love, Letter to Ambassador Robert Lighthizer, Knowledge Ecology International, March 14, 2018 [hereinafter “KEI Letter"], 1.

${ }^{358}$ Fifa Rahman, 'Malaysia Inclusion In Gilead Voluntary Licence - A Product Of Compulsory Licence Pressure', Intellectual Property Watch, August 24, 2017.

${ }^{359}$ See Kim (2016).

${ }^{360}$ TRIPS, Art 31b. Emphasis added.
} 
and conditions upon which authorisation from the rightsholder, as well as the period of time for which efforts have been unsuccessful must be 'reasonable' ${ }^{361}$

In light of the inclusion of reasonableness as a factor, the related concept of 'good faith' may play an important role in the interpretation of the Article 31b provisions, as a general principle of customary international law. ${ }^{362}$ This concept does not feature in the text of TRIPS itself, and therefore it is necessary to exercise some caution in applying it, but it has emerged in the course of WTO Dispute Settlement decisions. ${ }^{363}$ It is also consistent with the interpretative flexibility in Paragraph 5a the Doha Declaration, which states that "[i]n applying the customary rules of interpretation of public international law, each provision of the TRIPS Agreement shall be read in the light of the object and purpose of the Agreement as expressed, in particular, in its objectives and principles. ${ }^{364}$

Some commentators have further construed possible interpretations of the principle for various TRIPS purposes, including for compulsory licensing. ${ }^{365}$ Applying the principle of good faith to the issuance of compulsory licences gives rise to an obligation on the part of the host country to act in accordance with the principle, though a margin of discretion is offered for exercising the TRIPS flexibility. ${ }^{366}$ On a general basis, then, it appears that seeking to operate in good faith would preclude a government from issuing a compulsory licence where authorization for use on reasonable terms has already been granted by the rightsholder.

However, good faith duties are reciprocal. ${ }^{367}$ In cases where the rightsholder grants a voluntary licence on exorbitant terms, which effectively continue to impede access to the drugs, a good faith analysis may lead to a different outcome. By making an offer that does the opposite of fulfilling its promise, the bad faith would in that case be on the part of the

\footnotetext{
${ }^{361}$ Ibid.

362 Georg Schwarzenberger and Edward D Brown, A Manual of International Law (6th edn, Professional Books 1969), 35-36 cited in Alison Slade, 'Good faith and the TRIPS Agreement: putting flesh on the bones of the TRIPS 'objectives' (2014) 63(2) International \& Comparative Law Quarterly 353, 356.

${ }^{363}$ Andrew D Mitchell, 'Good Faith in WTO Dispute Settlement' (2006) 7 Melbourne Journal of International Law 339, 345; Slade (2014), 357.

${ }^{364}$ Doha Declaration, Para 5a; see also TRIPS, Art 8 (Principles): “Members may, in formulating or amending their laws and regulations, adopt measures necessary to protect public health ... provided that such measures are consistent with the provisions of this Agreement".

${ }^{365}$ Aditi Bagchi, 'Compulsory Licensing and the Duty of Good Faith in TRIPS' (2003) 55(5) Stanford Law Review 1529.

$366 \mathrm{lbid}, 1548$.

${ }^{367}$ Ibid.
} 
rightsholder. In such cases, permitting a compulsory licence to co-exist with the voluntary licence may not be inconsistent with notions of good faith, while at the same time not being precluded by the text of TRIPS Article 31b.

In the Malaysian case, it was suggested that the government went ahead with the compulsory licence because Gilead did not provide sufficiently timely notification of its decision to include Malaysia in its voluntary licensing scheme for the compulsory licensing procedures to be halted. ${ }^{368}$ This appears likely, since the voluntary licence and compulsory licence were granted and issued mere weeks apart. Therefore, it can be distinguished from the concerns around good faith that were outlined above on the basis of it possibly being the outcome of a clerical error, rather than an attempt to circumvent the voluntary licence and TRIPS procedures for compulsory licensing.

4.4 Viability of compulsory licensing pressure in access to medicines strategies: a collective action alternative?

As shown by the case studies from both Brazil and Malaysia, it is possible for compulsory licensing threats to feature prominently in developing country strategies for procuring cheaper medicines. However, it must be underlined that not all countries may be able to avail themselves of this as a negotiating tool. Firstly, Brazil's ability to consistently and successfully use compulsory licensing threats is shared by few others, in that many other low- or middleincome countries lack the same kind of negotiating capabilities due to their size and regional importance, but also their lack of domestic production capacity, all of which hinder the credibility of their threats. ${ }^{369}$ Much of Brazil's success in this area is predicated on its potential to attract continued foreign investment regardless of its compulsory licensing approach. Further, Brazil's large market and internal resources - including the ability to locally manufacture drugs - give its threats significant weight. ${ }^{370}$ Eventually, the effectiveness of any

\footnotetext{
368 KEI Letter, 2.

369 Beatrice Stirner, Harry Thangaraj, 'Learning from practice: compulsory licensing cases and access to medicines' (2013) 2(2) Pharmaceutical Patent Analyst 195, 195-196; Shyama V Ramani, Eduardo Urias, 'Access to Critical Medicines: When are compulsory licences effective in price negotiations?' (2015) 135 Social Science \& Medicine 75, 76.

${ }^{370}$ Abbott (2007); Robert C Bird, Daniel R Cahoy, 'The Impact of Compulsory Licensing on Foreign Direct Investment: A Collective Bargaining Approach' (2008) 45(2) American Business Law Journal 1, 32.
} 
threat without concrete backing wore off even for Brazil, implying that smaller, less powerful countries will have an even harder time pursuing such a strategy.

Since many developing countries lack the negotiating leverage of Brazil and similarly influential players and may therefore not be able to utilise compulsory licensing threats to the same extent, some have suggested that a collective bargaining approach could serve as an equaliser for these countries to achieve better access to medicines. ${ }^{371}$ Bird and Cahoy describe collective action as beneficial for smaller countries for countering the power of industry-backing developed countries, especially with regard to minimising potential losses in foreign direct investment. ${ }^{372}$ For these countries, pooled strategies and the coordination of efforts may therefore be more beneficial than pursuing compulsory licences or threats thereof on their own. ${ }^{373}$ The added bargaining power offered by greater numbers, as well as corresponding increases in market size, could push cooperating groups of smaller countries to be considered for voluntary licences in similar fashion to the compulsory licensing pressure for individual countries with more influence. This effect could gain additional prominence if such collective actions were to include countries which already possess the ability to use pressure on their own, as they could extend this ability to the other countries joining them in collective action. ${ }^{374}$

The Doha Declaration itself emerged based upon the building of a coalition between developing countries, which evidences the powerful nature of this type of approach. ${ }^{375}$ However, for countries seeking to make use of compulsory licensing as part of drug procurement strategies, such policies will remain subject to potential economic and political fallout from developed country backers of the pharmaceutical industry. ${ }^{376}$ As was highlighted in Chapter Three, pressure exerted by developed countries can deter developing countries from making use of the flexibilities available to them. While the effect of this pressure could be resisted more effectively by groups of countries rather than individual countries, getting multiple countries involved and in agreement on common strategies for compulsory

\footnotetext{
${ }^{371}$ Bird (2008), 34.

372 lbid, 35.

${ }^{373}$ Abbott (2007), 973.

374 Bird (2008), 48.

${ }^{375}$ Fredrick M Abbott, 'The Doha Declaration on the TRIPS Agreement and Public Health: Lighting a Dark Corner at the WTO' (2002) 5(2) Journal of International Economic Law 469, 469.

${ }^{376}$ Bird (2008), 44-45.
} 
procurement may prove difficult in light of binding free trade commitments. ${ }^{377}$ Moreover, since each country will face political and economic pressures, some countries which agree in principle could, in practice, become discouraged, especially if deterrent pressure is tailored to maximise effectiveness.

\subsection{Medicine patent pools}

In the past decade, a new trend has emerged which brings together the favourable aspects pharmaceutical companies find in voluntary licensing and some of the benefits present for developing country governments in collective approaches to drug procurement. The creation of patent pools for medicinal patents shows promise as a vehicle for expanding access to patented drugs in developing countries and avoids the deterrence strategies which accompany the compulsory licensing of developed country pharmaceutical patents by virtue of its voluntary nature. ${ }^{378}$

Currently, the most notable example is the Medicines Patent Pool (MPP). Founded in 2010 by Unitaid and based upon civil society proposals, the MPP is an international mechanism dedicated to facilitating the voluntary licensing of pharmaceuticals. ${ }^{379}$ The functioning of the MPP is described as follows by 't Hoen et al: in exchange for royalties, patent holders can license their patents via the MPP so that others can make use of the knowledge to produce lower-cost generic versions of the patented drug. ${ }^{380}$ As such, the mechanism fits in well with provisions in TRIPS on technology transfer to least-developed countries, ${ }^{381}$ as its functioning gives local manufacturers in lower- and middle-income countries further opportunities for partnerships and capacity building.

If patent pools are used, patent owners and manufacturers of generics alike benefit, in terms of certainty and transparency, from having a single platform through which to share information and licences. ${ }^{382}$ Therein lies the current issue with these mechanisms. At the time of writing, 17 products are licensed to the MPP, while 92 to 131 countries covered by MPP

\footnotetext{
377 Ibid, 45-47.

${ }^{378}$ Jorge Bermudez, Ellen FM 't Hoen, 'The UNITAID Patent Pool Initiative: Bringing Patents Together for the Common Good' (2010) 4 The Open AIDS Journal 37, 37.

${ }^{379}$ Krista L Cox, 'The Medicines Patent Pool: Promoting Access and Innovation for Life-Saving Medicines Through Voluntary Licenses' (2012) 4(2) Hastings Science \& Technology Journal 293, 293-294.

380 't Hoen (2011), 8.

381 TRIPS, Article 66.2.

382 HLP Report, 22.
} 
adults licences. ${ }^{383}$ Moreover, MPP adult licences cover $87 \%$ to $91 \%$ of people living with HIV in developing countries. ${ }^{384}$ These numbers are promising for a mechanism launched less than a decade ago. However, they also show clearly that uptake is far from complete, as neither territorial coverage nor broad product coverage are achieved.

Voluntary licensing would be preferable from the perspective of patent holders because of the goodwill it can foster. ${ }^{385}$ It could also be desirable for countries afraid of retaliation that accompanies non-voluntary measures. To date, voluntary licensing by individual pharmaceutical companies has only occurred sporadically - and even then often under the influence of compulsory licensing pressures, ${ }^{386}$ while voluntary licensing as part of collective action mechanisms such as patent pools has yet to reach full coverage.

In light of this, compulsory licensing and threats thereof can continue to play an important role in the strategies of low- and middle-income countries. ${ }^{387}$ However, beyond the diplomatic and political efforts of developed countries, there is a further layer of restrictions on compulsory licensing in the sphere of international law which must be discussed to comprehend its continued value as a tool for effecting access to medicines. This layer stems from a growing body of free trade agreements, the implications of which are discussed in the final Chapter.

\footnotetext{
383 Medicines Patent Pool, 'Our Work' <https://medicinespatentpool.org/what-we-do/our-work/> accessed $16 / 06 / 2018$.

384 Ibid.

${ }^{385}$ Attaran (2004), 162.

${ }^{386}$ Kim (2016); Zachary Brennan, 'Malaysia Issues Compulsory License for Gilead Hepatitis C Drug', Regulatory Focus, September 15, 2017.

${ }^{387}$ Shyama V Ramani, Eduardo Urias, 'When access to drugs meets catch-up: Insights from the use of CL threats to improve access to ARV drugs in Brazil' (2018) 47 Research Policy 1538, 1548-1549.
} 


\section{5.'Free' Trade Agreements and the Compulsory Licence: Restrictions to Legitimate Development Space Through TRIPS-plus Provisions}

Compulsory licensing strategies do not operate in a vacuum, as they are subject to the bodies of rules that states build up both internally and between one another. One particularly relevant area is the growing body of bilateral and plurilateral trade agreements that has been developed in recent decades and continues to grow today. ${ }^{388}$ In this Chapter it will be argued that some TRIPS-plus clauses included in these agreements can have a detrimental effect on the functioning of health systems and thus produce issues regarding access to medicines, while other such clauses can restrict the ability of countries to respond, to these same issues, through compulsory licensing and other flexibilities permitted under TRIPS.

\subsection{Free trade agreements as a vehicle for regulatory control}

Regional and bilateral free trade agreements (FTAs) have proliferated under the TRIPS regime. The first such agreement, signed between Germany and Pakistan in 1959, paved the way for the subsequent explosion of use. Over 3000 trade agreements of different scope have been crafted in the past sixty years between bilateral investment treaties and broader FTAs. ${ }^{389}$ In recent times the overarching trend has been for FTAs, especially, to constantly expand in both territorial coverage and scope. ${ }^{390}$ Initially, agreements of this type were developed primarily to remove barriers to trade such as tariffs, import quotas, as well as to protect foreign investors. Increasingly, however, the scope of regulations contained in FTAs has expanded to include subject matter such as intellectual property and investment. ${ }^{391}$ As a result of this

\footnotetext{
388 United States House of Representatives, Trade Agreements and Access to Medications under the Bush Administration, Committee on Government Reform - Minority Staff Special Investigations Division, prepared for Rep. Henry A. Waxman (June 2005), 13.

${ }^{389}$ Bryan Mercurio, 'Safeguarding Public Welfare? - Intellectual Property Rights, Health and the Evolution of Treaty Drafting in International Investment Agreements' (2015) 6 Journal of International Dispute Settlement 252, 252-254.

${ }^{390}$ Ronald Labonté, Ashley Schram, Arne Ruckert, 'The Trans-Pacific Partnership Agreement and health: few gains, some losses, many risks' (2016) 12(25) Globalization and Health, 3.

${ }^{391}$ Katherine Hirono et al, 'Is health impact assessment useful in the context of trade negotiations? A case study of the Trans Pacific Partnership Agreement' (2016) 6 BMJ Open 2016, 1. The growth of regional and bilateral intellectual property arrangements was predicted at an early stage by some commentators, see Reidenberg (1993), 283.
} 
scope creep, some of these agreements now have troublesome implications in relation to public health and access to medicines in general, and specifically compulsory licensing.

Such bilateral or plurilateral investment treaties, as well as their more comprehensive counterparts in free trade agreements, are pursued by both developed and developing countries. However, the underlying motivations for this interest will often differ between the two groups. Free trade is desirable for many countries as it promises increased market penetration for their own manufactured products, as well as increased foreign investment. ${ }^{392}$ The main benefit free trade agreements is purportedly increased societal wealth. Protection of investments made by foreign nationals can help attract investors, on the assurance that their investments will have a decreased probability of being lost to various national factors. ${ }^{393}$ Due to this, they have become a desirable prospect for developing countries looking to increase their international standing and expand their trade capacity. Developed countries, however, see additional opportunities for obtaining control in the rules and requirements that these agreements contain, especially in terms of economic management and risk reduction. ${ }^{394}$

On a general level, free trade agreements can be a vehicle for developed countries to impose stronger IP protections on developing countries than those required by TRIPS. 'TRIPS-plus' protections of this kind can have the effect of increasing public health and pharmaceutical procurement costs for developing countries. They can also reduce the effectiveness of, or make fully ineffective, development-oriented policy options available to these countries, such as compulsory licences. ${ }^{395}$ In addition to bringing multiple parties to an agreement up to the same regulatory standard, common intellectual property rules can also have the effect of increasing developed country control over the health policies of developing countries that are participants to the agreements, which in turn restricts their ability to pursue such policies for the benefit of their population. ${ }^{396}$ The increased sway that is thus obtained is the trade-off

\footnotetext{
392 Kenneth C Shadlen, 'Exchanging Development for Market Access? Deep Integration and Industrial Policy under Multilateral and Regional-Bilateral Trade Agreements' (2005) 12(5) Review of International Political Economy 750.

${ }^{393}$ Andrew T Guzman, 'Why LDCs Sign Treaties That Hurt Them: Explaining the Popularity of Bilateral Investment Treaties', (1998) 38 Va J Int'I L 639, 669-670.

394 United States International Trade Commission, Economic Impact of Trade Agreements Implemented Under Trade Authorities Procedures, 2016 Report (June 2016), 19-20.

395 Wade (2003), 621.

${ }^{396}$ Said (2010), 165-166
} 
that developed countries obtain in exchange for allowing industrial players from the developing country to be competitive in their own markets. In addition to this, the lobbying influence of the pharmaceutical industry over developed country governments is often decisive in shaping the intellectual property rules to be more stringent than the requirements of TRIPS. ${ }^{397}$

The influence powerful developed countries have in dictating what such agreements stipulate has been most obvious following the US decision to abandon the Trans-Pacific Partnership (TPP). As negotiations have continued following the exit of the largest trading partner, various changes have been brought into the TPPs intellectual property chapter with the effect of removing some of the regulatory grip that had previously been proposed. ${ }^{398} \mathrm{~A}$ similar negotiating landscape is becoming apparent in the negotiations regarding a proposed EUMercosur FTA which are currently ongoing between the EU and the four founding members of Mercosur - Brazil, Argentina, Uruguay, Paraguay. ${ }^{399}$ These examples, and more general considerations relating to the regulative role of free trade agreements, will be examined in this part to obtain a clearer picture of how the issues raised by free trade agreements translate into effects impacting compulsory licensing strategies. Specific clauses that have an impact on the implementation and effectiveness of compulsory licences will also be considered here.

These factors of asymmetrical power relations, pharmaceutical lobbying in developed countries and the general desire to be allowed to trade freely on the part of developing countries lead to the introduction of policy that is ultimately detrimental to the weaker party. ${ }^{400}$ The ultimate result of this process is a reduction of the 'development space' available to developing countries. ${ }^{401}$ The rules of the game are dictated by industrialised countries and to a large extent, serve to prevent developing governments from adopting measures that the developing countries view as harmful to their own interests. ${ }^{402}$ Indeed, there is some

\footnotetext{
397 Sell (2007), 41.

398 Dan Ciuriak, Jingliang Xiao, Ali Dadkhah, 'Quantifying the Comprehensive and Progressive Agreement for Trans-Pacific Partnership' (2017) 21(4) East Asian Economic Review 344, 344.

${ }^{399}$ See European Commission, 'Report from the XXXth round of negotiations of the Trade Part of the Association Agreement between the European Union and Mercosur', November 27, 2017 EC Directorate General Trade <http://trade.ec.europa.eu/doclib/docs/2017/november/tradoc 156408.pdf> accessed 12/12/2017.

400 Sell (2007), 41.

401 Labonté (2016), 3.

402 Wade (2003), 622
} 
evidence to support the notion that TRIPS-plus provisions in FTAs can lead to higher costs for developing countries which implement them. ${ }^{403}$ Large increases of costs can overwhelm health systems in developing countries, and the developing country may consider compulsory licensing of certain drugs - or threats thereof - to reduce costs in response to this. At the same time, the issuance or effectiveness of compulsory licences and related parallel importation can be limited by FTAs. ${ }^{404}$

The discussion surrounding the Trans-Pacific Partnership offers an opportunity to examine influence of developed countries in regulating the development space of other countries. In addition, the initial inclusion in this agreement of extensive investor-state dispute resolution (ISDS) provisions allows for an examination of the potentially nefarious effects of ISDS on compulsory licensing. ${ }^{405}$ The potential impact on health systems and development strategies of the EU-Mercosur free trade agreement, which is still under negotiation, has already generated impact studies examining in detail the effects on public health of specific clauses proposed by the EU. Drawing upon these, it is possible to identify further TRIPS-plus clauses that can harm access to medicines such as patent term extensions and mandatory exhaustion regimes.

\subsection{Trans-Pacific Partnership}

\section{a. TPP 1.0 \& 2.0: renegotiation following US departure}

The Trans-Pacific Partnership is a free trade agreement that involves multiple countries on both sides of the Pacific including the Canada, Japan and developing countries such as Malaysia and Brunei, and initially included the US. ${ }^{406}$ The circumstances surrounding this free trade agreement, which covers a broad range of issues, constitute an exemplary instance of developed countries employing this type of agreement to dictate legal rules in developing countries. Negotiations had been in the works for a number of years and a text had been

\footnotetext{
${ }^{403}$ Chutima Akaleephan et al, 'Extension of market exclusivity and its impact on the accessibility to essential medicines, and drug expense in Thailand: Analysis of the effect of TRIPs-Plus proposal' (2009) 91 Health Policy $174,175$.

${ }^{404}$ Charles T Collins-Chase, 'The Case against TRIPS-Plus Protection in Developing Countries Facing Aids Epidemics' (2008) 29 U Pa J Int'l L 763, 780.

${ }^{405}$ Lise Johnson, Lisa Sachs, 'The TPP's Investment Chapter: Entrenching, rather than reforming, a flawed system' (2015) CCSI Policy Paper, 11.

${ }^{406}$ Muhammad A Khan, Naseeb Zada, Kakali Mukhopadhyay, 'Economic implications of the Comprehensive and Progressive Agreement for Trans-Pacifc Partnership (CPTPP) on Pakistan: a CGE approach' (2018) 7(2) Economic Structures 1, 2.
} 
finalised and signed pending ratification, when the entering US administration decided in 2016 to withdraw from the TPP 1.0 altogether. ${ }^{407}$ Undeterred, the other participating countries renegotiated the TPP without US involvement, reaching an agreement for a new text in early $2018 .^{408}$

The new TPP 2.0 - now called the Comprehensive and Progressive Agreement for TransPacific Partnership - features significant textual alterations, including a rewritten chapter on intellectual property which excludes many of the previous provisions. ${ }^{409}$ Several IP-related requirements that had formed the cornerstone of the US negotiating position were considerably diluted from the original text. ${ }^{410}$ This clarifies the decisive role played by the US in pushing for stronger intellectual property protections in the earlier TPP 1.0 text. It also indicates that after the US influence was removed due to its withdrawal from the negotiations, the remaining parties sought to rebalance the chapter on intellectual property to remove the most stringent requirements which had previously been imposed on them by the most powerful party to the partnership.

Some studies have been dedicated to examining the impact of FTAs on health systems. These studies identify specific clauses as having potential detrimental effect on access to medicines, and seek to gauge the impact, financial or otherwise, that implementation thereof would have on health systems. Therefore, they constitute useful sources for examining how specific clauses identified by these studies can relate to the costs borne by health systems, and how these clauses affect the effectiveness of compulsory licences. A study titled 'The Trans-Pacific Partnership Agreement and health: few gains, some losses, many risks' examines the TPP from a health policy perspective. ${ }^{411}$ Despite the preliminary nature of the findings, the study's health impact assessment identified multiple health-related issues within the original text of the TPP, some with direct bearing on access to medicines. The study identifies several TPP 1.0

\footnotetext{
407 David Smith, 'Trump withdraws from Trans-Pacific Partnership amid flurry of orders', The Guardian, January 23, 2017.

${ }^{408}$ Charlotte Colin Packham, 'Final version of Trans-Pacific trade deal released, rules pushed by U.S. on ice', Reuters, February 21, 2018.

409 Electronic Frontier Foundation, 'Trans-Pacific Partnership Agreement', Electronic Frontier Foundation, $<$ https://www.eff.org/issues/tpp> accessed 18/06/2018.

${ }^{410}$ For a discussion of the US proposal for an IP chapter see: Sean M Flynn et al, 'The U.S. Proposal for an Intellectual Property Chapter in the Trans-Pacific Partnership Agreement' (2012) 28 Am U Int'l L Rev 105.

${ }^{411}$ Ronald Labonté, Ashley Schram, Arne Ruckert, 'The Trans-Pacific Partnership Agreement and health: few gains, some losses, many risks' (2016) 12(25) Globalization and Health.
} 
clauses as especially concerning from a public health perspective, including clauses for the 'evergreening' of patents, data exclusivity and Investor State Dispute Settlement (ISDS), which will be considered here. ${ }^{412}$ As ISDS clauses have great potential to render government strategies for compulsory licensing ineffective, but do not necessarily do so in obvious ways, their implications will be considered in the greatest detail.

\section{b. TPP 1.0 health-related clauses}

Evergreening clauses, which allow manufacturers to patent new uses, new methods of using, and new processes for the same drug, can serve to extend the patent monopoly beyond the patent term of 20 years required by TRIPS. ${ }^{413}$ The implications these clauses have for access to medicines are clear, stemming from their potential to consolidate the monopoly of the patent holder through the granting of further patents for incremental innovations. By seeking and obtaining new patents for marginal improvements in effectiveness, or other minor innovations, the patent owner is then able to extend the monopoly beyond the TRIPS term of 20 years, thus delaying the market entry of generic competitors and the consequent drop in drug prices. ${ }^{414}$

Data exclusivity clauses contribute to the extension of the patent monopoly through a similar 'evergreening' effect. ${ }^{415}$ TRIPS Article 39.3 only requires WTO member states to protect undisclosed test data against commercial use. ${ }^{416}$ The US sought to include in the TPP provisions that all test data be protected for a minimum of 12 years, which other countries negotiated down to a 5 -year minimum. ${ }^{417}$ Requiring all test data to be replicated by generic manufacturers before marketing approval is granted saddles them with burdensome costs, and prevents the entry of generic medicines on the market. ${ }^{418}$ Since compulsory licensing and similar flexibilities rely on the production and distribution of generic versions of the drug, this

\footnotetext{
412 Labonté (2016), 1.

413 Labonté (2016), 2.

414 Roffe (2006), 80.

${ }^{415}$ Correa (2006), 401-402; Roffe (2006), 83; Lisa Diependale, Julian Cockbain, Sigrid Sterckx, 'Raising the barriers to access to medicines in the developing world - the relentless push for data exclusivity' (2017) 17(1) Developing World Bioethics 11, 11-12.

416 TRIPS, Article 39.3. Emphasis added.

${ }^{417}$ Inside U.S. Trade, 'USTR Signals Support for Longer Data Protection for Biologics in TPP', Inside U.S. Trade, 27 May, 2011; Julia Belluz, 'How the Trans-Pacific Partnership could drive up the cost of medicine worldwide', Vox, October 5, 2015.

${ }^{418}$ Greg Perry, 'Data Exclusivity-A Major Threat to Access to Affordable Medicines' (2002) Business Briefing: Pharmagenerics, 16; Correa (2006), 401.
} 
type of provision can prevent the effectiveness of compulsory licences altogether if generic medicines become contingent on the data owner's consent for marketing. ${ }^{419}$

ISDS clauses constitute another major way in which the development space available to developing countries is encroached upon by TRIPS-plus free trade agreements. These clauses have long existed in investment treaties as a mechanism by which foreign investors can directly sue host governments through arbitral tribunals for treatment that results in loss of the investor's asset values. ${ }^{420}$ ISDS clauses have proven popular and feature in a multitude of bilateral and plurilateral agreements. ${ }^{421}$ The much-discussed original text of the TPP is among the many agreements featuring broad ISDS clauses. ${ }^{422}$ Due to the growing inclusion of these clauses in FTAs, potential exists for ISDS to eventually be used to undermine domestic pharmaceutical policies. ${ }^{423}$

Thanks to the way in which ISDS functions at present, submitting disputes to ISDS raises significant procedural issues. ${ }^{424}$ Decisions are commonly made behind closed doors by threemember tribunals, which prompts questions regarding the transparency of the process. ${ }^{425}$ Some of the arbitrators are repeat arbitrators or at times have connections to the corporations whose disputes they are arbitrating upon. ${ }^{426}$ ISDS also lacks an appeal process. ${ }^{427}$ Moreover, the public costs for governments involved in such suits can be considerable, especially in light of the mounting size of awards. ${ }^{428}$ Arbitral proceedings under ISDS can last for several years, which adds to the burden faced by governments involved in such disputes. Ultimately, these costs are shifted back to the taxpayer or are added onto

\footnotetext{
419 Jean-Frédéric Morin, 'Tripping up TRIPS debates IP and health in bilateral agreements' (2006) 1(1-2) International Journal of Intellectual Property Management 37, 42.

${ }^{420}$ Daniel J Ikenson, 'A Compromise to Advance the Trade Agenda: Purge Negotiations of Investor-State Dispute Settlement' (2014) Free Trade Bulletin No. 57, Cato Institute, March 4, 2014.

${ }^{421}$ Rachel L Wellhausen, 'Recent Trends in Investor-State Dispute Settlement' (2016) Journal of International Dispute Settlement 1, 1.

${ }^{422}$ Gary C Hufbauer, 'Investor-State Dispute Settlement' in 'Assessing the Trans-Pacific Partnership Volume 1: Market Access and Sectoral Issues' (2016) PIIE Briefing 16-1, 109; Ikenson (2014).

${ }^{423}$ Labonté (2016), 3.

${ }^{424}$ See David A Gantz, 'An Appellate Mechanism for Review of Arbitral Decisions in Investor-State Disputes: Prospects and Challenges' (2006) 39 Vand I Transnat'I L 39, 40-42.

425 UNCTAD, IIA Issues Note No.2 Reform of investor-state dispute settlement: in search of a roadmap (June 2013), 3.

426 Ibid, 4.

${ }^{427}$ Michael Nolan, 'Challenges to the Credibility of the Investor-State Arbitration System' (2016) 5 American Universities Business Law Review 429, 438.

${ }^{428}$ Labonté (2016), 3-4.
} 
public debt, thus compounding the existing issues related to access to medicines by lowering individual or public spending power.

The idea of ISDS claims being brought for compulsory licences has to date not appeared in public arbitration awards. ${ }^{429}$ However, some commentators have explored the possibility of compulsory licences falling foul of investment clauses in bilateral or plurilateral agreements. ${ }^{430}$ Such agreements often cover matters relating to intellectual property investments, with the more comprehensive free trade agreements dedicating entire chapters to intellectual property. Compulsory licensing can be construed as an 'indirect expropriation' of patent rights, as the rates of compensation under a compulsory licence are lower than what the patent holder would be able to obtain under normal circumstances. A financial loss on the part of the patent holder is thus not an unlikely outcome from a compulsory licensing decision. ${ }^{431}$ If a tribunal were to consider a compulsory licence an indirect expropriation, this could have repercussions on future compulsory licensing decisions. Previous ISDS decisions are not binding on later tribunals, but they can carry significant persuasive or quasiprecedential weight, particularly where similar claims are being arbitrated upon. ${ }^{432}$

Though compulsory licensing matters have not been tested in arbitral tribunals as investment disputes, other IP-related disputes under investor-state dispute settlement rules give some insight into what the proceedings could look like; they highlight that even if the defendant government wins the case, there may be negative repercussions for access to medicines. Two major arbitral decisions in relation to public health, namely Phillip Morris v Uruguay and Eli Lilly $v$ Canada, are for this purpose deserving of examination..$^{433}$ In both cases, a public healthrelated decision by a sovereign government was challenged in ISDS disputes which led to lengthy and costly proceedings. The implications which arose as a result of these cases would also apply to potential compulsory licensing cases.

\footnotetext{
${ }^{429}$ For the same assessment in 2010, see Gibson (2010).

${ }^{430}$ Tsai-yu Lin, 'Compulsory License for Access to Medicines, Expropriation and Investor-State Arbitration under Bilateral Investment Agreements: Are There Issues beyond the Trips Agreement?' (2009) 40 International Review of Intellectual Property and Competition Law 123.

${ }^{431}$ Gibson (2010), 383-385.

432 August Reinisch, 'The Role of Precedent in ICSID Arbitration' (2008) 2 Austrian Arbitration Yearbook 495, 498.

433 Philip Morris Brands Sàrl, Philip Morris Products S.A. and Abal Hermanos S.A. v. Oriental Republic of Uruguay, ICSID Case No. ARB/10/7; Eli Lilly and Company v. The Government of Canada, UNCITRAL, ICSID Case No. UNCT/14/2.
} 
The issues raised by the Phillip Morris $v$ Uruguay case, which was decided under the arbitral rules of the International Centre for Settlement of Investment Disputes (ICSID), concerned Uruguay's strict regulation of tobacco packaging. ${ }^{434}$ The claimant tobacco companies initiated arbitral proceedings in 2010, alleging that Uruguay's measures were detrimental to their sales, and argued that Uruguay was contravening the protection of foreign investment provided for by the Switzerland-Uruguay bilateral investment treaty. 435

After protracted discussions around the jurisdiction of the tribunal, an award was finally rendered in 2016, six years after the start of proceedings. ${ }^{436}$ The tribunal dismissed the claims in full, and ordered the claimants to pay USD 7 million of costs to the government of Uruguay. ${ }^{437}$ Despite the tribunal's ultimate rejection of the claims, the case constituted a major strategic victory for the tobacco company. ${ }^{438}$ Due to pending arbitration and national court proceedings, implementation of the Uruguayan measures on tobacco packaging was stayed, preventing the tobacco company's sales from being affected in the intervening period. ${ }^{439}$

Although the award rendered by the tribunal went some way to covering the costs borne by the government of Uruguay in contesting the case, millions more were spent by Uruguay in legal fees for the dispute - USD 1.5 million which ultimately passed on to the Uruguayan population through taxation, as they were not otherwise covered. ${ }^{440}$ An additional implication here is that the public funds spent by Uruguay on contesting the decision were not available for other projects in the public interest. Uruguay's measures, initially designed to protect the public by aiming to ameliorate public health, led to financial costs for the public as a result of the dispute, and were not put into practice for their beneficial effects to work until long after the initial promulgation. The direct challenge through ISDS to a government's

\footnotetext{
${ }^{434}$ FTR Holding et al (Request for Arbitration), February 19, 2010, [2]-[5].

435 Ibid, [1], [6].

${ }^{436}$ ICSID Case No. ARB/10/7 (Decision on Jurisdiction), July 2, 2013; ICSID Case No. ARB/10/7 (Award), July 8, 2016.

437 ICSID Case No. ARB/10/7 (Award), 169.

${ }^{438}$ Eric Crosbie, Patricia Sosa, Stanton A Glantz, 'Defending strong tobacco packaging and labelling regulations in Uruguay: transnational tobacco control network versus Philip Morris International' (2018) 27 Tobacco Control 185, 190.

439 Ibid, 186-187.

440 Ibid, 190.
} 
sovereign discretion to preserve the public health of its citizens was in this regard highly successful as a delaying tactic. ${ }^{441}$

The Eli Lilly $v$ Canada case is the ISDS decision which is perhaps closest to one on compulsory licensing. Decided in 2017 after almost five years of proceedings, it constitutes the first investor-state arbitral claim by a patent-holding pharmaceutical company under a U.S. free trade agreement. ${ }^{422}$ This complex case, which arose under the North American Free Trade Agreement (NAFTA), revolved around Canada's decision to revoke patents on two drugs for lack of demonstrable utility at the time of filing. ${ }^{443}$ In the final decision, the claims of the applicant pharmaceutical company were rejected by the arbitral tribunal. ${ }^{444}$ However, the case does highlight that foreign pharmaceutical investors can employ ISDS under free trade agreements such as NAFTA to challenge internal IP-related decisions. In light of this, there have been suggestions that current protections for lawful measures which promote access to affordable medicines are inadequate to truly safeguard these measures. ${ }^{445}$

The prospect of such foreign investor claims being brought against developing country governments' issuance of compulsory licences is becoming increasingly realistic. ${ }^{446} \mathrm{~A}$ document published by law firm Jones Day advises pharmaceutical companies about the potential for foreign investor claims against India. ${ }^{447}$ In addition to being troublesome from an access to medicines perspective, the document is problematic due to its inaccuracy on the legal matters it discusses. ${ }^{448}$ The document contains a number of inaccurate statements, including the following short passage:

\footnotetext{
441 Sergio Puig, 'The Internationalization of Tobacco Tactics' (2018) 28 Duke Journal of Comparative \& International Law 495, 511.

${ }^{442}$ Brook K Baker, 'Corporate Power Unbound: Investor-State Arbitration of IP Monopolies on Medicines - Eli Lilly and the TPP' (2013) PIJIP Research Paper Series. Paper 36, 3.

443 Labonte (2016), 2.

444 UNCT/14/2, 137.

${ }^{445}$ Baker (2013), 7.

446 Ibid, 9.

447 Jones Day, 'Treaty Protection for Global Patents: A Response to a Growing Problem for Multinational Pharmaceutical Companies' (October 2012).

${ }^{448}$ See Baker (2013).
} 
"[T] he fact that no national health "emergency" exists to justify such a license over a "non-life saving drug," are just two reasons to suggest that India has run afoul of Article 31 of TRIPs" ${ }^{449}$

This is patently incorrect. TRIPS Article 31 contains no requirement for compulsory licences to be granted only for health emergencies, or to be limited to life saving drugs. ${ }^{450}$ This is apparent both from the text of Article 31b of TRIPS itself, and from the clarifying Declaration made in Doha. Statements such as the above undermine principles of interpretation for the TRIPS Agreement which were adopted in Paragraph 5 of the Doha Declaration, and serve to delegitimise lawful practices used by developing country governments to increase access to medicines. ${ }^{451}$ Arguments premised on similarly faulty readings of the provisions of Article 31 of TRIPS also appear in some scholarly writings, where unfounded claims of a 'national emergency' requirement in TRIPS are made. ${ }^{452}$

The effect of such undermining efforts, intentional or otherwise, is especially pronounced in the international arena, where custom and adherence to norms are instrumental in dictating their normative effect and continued validity. In international law, consistent statements to contravene norms can have normative relevance of their own and can eventually lead to a new custom being adopted at the expense of the previous rule. ${ }^{453}$ The Doha Declaration on TRIPS and Public Health was introduced to clarify the previously existing regime, and statements such as those contained in Jones Day's advice serve only to muddy the waters of the applicability of both the TRIPS Agreement and the Doha Declaration itself.

Such advice is particularly dangerous because it could induce pharmaceutical companies to pursue claims under ISDS in the future against decisions made by governments in relation to TRIPS flexibilities. ${ }^{454}$ If these decisions encounter similar arbitral proceedings as showcased by the Phillip Morris and Eli Lilly cases, this would further restrict the legitimate and internationally recognised development space available to developing country governments, as they would constantly be under threat of extended and expensive arbitration proceedings

\footnotetext{
449 Jones Day (2012), 3

${ }^{450}$ See Baker (2013), 9, footnote 37.

451 Jan Klabbers, International Law ( $2^{\text {nd }}$ edn, CUP, 2017), 'The Making of International Law'.

452 Epstein (2011), 4.

453 Joyner (2005), 12.

454 Brook K Baker, 'Leaked TPP Investment Chapter Presents a Grave Threat to Access to Medicines' (2012) Northeastern University School of Law Faculty Publications, 1-2.
} 
for their lawful decisions to compulsorily licence pharmaceutical patents. ${ }^{455}$ Moreover, their institutions would be burdened with the economic and temporal costs associated with the disputes, as well as decreased legal certainty of decision making capabilities. Additionally, any financial costs are eventually passed on to the ultimate funder of government institutions, the public.

\subsection{TRIPS-plus provisions in the ongoing negotiations for an EU-Mercosur FTA}

A similar picture in which the most powerful party to an FTA is seeking to impose TRIPS-plus provisions on the other parties via the agreement has become apparent from the negotiations that are currently ongoing between the European Union and Mercosur. The EU has endeavoured to negotiate with the different players in South America and especially with the two main groupings of aligned countries in the region, namely the Andean Community (Colombia, Peru, and subsequently Ecuador are currently part of the agreement) and Mercosur (composed of Brazil, Argentina, Uruguay, Paraguay). ${ }^{456}$

The European Commission released a draft proposal for the chapter on intellectual property rights in the EU-Mercosur FTA to the public in 2017. Though this document states that it is without prejudice to the EU and that positions may well change over the course of the negotiations process, it helps shed some light on the expected positions of the EU in the negotiations with Mercosur, which are held in secret. ${ }^{457}$ On intellectual property rights exhaustion, the document provides in Article 3 that "[e]ach Party shall provide for a regime of national or regional exhaustion of intellectual property rights". ${ }^{458}$ In Article 8.3, the proposal also contains a provision on extending the period of protection conferred by a patent on medicinal products. ${ }^{459}$

A study conducted by researchers at the Escola Nacional de Saúde Pública (ENSP) in Brazil suggests that the TRIPS-plus measures proposed by the EU for the EU-Mercosur deal may have a detrimental effect on access to antiretrovirals (ARVs) and Hepatitis C medicines in

\footnotetext{
${ }^{455}$ See, in reference to a different agreement, Christian Tietje, Freya Baetens, 'The Impact of Investor-StateDispute Settlement (ISDS) in the Transatlantic Trade and Investment Partnership' (2014) MINBUZA-2014.78850, 9.

${ }^{456}$ European Commission Press Release, Ecuador joins EU-Colombia/Peru trade agreement, November 11, 2016.

${ }^{457}$ European Commission, EU Proposal on Chapter on Intellectual Property Rights (November 2016) [“EUMercosur Proposal"].

458 Ibid, 1.

459 Ibid, 14.
} 
Brazil. ${ }^{460}$ The study finds that the TRIPS-plus measures in the EU proposal would lead to major increases in public health expenditure and could simultaneously result in a reduction of the policy space available to the Brazilian government. ${ }^{461}$ Overall, the study estimates that, if introduced, the TRIPS-plus regulations from the EU proposal would add an average of BRL 142.7 million per year, or the equivalent of the HIV treatment of 57,975 people in Brazil at current rates. ${ }^{462}$ As outlined in Chapter Four, Brazil has in the past strategically employed TRIPS flexibilities, especially compulsory licensing and threats thereof, to negotiate prices and remove patent barriers, which has allowed it to achieve relative stability in ARV prices. ${ }^{463}$ With the measures proposed by the EU in place, such strategies would become less feasible. Thus, the restrictions to Brazil's policy space would lead to further issues for drug access, in addition to those which would naturally result from increased health spending due to patent term extensions. ${ }^{464}$

The study identifies several TRIPS-plus provisions in the EU proposal which may have an impact on public health: mandatory adoption of regional or national exhaustion of IPRs, extension of the period of protection conferred by a patent on medicinal product, and, once again, exclusivity of data submitted to obtain market authorization. ${ }^{465}$ As the latter type of clause has been considered when dealing with the TPP, it is the former two which must now be examined in more detail to determine their potential effects on access to medicines.

\section{a. Patent term extension}

Patent term extensions in free trade agreements can have the effect of raising costs for the health system. The EU proposal puts forward an extension of patent terms for medicinal products by including the period between the filing of the initial patent application and the administrative authorisation as part of the patent protection. ${ }^{466}$ The ENSP study identifies multiple medicines as being impacted by the patent term extension clause. In particular, it

\footnotetext{
${ }^{460}$ Gabriela Costa Chaves, Walter Britto Gaspar, Marcela Fogaça Vieira, 'Mercosur-EU Free Trade Agreement: Impact analysis of TRIPS-plus measures proposed by the EU on public purchases and domestic production of HIV and Hepatitis C medicines in Brazil' (2017) ENSP Fiocruz, 5-7.

461 Ibid, 9-10.

462 Chaves (2017), 55.

463 Jillian C Cohen, Kristina M Lybecker, 'AIDS Policy and Pharmaceutical Patents: Brazil's Strategy to Safeguard Public Health' (2005) 28 The World Economy 211, 218.

${ }^{464}$ Chaves (2017), 55.

465 EU Mercosur Proposal, 16-17; Chaves (2017), 5.

${ }^{466}$ EU Mercosur Proposal, Art 8.3.
} 
identifies essential medicines for combating HIV (darunavir, etravirine, raltegravir), Hepatitis C (sofosbuvir, daclatasvir) and cancer (dasatinib) as affected by the clause. ${ }^{467}$

Extending the patent protection for these and other medicines would massively overburden the Brazilian health system, which already faces rising overall costs and at times struggles to provide services effectively. ${ }^{468} \mathrm{~A}$ preliminary report to the study found, through use of a health impact assessment process, that the patent term extensions resulting from the proposed agreement could by themselves increase expenditure of the Brazilian Ministry of Health by a figure of $\$ 444$ million. ${ }^{469}$ Since Brazil practices a policy of universal access to essential medicines, such added costs are unavoidable if stricter requirements are imposed through legislation or plurilateral agreements. ${ }^{470}$ Massive increases in costs can severely hinder the effectiveness of health systems to fulfil their duty of delivering adequate health services to patients. In response to such increases of expenditure on drugs, a government in charge of procurement will be compelled by its financial needs to pursue options such as issuing compulsory licences to limit its expenditure on drugs. It may then find itself restricted in doing so, as the patent owner will hold additional leverage if the patent over the drug is further away from expiration.

\section{b. Mandatory Exhaustion}

The final ENSP study published in 2017 builds on the findings of the preliminary report by identifying and analysing the impact of further TRIPS-plus clauses in the EU proposal with potential repercussions on public health policy. One such clause is contained in Article 3 of the EU proposal, with the aim of introducing a national or regional regime of intellectual property exhaustion in the territories of the parties. ${ }^{471} \mathrm{It}$ may be useful now to examine in more detail some general considerations of exhaustion regimes in relation to public health and access to medicines, as the EU-Mercosur agreement is only one of many bilateral and

\footnotetext{
467 Chaves (2017), 6.

${ }^{468}$ Hooman Momen, Maria Goreti Rosa-Freitas, 'Brazil: The Challenge of Universal Health Coverage' in Alexander Medcalf et al (eds), Health for All: The Journey to Universal Health Coverage (Orient BlackSwan, 2015), 106.

${ }^{469}$ Chaves (2017), 6.

470 Momen (2015), 104.

${ }^{471}$ EU Mercosur Proposal, Art 3.
} 
plurilateral deals wherein restricted intellectual property exhaustion regimes are introduced or pushed. ${ }^{472}$

Exhaustion regimes of intellectual property rights contained in free trade agreements such as the EU's proposal for EU-Mercosur affect access to medicines differently from patent term extensions. The EU's suggested third article proposes that "[e]ach Party shall provide for a regime of national or regional exhaustion of intellectual property rights". ${ }^{473}$ Both the TRIPS Agreement and the Doha Declaration on TRIPS and public health allow countries to choose the exhaustion regime - national, regional, or international - that they consider most appropriate. ${ }^{474}$ The EU proposal restricts the options available to the parties to the former two and thus constitutes a TRIPS-plus provision on exhaustion. The possibility of international exhaustion of intellectual property rights is especially relevant to patent-protected pharmaceutical products. The ENSP report notes that Brazil has already introduced a national regime of exhaustion of patents, and that the EU-proposed restriction will therefore not have a direct impact on Brazil's public health spending. ${ }^{475}$ However, other countries which currently operate broader regimes of exhaustion may see their options restricted by the same type of rule in FTAs.

Products for which the patent rights have not been exhausted will, depending on jurisdiction, require the formal agreement of the rightsholder to allow the sale of these products abroad. ${ }^{476}$ Under national exhaustion regimes, the IP owner will be able to oppose the importation of goods marketed abroad. Regional exhaustion means the first sale with the IP owner's consent within the region will exhaust any IP rights. Any further sales, whether domestic or regional, are no longer protected by IP, and the IP owner will therefore no longer be able to oppose the parallel importation of the product from within the region. International exhaustion goes further, as it makes the first sale anywhere in the world with the IP owner's consent will exhaust the IP rights. The effect on importation is the same as with regional exhaustion, but applied to the whole world. ${ }^{477}$

\footnotetext{
472 Roffe (2006), 81.

473 EU Proposal, Art 3. Emphasis added.

474 TRIPS, Articles 6, 28; Doha Declaration, Paragraph 5(d).

475 Chaves (2017), 6.

476 World Intellectual Property Organization, 'International Exhaustion and Parallel Importation' <http://www.wipo.int/sme/en/ip_business/export/international_exhaustion.htm> accessed 12/02/2018.

477 Ibid.
} 
Stricter exhaustion regimes impact the price of, and access to, pharmaceutical products by maintaining the initial intellectual property monopoly past the first sale of the product, or until the product is sold within the territory to which the exhaustion of rights is applicable. ${ }^{478}$ This allows the IP owner to restrict competition from its own products first sold in other countries, meaning it can maintain high prices through its continued monopoly power. ${ }^{479}$ Some valid arguments have been made to limit parallel trade, with some suggesting that a reduction of instances in which poorer markets are avoided entirely by pharmaceutical companies to prevent parallel trade to more profitable developed country markets can help preserve global welfare. ${ }^{480}$ However, strict exhaustion regimes necessarily affect access, as prices can be maintained at a higher level, which constitutes a form of rationing that may be unaffordable for some. ${ }^{481}$ Additionally, there will be a smaller quantity of pharmaceuticals available if importation is forbidden, further reducing access.

Although exhaustion regimes generally have a role to play in balancing the rights of the intellectual property owner against those of the consumer, strict exhaustion regimes skew this balance by increasing the protections enjoyed by IP owners, without correspondingly protecting the consumers. ${ }^{482}$ Universal exhaustion is the preference of developing countries, whilst unsurprisingly, developed countries prefer stricter exhaustion regimes which offer more protection to their IP owners. ${ }^{483}$

Domestic exhaustion is especially disruptive for access to medicines in countries which lack the capacity to manufacture pharmaceuticals in their own territory, and are therefore reliant on drugs imported from elsewhere to fulfil the needs of their patients. The WTO Decision on the implementation of Paragraph 6 of the Doha Declaration recognizes the parallel importation of drugs for the purposes of public health for countries lacking domestic

\footnotetext{
${ }^{478}$ Carsten Fink, 'Entering the Jungle of Intellectual Property Rights Exhaustion and Parallel Importation' in Keith E Maskus, Carsten Fink (eds), Intellectual Property and Development: Lessons from Recent Economic Research (World Bank \& OUP, 2005), 176.

${ }^{479}$ Margaret K Kyle, 'Parallel trade in pharmaceuticals: Firm responses and competition policy' in Barry E Hawk (ed), International Antitrust Law \& Policy: Fordham Competition Law (Juris Publishing, 2009), 339.

480 Kyle (2009), 345.

${ }^{481}$ Sell (2007), 44.

${ }^{482}$ World Intellectual Property Organization, Exceptions and Limitations to Patent Rights: Exhaustion of Patent Rights, Document SCP/21/7 (October 6, 2014), 2.

${ }^{483}$ Correa (2002), 17; Alexander J Stack, 'TRIPS, Patent Exhaustion and Parallel Imports' (2005) 1(4) Journal of World Intellectual Property 657, 657.
} 
manufacturing capacity as legitimate. ${ }^{484}$ If these countries wish to grant compulsory licenses to import drugs from other countries which are bound by strict provisions on IPR exhaustion, the stricter exhaustion regimes could prove to be an additional hurdle for obtaining generics in countries which are already reliant on external assistance. Thus, strict exhaustion provisions in FTAs disproportionately restrict the ability of countries lacking in manufacturing capabilities to utilise legitimate measures such as compulsory licences to import drugs to meet their population's health needs. ${ }^{485}$

\subsection{Canada in the TPP renegotiation}

Curiously, in the aftermath of the US withdrawal from the TPP, the pushback against the USimposed intellectual property regime in the TPP was spearheaded by Canada, which had previously aligned itself closely with the US in TPP negotiations. The 2015 Canadian federal election saw the Liberal Party, headed by Justin Trudeau, defeat the Conservative Party led by incumbent Prime Minister Stephen Harper. Widely regarded as a shift in Canadian politics, the 2015 electoral result could prove to be of special interest for developing countries interested in issuing compulsory licences or otherwise using TRIPS flexibilities to provide cheaper medicines to their citizens. ${ }^{486}$ Under Harper, the Canadian government had expressed positive feelings about the original text of the TPP, with the Prime Minister lauding the deal as "without any doubt whatsoever, in the best interests of the Canadian economy". ${ }^{487}$

The 2015 election signalled a shift in tone from the Canadian government on global development issues, towards a more development-oriented approach. ${ }^{488}$ The renewed TPP negotiations therefore constituted the perfect opportunity for a statement of intent on these issues. Indeed, Canada took a leading role in rebalancing the TPP intellectual property

\footnotetext{
${ }^{484}$ World Trade Organization, Decision of the General Council of 30 August 2003 on Implementation of paragraph 6 of the Doha Declaration on the TRIPS Agreement and public health, WT/L/540 and Corr.1, September 1, 2003.

${ }^{485}$ See Sell (2007), 61-62.

${ }^{486}$ Norman Hillmer, Philippe Lagassé, 'The Age of Trudeau and Trump' in Norman Hillmer, Philippe Lagassé (eds), Justin Trudeau and Canadian Foreign Policy (Palgrave Macmillan, 2018), 1.

487 Janyce McGregor, 'TPP deal 'in best interests' of Canadian economy, Stephen Harper says' CBC Canada October 5, 2015.

${ }^{488}$ See Meredith B Lilly, 'International Trade: The Rhetoric and Reality of the Trudeau Government's Progressive Trade Agenda' (2018) Justin Trudeau and Canadian Foreign Policy 125.
} 
chapter, which could have promising implications for future development-oriented negotiations. ${ }^{489}$

If Canada decided to take up the mantle of being a developed country voice for inclusive global welfare more broadly, it would be ideally placed to do so. For geographical, economic, and cultural reasons, Canada has historically been one of the closest allies of the US. If the pleas of developing countries might be readily disregarded by US administrations, few US governments would be willing to ignore similar appeals from Canada. That said, the current Trump administration is likely an exception, as evidenced by the Trump administration's rhetoric and the placement of Canada on the Priority Watch List of the 2018 Special 301 Report. $^{490}$

Canadian advocacy, then, could be an influential factor for improving the negotiating positions of developing countries, especially those developing countries which lack sufficient global standing of their own. Canada has itself in the past made use of compulsory licences and compulsory licensing threats to reduce prices of drugs for its own market prior to TRIPS. ${ }^{491}$ In fact, the Eastman Commission, tasked with identifying the effects on innovation of Canada's compulsory licensing regime, noted little impact on innovation, despite around 20 compulsory licences being issued each year in Canada in the period examined by the Commission (1969-1983). ${ }^{492}$ Research by Chien suggests that this is due to Canada's relative insignificance in the worldwide market for pharmaceuticals. ${ }^{493}$ Since several of the more prolific lower- and middle-income countries which have made use of compulsory licences have similarly-sized markets, there is reason to believe that the impact of their compulsory licensing regimes on both innovation and the profit margins of pharmaceutical companies will remain low.

Canada's past propensity for compulsory licensing, together with its current repositioning on development issues, should be noted by developing countries looking into the compulsory licensing of pharmaceuticals. If developing countries were, through diplomatic and political

\footnotetext{
${ }^{489}$ Matt Peterson, 'A Glimpse of a Canadian-Led International Order', The Atlantic, January 24, 2018.

${ }^{490}$ Office of the United States Trade Representative, 2018 Special 301 Report (April 2018), 6

491 Chien (2003), 876.

492 Commission of Inquiry on the Pharmaceutical Industry, Report of The Commission of Inquiry on the Pharmaceutical Industry (1985); Chien (2003), 876-877.

${ }^{493}$ Chien (2003), 877.
} 
channels, able to more deeply engage Canada's support for compulsory licensing as a tool for improving access to medicines, this could increase the legitimacy of this practice. Although the rhetoric and promises could prove to be hollow, Canada's shifting priorities under the Trudeau government should nevertheless be of interest for developing country governments in search of allies for their policies. ${ }^{494}$

\subsection{FTA conclusions}

An increased use of compulsory licensing of pharmaceuticals in developing countries has traditionally been viewed as a threat to the income of the pharmaceutical industry by developed countries. It is therefore perhaps unsurprising that developed countries seek to include TRIPS-plus protections of intellectual property in trade agreements which restrict or preclude compulsory licensing. ${ }^{495}$ The shrinkage of development space through bilateral and plurilateral agreements presents itself here in the form of both substantive and procedural clauses, which are contained in these agreements, and which have a detrimental impact on the developing country's ability to take measures that can help achieve improved access to medicines, such as compulsory licences.

Thus, the primary effect of the scope creep of intellectual property protections in free trade agreements on compulsory licensing and other TRIPS flexibilities lies in the reduced effectiveness of these as a tool for improving access to medicines. ${ }^{496}$ Their value as a legal tool is decreased because the clauses in free trade agreements can make it more difficult for governments to issue compulsory licences, or otherwise restrict their applicability beyond the terms of TRIPS and Doha. ${ }^{497}$ As a negotiating tool, the mutual knowledge that the compulsory licence can effectively not be issued because of TRIPS-plus provision means that much of a government's leverage to induce concessions from patent holders that result in improved access to medicines through compulsory licensing threats is also lost. 498

As has been noted by academic and civil society commentators, several types of TRIPS-plus rules often found in FTAs - such as extended patent terms, data exclusivity clauses, national

\footnotetext{
${ }^{494}$ Richard Horton, 'Offline: Canada and global health-iconic or ironic?' (2018) 391 The Lancet 823.

${ }^{495}$ Susan K Sell, 'TRIPs Was Never Enough: Vertical Forum Shifting, FTAS, ACTA, and TPP' (2011) 18 Journal of Intellectual Property Law 447, 453.

${ }^{496}$ Wade (2003), 623-624.

${ }^{497}$ Sell (2007), 59-60.

${ }^{498}$ Ramani (2015), 2.
} 
exhaustion requirements and, potentially, ISDS clauses - can have a detrimental impact on access to drugs. ${ }^{499}$ Moreover, FTAs can become a vehicle for countries with economic interests in relation to the pharmaceutical industry to pre-emptively launch lengthy and costly arbitration proceedings against decisions to use TRIPS flexibilities in developing countries, potentially further stymying access through the creation of additional procedural or substantive hurdles and delays. ${ }^{500}$

In order to prevent the detrimental impact of the EU-Mercosur FTA on access to medicines, public health more generally, and additional impact on the development options available to respond to these issues, the ENSP study makes several recommendations in a bid to address the public health concerns raised by the EU proposal. ${ }^{501}$ The study calls, in particular, on the Brazilian government to reject the introduction of TRIPS-plus provisions contained in the EU proposal, and to make all efforts necessary to ensure that the TRIPS-plus measures already present in Brazil's legislation are removed. ${ }^{502}$

While these are perhaps useful suggestions in the context of the EU-Mercosur negotiations, where the EU may be willing to make some concessions on TRIPS-plus rules in exchange for a successful outcome of FTA negotiations, ${ }^{503}$ in other cases, the most powerful party may have an overwhelming negotiating position. This situation can be exploited to its advantage, such as by leaving negotiations on contentious intellectual property chapters for last, when the other parties will be less inclined to refuse stronger IPR protections for fear of losing all progress previously made, thus leaving detrimental clauses to be more easily accepted. Moreover, TRIPS-plus rules can still be introduced via other channels, such as the ill-fated Anti-Counterfeiting Trade Agreement, which was heavily backed by industry actors and sought to bunch together practices with disparate legitimacy such as counterfeiting and generic medicines. ${ }^{504}$ In sum, the global scope creep of intellectual property protections in

\footnotetext{
${ }^{499}$ Sell (2007), 59.

500 Bird (2008), 45-46; Gibson (2010), 419.

${ }^{501}$ Chaves (2017), 10, 55.

502 Chaves (2017), 55.

${ }^{503}$ Reuters Staff, 'Germany's Merkel: EU must compromise to get trade deal with Mercosur' Reuters, June 8, 2017.

504 Charles R McManis, 'The Proposed Anti-Counterfeiting Trade Agreement (ACTA): Two Tales of a Treaty' (2009) 46 Houston Law Review 1235, at 1247, 1253; Andreas Dür, Gemma Mateo, 'Public opinion and interest group influence: how citizen groups derailed the Anti-Counterfeiting Trade Agreement' (2014) 21(8) Journal of European Public Policy 1199, 1199.
} 
FTAs and other international agreements can, if unresisted, be damaging for not just access to medicines and public health systems, but also for policy responses recognised as legitimate under the TRIPS-Doha regime. 


\section{Conclusion}

Over the course of this dissertation, a narrative was built to examine the continued value of compulsory licences as a tool for effecting access to medicines. Beginning with several general considerations in relation to access to medicines, the discussion moved to the compulsory licensing regime included in the TRIPS Agreement. Compulsory licences have been a contentious instrument on the international stage since TRIPS introduced new global standards for intellectual property protection. ${ }^{505}$ The extent to which these intellectual property rules should be strictly enforced, or subject to exceptions and flexibilities, has deeply divided and continues to divide states. ${ }^{506}$ Drawing upon multiple examples in different countries, it was shown that the divisions involved developed countries taking active steps to discourage developing countries from using compulsory licences ever since TRIPS came into force.

Subsequently, the discussion turned to compulsory licensing pressure, particularly threats of compulsory licensing, as part of developing country strategies for the procurement of cheaper medicines. Brazil and Malaysia were used as case studies for examining the effectiveness of these strategies for larger middle-income countries. The different characteristics of compulsory and voluntary licensing were also examined, with reference to Gilead's voluntary licensing model. The expansion of medicine patent pools was also highlighted as a way forward which could be beneficial for all parties. ${ }^{507}$

Finally, FTAs were discussed as a further layer of restriction on compulsory licensing strategies. Through different provisions in FTAs, developed countries exercise some degree of control over the ability of developing countries to issue compulsory licences. As a result, much of the effectiveness of compulsory licensing is lost. In a similar vein, these restrictions affect the usefulness of compulsory licence threats as a bargaining tool. Considering these restrictions placed on compulsory licensing strategies, developing countries may need to pursue collective bargaining strategies to a higher degree, although organising this may prove

\footnotetext{
${ }^{505}$ Helfer (2004), 323-324.

${ }^{506}$ Contrast, for instance, the views expressed in Richard A Epstein and F Scott Kieff, 'Questioning the Frequency and Wisdom of Compulsory Licensing for Pharmaceutical Patents' (2011) 78(1) The University of Chicago Law Review 1, with the text of the Doha Declaration on TRIPS and Public Health, paragraph 4.

${ }^{507}$ See 't Hoen (2011).
} 
difficult. ${ }^{508}$ Further, partnerships with developed countries which indicate alignment on these issues could be beneficial in a bid to get further backing for the legitimacy of these developing country measures.

Access to medicines cannot continue to be viewed as a two-world issue, wherein one part of the world seeks to block, deter, or restrict measures taken to improve human health in other parts of the world. Continuing to do so damages an international legal order which recognises the right of all persons to the highest attainable standard of health. ${ }^{509}$ Actions by governments and industry actors that prevent legitimate policy-making in this area should, where possible, be resisted and strongly condemned to ensure that access to medicines for all persons, notwithstanding the circumstances of their birth, is not prevented, and a world which sees to the health and wellbeing of all people is made possible.

\footnotetext{
508 See Abbott (2007).

509 Universal Declaration of Human Rights, Article 25, read together with Article 28: "Everyone is entitled to a social and international order in which the rights and freedoms set forth in this Declaration can be fully realized."
} 


\section{Bibliography}

\section{Statutory Instruments}

World Health Organization Constitution, 1946.

United Nations General Assembly, Universal Declaration of Human Rights, United Nations, 217 (III), 1948.

United Nations General Assembly, International Covenant on Economic, Social and Cultural Rights, International Covenant on Civil and Political Rights and Optional Protocol to the International Covenant on Civil and Political Rights, 16 December 1966, A/RES/2200.

U.S. Code.

North American Free Trade Agreement, December 22, 1991

General Agreement on Tariffs and Trade, Annex 1A to the Final Act Embodying the Results of the Uruguay Round of Multilateral Trade Negotiations, Marrakesh, 15 April 1994.

TRIPS: Agreement on Trade-Related Aspects of Intellectual Property Rights, 15 April 1994, Marrakesh Agreement Establishing the World Trade Organization, Annex 1C, 1869 U.N.T.S. 299, 33 I.L.M. 1197 (1994).

Law No. 9.279 of May 14, 1996 (Law on Industrial Property) (Brazil).

Medicines and Related Substances Control Amendment Act No. 90 of 1997 (South Africa).

US Public Law 105-277 (105th Congress, 1999).

World Trade Organization, Doha Declaration on the TRIPS Agreement and Public Health, WT/MIN(01)/DEC/W/2, 14 November 2001.

World Trade Organization, Decision of the General Council of 30 August 2003 on Implementation of paragraph 6 of the Doha Declaration on the TRIPS Agreement and public health, WT/L/540 and Corr.1, September 1, 2003. World Trade Organization, Amendment of the TRIPS Agreement, WT/L/641 8 December 2005, Decision of December 6, 2005.

\section{Cases and Arbitral Awards}

Pharmaceutical Manufacturers' Association of South Africa and others v. The President of the Republic of South Africa the Honourable Mr. N.R. Mandela and Others, Case no. 4183/98, High Court of South Africa (Transvaal Provincial Division).

World Trade Organization, DS199: Brazil - Measures Affecting Patent Protection.

Philip Morris Brands Sàrl, Philip Morris Products S.A. and Abal Hermanos S.A. v. Oriental Republic of Uruguay, ICSID Case No. ARB/10/7.

Eli Lilly and Company v. The Government of Canada, UNCITRAL, ICSID Case No. UNCT/14/2.

\section{Books}

Angell M, The Truth About Drug Companies: How They Deceive Us And What To Do About It (Random House, 2005).

Devereux C, Lawrence RZ, Watkins MD, Case Studies in US Trade Negotiation Volume 1: Making the Rules (Columbia University Press, 2006).

Drahos P, Braithwaite J, Information Feudalism (Earthscan Publications, 2002).

El Said MK, Public health related TRIPS-plus provisions in bilateral trade agreements (WHO/ICTSD, 2010).

Gutner T, International organizations in world politics (2nd ed., CQ Press 2016). 
Joyner CC, International Law in the 21st Century: Rules for Global Governance (Rowman \& Littlefield, 2005).

Klabbers J, International Law (2 ${ }^{\text {nd }}$ edn, CUP, 2017).

Thirlwall AP, Economic Growth in an Open Developing Economy: The Role of Structure and Demand (Edward Elgar, 2013).

Tobin J, The Right to Health in International Law (OUP, 2012).

\section{Journal Articles and Book Chapters}

't Hoen EFM, 'TRIPS, Pharmaceutical Patents and Access to Essential Medicines: Seattle, Doha and Beyond' (2002) 3(1) Chicago Journal of International Law 39.

't Hoen EFM et al, 'Driving a decade of change: HIV/AIDS, patents and access to medicines for all' (2011) 14 Journal of the International AIDS society 1.

't Hoen EFM et al, 'Medicine procurement and the use of flexibilities in the Agreement on Trade-Related Aspects of Intellectual Property Rights, 2001-2016' (2018) 96 Bull World Health Organ 185.

Abbott FM, 'The Doha Declaration on the TRIPS Agreement and Public Health: Lighting a Dark Corner at the WTO' (2002) 5(2) Journal of International Economic Law 469.

Abbott FM, Reichman JH, 'The Doha Round's Public Health Legacy: Strategies for the Production and Diffusion of Patented Medicines Under the Amended TRIPS Provisions' (2007) 10(4) Journal of International Economic Law 921.

Akaleephan C et al, 'Extension of market exclusivity and its impact on the accessibility to essential medicines, and drug expense in Thailand: Analysis of the effect of TRIPs-Plus proposal' (2009) 91 Health Policy 174.

Attaran A, 'How Do Patents And Economic Policies Affect Access To Essential Medicines In Developing Countries?' (2004) 23(3) Health Affairs 155.

Bagchi A, 'Compulsory Licensing and the Duty of Good Faith in TRIPS' (2003) 55(5) Stanford Law Review 1529.

Baker BK, 'Leaked TPP Investment Chapter Presents a Grave Threat to Access to Medicines' (2012) Northeastern University School of Law Faculty Publications.

Baker BK, 'Corporate Power Unbound: Investor-State Arbitration of IP Monopolies on Medicines - Eli Lilly and the TPP' (2013) PIJIP Research Paper Series. Paper 36.

Bale HE, 'The Conflicts between Parallel Trade and Product Access and Innovation: The Case of Pharmaceuticals' (1998) 1 Journal of International Economic Law 637.

Barnard D, 'In the High Court of South Africa, Case No. 4138/98: The Global Politics of Access to Low-Cost AIDS Drugs in Poor Countries' (2002) 12(2) Kennedy Institute of Ethics Journal 159.

Barton JH, 'TRIPS And The Global Pharmaceutical Market' (2004) 23(3) Health Affairs 146.

Baskaran A, Boden R, 'Globalization and the commodification of science' 42-72 in Muchie M (ed), Globalization, Inequality and the Commodification of Life and Well-Being (Adonis \& Abbey, 2006).

Bass NA, 'Implications of the TRIPS agreement for developing countries: pharmaceutical patent laws in Brazil and South Africa in the 21st Century' (2002) 34(1) The George Washington International Law Review 191.

Beall R, Kuhn R, 'Trends in Compulsory Licensing of Pharmaceuticals Since the Doha Declaration: A Database Analysis' (2012) 9(1) PLoS Med.

Bello JH, Holmer AF, “'Special 301": Its Requirements, Implementation, and Significance' (1989) 13(3) Fordham International Law Journal 259.

Berman A et al, 'Curbing Unfair Drug Prices: A Primer for States by the Global Health Justice Partnership' (2017) Global Health Justice Partnership Policy Paper. 
Bermudez J, 't Hoen EFM, 'The UNITAID Patent Pool Initiative: Bringing Patents Together for the Common Good' (2010) 4 The Open AIDS Journal 37.

Beyer P, 'Developing socially responsible intellectual property licensing policies: non-exclusive licensing initiatives in the pharmaceutical sector' in De Werra J (ed), Research Handbook on Intellectual Property Licensing (Edward Elgar, 2012).

Bird RC, Cahoy DR, 'The Impact of Compulsory Licensing on Foreign Direct Investment: A Collective Bargaining Approach' (2008) 45(2) American Business Law Journal 1

Bird RC, 'Developing Nations and the Compulsory License. Maximizing Access to Essential Medicines While Minimizing Investment Side Effects' (2009) 37 Journal of Law, Medicine \& Ethics 209.

Bond E, Saggi K, 'Compulsory licensing, price controls, and access to patented foreign products' (2014) 109 Journal of Development Economics 217.

Bond P, 'Globalization, pharmaceutical pricing, and South African health policy: managing confrontation with US firms and politicians' (1999) 29(4) International Journal of Health Services 765.

Cahoy DR, 'Breaking Patents' (2011) 32(3) Michigan Journal of International Law 461.

Calfee JE, 'Pharmaceutical Price Controls and Patient Welfare' (2001) 134 Ann Intern Med 1060.

Cerón A, Godoy AS, 'Intellectual property and access to medicines: an analysis of legislation in Central America' (2009) 87 Bulletin of the World Health Organization 787.

Champ P, Attaran A, 'Patent Rights and Local Working Under the WTO TRIPS Agreement: An Analysis of the U.S.Brazil Patent Dispute' (2002) 27(2) Yale Journal of International Law 365.

Chaudry R, 'Compulsory licensing of patents in India' (2016) 5(6) Pharmaceutical Patent Analyst 401.

Chien C, 'Cheap Drugs at What Price to Innovation: Does the Compulsory Licensing of Pharmaceuticals Hurt Innovaton?' (2003) 18 Berkeley Tech L J 853.

Chopra M, Galbraith S, Darnton-Hill I, 'A global response to a global problem: the epidemic of overnutrition' (2002) 80(12) Bulletin of the World Health Organization 952.

Ciuriak D, Xiao J, Dadkhah A, 'Quantifying the Comprehensive and Progressive Agreement for Trans-Pacific Partnership' (2017) 21(4) East Asian Economic Review 344.

Cockburn I, Long G, 'The importance of patents to innovation: updated cross-industry comparisons with biopharmaceuticals' (2015) 25(7) Expert Opinion on Therapeutic Patents 739.

Cohen FJ, 'Macro trends in pharmaceutical innovation' (2005) 4 Discovery Medicine 78.

Cohen JC, Lybecker KC, 'AIDS Policy and Pharmaceutical Patents: Brazil's Strategy to Safeguard Public Health' (2005) 28 The World Economy 211.

Cohen-Kohler J, Forman L, Lipkus N, 'Addressing legal and political barriers to global pharmaceutical access: Options for remedying the impact of the Agreement on Trade-Related Aspects of Intellectual Property Rights (TRIPS) and the imposition of TRIPS-plus standards' (2008) 3 Health Economics, Policy and Law 229.

Collins-Chase CT, 'The Case against TRIPS-Plus Protection in Developing Countries Facing Aids Epidemics' (2008) 29 U Pa J Int'I L 763.

Correa CM, 'Implications of the Doha Declaration on the TRIPS Agreement and Public Health' (2002) WHO Health and Economics and Drugs EDM 12.

Correa CM, 'Implications of bilateral free trade agreements on access to medicines' (2006) 84 Bulletin of the World Health Organization 399.

Costa Chaves $\mathrm{G}$ et al, 'Strategies for price reduction of HIV medicines under a monopoly situation in Brazil' (2015) 49 Rev Saúde Pública 1. 
Cox KL, 'The Medicines Patent Pool: Promoting Access and Innovation for Life-Saving Medicines Through Voluntary Licenses' (2012) 4(2) Hastings Science \& Technology Journal 293.

Crosbie E, Sosa P, Glantz SA, 'Defending strong tobacco packaging and labelling regulations in Uruguay: transnational tobacco control network versus Philip Morris International' (2018) 27 Tobacco Control 185.

Cullet P, 'Patents and Medicines: The Relationship between TRIPS and the Human Right to Health' (2003) 79(1) International Affairs 139.

Danzon PM, Towse A, 'Differential Pricing for Pharmaceuticals: Reconciling Access, R\&D and Patents' (2003) 3(3) International Journal of Health Care Finance and Economics 183.

Desai MA, 'Compulsory licensing: Procedural requirements under the TRIPS Agreement.' (2016) 18(1-4) Pharmaceuticals Policy \& Law 31.

Diependale L, Cockbain J, Sterckx S, 'Raising the barriers to access to medicines in the developing world - the relentless push for data exclusivity' (2017) 17(1) Developing World Bioethics 11.

DiMasi JA, Hansen RW, Grabowski HG, 'The price of innovation: new estimates of drug development costs' (2003) 22 Journal of Health Economics 151.

Dosi G, Stiglitz JE, 'The Role of Intellectual Property Rights in the Development Process, with Some Lessons from Developed Countries: An Introduction' (2013) LEM Working Paper Series, No. 2013/23.

Drahos P, 'Negotiating Intellectual Property Rights: Between Coercion and Dialogue' (2002) 7 International Intellectual Property Law \& Policy 82-1.

Dukes MNG, 'Accountability of the pharmaceutical industry' (2002) 360 The Lancet 1682.

Dür A, Mateo G, 'Public opinion and interest group influence: how citizen groups derailed the Anti-Counterfeiting Trade Agreement' (2014) 21(8) Journal of European Public Policy 1199

Epstein RA and Kieff FS, 'Questioning the Frequency and Wisdom of Compulsory Licensing for Pharmaceutical Patents' (2011) 78(1) The University of Chicago Law Review 1.

Field C, 'Negotiating for the United States' in Watal J, Taubman A (eds), The Making of the TRIPS Agreement: Personal Insights from the Uruguay Round Negotiations (WTO, 2015).

Fink C, 'Entering the Jungle of Intellectual Property Rights Exhaustion and Parallel Importation' in Maskus KE, Fink C (eds), Intellectual Property and Development: Lessons from Recent Economic Research (World Bank \& OUP, 2005).

Fisher WW, Rigamonti CP, 'The South Africa AIDS Controversy: A Case Study in Patent Law and Policy' (2005) Harvard Law School: The Law and Business of Patents 1.

Flynn M, 'Public Production of Anti-Retroviral Medicines in Brazil, 1990-2007' (2008) 39(4) Development and Change 513.

Flynn SM et al, 'The U.S. Proposal for an Intellectual Property Chapter in the Trans-Pacific Partnership Agreement' (2012) 28 Am U Int'l L Rev 105.

Ford N, 'Patents, access to medicines and the role of non-governmental organisations' (2003) 1(2) Journal of Generic Medicines 137.

Ford SM, 'Compulsory Licensing Provisions Under the TRIPs Agreement: Balancing Pills and Patents' (2000) Volume 15(4) American University International Law Review 941.

Gabble R, Kohler JC, 'To patent or not to patent? the case of Novartis' cancer drug Glivec in India' (2014) 10(3) Globalization and Health.

Gad MO, 'Impact of Multinational Enterprises on Multilateral Rule Making: The Pharmaceutical Industry and the TRIPS Uruguay Round Negotiations' (2003) 9 Law and Business Review of the Americas 667. 
Galvão J, 'Access to antiretroviral drugs in Brazil' (2002) 360 The Lancet 1862.

Gana RL, 'Prospects for Developing Countries Under the TRIPs Agreement' (1996) 29(4) Vanderbilt Journal of Transnational Law 735.

Gantz DA, 'An Appellate Mechanism for Review of Arbitral Decisions in Investor-State Disputes: Prospects and Challenges' (2006) 39 Vand J Transnat'I L 39

GBD 2013 Mortality and Causes of Death Collaborators, 'Global, regional, and national age-sex specific all-cause and cause-specific mortality for 240 causes of death, 1990-2013: a systematic analysis for the Global Burden of Disease Study 2013' (2015) 385 Lancet 117.

Germano S, 'Compulsory Licensing of Pharmaceuticals in Southeast Asia: Paving the Way for Greater Use of the TRIPS Flexibility in Low-and Middle-Income Countries' (2007) 76 UKMC L Rev 251.

Gero J, Lanna K, 'Trade and Innovation: Unilateralism v. Multilateralism' (1995) 21 Canada-United States Law Journal 81.

Gibson C, 'A Look at the Compulsory License in Investment Arbitration: The Case of Indirect Expropriation' (2010) 25 American University Law Review 357.

Golec JA, Vernon JA, 'New Estimates of Pharmaceutical Research and Development Spending by US-based Firms from 1984 to 2003' (2007) 28 Managerial and Decision Economics 481.

Gomes CF, Yasin MM, Yasin Y, 'Assessing Operational Effectiveness in Healthcare Organizations: A Systematic Approach' (2010) 23(2) International Journal of Health Care Quality Assurance 127.

Grabowski HG, 'Patents, Innovation and Access to New Pharmaceuticals' (2002) 5(4) Journal of International Economic Law 849.

Guzman AT, 'Why LDCs Sign Treaties That Hurt Them: Explaining the Popularity of Bilateral Investment Treaties', (1998) 38 Va J Int'l L 639.

Haag TA, 'TRIPS Since Doha: How Far Will the WTO Go Toward Modifying the Terms for Compulsory Licensing?' (2002) 84 J Pat \& Trademark Off Soc'y 945.

Harris D, 'TRIPs after Fifteen Years: Success or Failure, as Measured by Compulsory Licensing' (2011) 18 Journal of Intellectual Property Law 367.

Hartung DM et al, 'The cost of multiple sclerosis drugs in the US and the pharmaceutical industry'. (2015) 84(21) Neurology 2185.

Harvey KJ et al, 'Will the Australia-United States free trade agreement undermine the pharmaceutical benefits scheme?' (2004) 181(5) MJA 256.

Helfer L, 'Regime Shifting: The TRIPs Agreement and New Dynamics of International Intellectual Property Lawmaking' (2004) 29 Yale Journal of International Law 1.

Helfer L, 'Pharmaceutical Patents and the Human Right to Health: The Contested Evolution of the Transnational Legal Order on Access to Medicines' in Halliday T, Shaffer G (eds), Transnational Legal Orders (Cambridge University Press, 2014).

Henry D, Lexchin J, 'The pharmaceutical industry as a medicines provider' (2002) 360 The Lancet 1590.

Hillmer N, Lagassé P, 'The Age of Trudeau and Trump' in Norman Hillmer, Philippe Lagassé (eds), Justin Trudeau and Canadian Foreign Policy (Palgrave Macmillan, 2018).

Hirono K et al, 'Is health impact assessment useful in the context of trade negotiations? A case study of the Trans Pacific Partnership Agreement' (2016) 6 BMJ Open 2016.

Hogerzeil HV et al, 'Is access to essential medicines as part of the fulfilment of the right to health enforceable through the courts?' (2006) 368 Lancet 305. 
Hollis A, Pogge T, 'The Health Impact Fund: Making new medicines accessible for all' in Hollis A, Pogge T, The Health Impact Fund: Making New Medicines Accessible for All (Incentives for Global Health, 2008).

Horton R, 'Offline: Canada and global health-iconic or ironic?' (2018) 391 The Lancet 823.

Hufbauer GC, 'Investor-State Dispute Settlement' in 'Assessing the Trans-Pacific Partnership Volume 1: Market Access and Sectoral Issues' (2016) PIIE Briefing 16-1.

Hunt $P$, 'The human right to the highest attainable standard of health: new opportunities and challenges' (2006) 100 Transactions of the Royal Society of Tropical Medicine and Hygiene 603.

Ikenson DJ, 'A Compromise to Advance the Trade Agenda: Purge Negotiations of Investor-State Dispute Settlement' (2014) Free Trade Bulletin No. 57, Cato Institute, March 4, 2014.

Islam T, 'TRIPS Agreement of the WTO: Implications and Challenges for Bangladesh' (2011) 17 Int Trade Law Reg 10.

Jamar SD, 'The International Human Right to Health' (1994) 22 SU L Rev 1.

Johnson L, Sachs L, 'The TPP's Investment Chapter: Entrenching, rather than reforming, a flawed system' (2015) CCSI Policy Paper

Kamal-Yanni M, ‘Hepatitis C drug affordability’ (2015) 3(2) Global Health 73.

Kapczynski A, 'Harmonization and Its Discontents: A Case Study of TRIPS Implementation in India 's Pharmaceutical Sector' (2009) 97(6) California Law Review 1571.

Khan MA, Zada N, Mukhopadhyay K, 'Economic implications of the Comprehensive and Progressive Agreement for Trans-Pacifc Partnership (CPTPP) on Pakistan: a CGE approach' (2018) 7(2) Economic Structures 1

Kim DD, 'Voluntary Licensing of Pharmaceuticals: The Strategy against Compulsory Licensing' (2016) 8 Intellectual Property Brief 63.

Kyle MK, 'Pharmaceutical Price Controls and Entry Strategies' (2007) 89 Review of Economics and Statistics 88.

Kyle MK, 'Parallel trade in pharmaceuticals: Firm responses and competition policy' in Hawk BE (ed), International Antitrust Law \& Policy: Fordham Competition Law (Juris Publishing, 2009)

Labonté R, Schram A, Ruckert A, 'The Trans-Pacific Partnership Agreement and health: few gains, some losses, many risks' (2016) 12(25) Globalization and Health

Lamy P, 'The Place of the WTO and its Law in the International Legal Order' (2007) 17(5) European Journal of International Law 969.

Land M, 'Rebalancing TRIPS' (2012) 33(3) Michigan Journal of International Law 433.

Lanjouw JO, 'Patents, Price Controls and Access to New Drugs: How Policy Affects Global Market Entry' (2005) National Bureau of Economic Research Working Paper No. 11321.

Light DW, 'Foreign free riders and the high price of US medicines' (2005) 331 BMJ 958.

Light DW, 'Basic research funds to discover important new drugs: Who contributes how much?' in Burke MA (ed), Monitoring the Financial Flows for Health Research 2005: Behind the Global Numbers (Global Forum for Health Research, 2006).

Lilly MB, 'International Trade: The Rhetoric and Reality of the Trudeau Government's Progressive Trade Agenda' (2018) Justin Trudeau and Canadian Foreign Policy 125.

Lima Lopes G, de Souza J, Barrios C, 'Access to cancer medications in low and middle-income countries' (2013) 10 Nat. Rev. Clin. Oncol 314.

Lin T, 'Compulsory License for Access to Medicines, Expropriation and Investor-State Arbitration under Bilateral Investment Agreements: Are There Issues beyond the Trips Agreement?' (2009) 40 International Review of Intellectual Property and Competition Law 123. 
Liu PCB, 'U.S. Industry's Influence on Intellectual Property Negotiations and Special 301 Actions' (1994) 13 UCLA Pac Basin LJ 87.

Love J, 'Recent examples of the use of compulsory licenses on patents' (2007) KEI Research Note 2007:2.

Maskus KE, 'Ensuring Access to Essential Medicines: Some Economic Considerations' (2001-2002) 20 Wisconsin International Law Journal 563.

Matthews DN, 'TRIPS flexibilities and access to medicines in developing countries: the problem with technical assistance and free trade agreements' (2005) 11 European Intellectual Property Review 420.

Mazzoleni R, Nelson RR, 'The benefits and costs of strong patent protection: a contribution to the current debate' (1998) 27 Research Policy 273.

McManis CR, 'The Proposed Anti-Counterfeiting Trade Agreement (ACTA): Two Tales of a Treaty' (2009) 46 Houston Law Review 1235.

Meier BM, Shelley D, 'The Fourth Pillar of the Framework Convention on Tobacco Control: Harm Reduction and the International Human Right to Health' (2006) 121 Public Health Reports 494.

Mercurio B, 'Resolving the Public Health Crisis in the Developing World: Problems and Barriers of Access to Essential Medicines' (2006) 5(1) Northwestern Journal of International Human Rights 1.

Mercurio B, 'Safeguarding Public Welfare? - Intellectual Property Rights, Health and the Evolution of Treaty Drafting in International Investment Agreements' (2015) 6 Journal of International Dispute Settlement 252.

Merges RP, 'Intellectual Property Rights and Bargaining Breakdown: The Case of Blocking Patents', 62 Tennessee Law Review 75

Mitchell AD, 'Good Faith in WTO Dispute Settlement' (2006) 7 Melbourne Journal of International Law 339.

Momen H, Goreti Rosa-Freitas M, 'Brazil: The Challenge of Universal Health Coverage' in Medcalf A et al (eds), Health for All: The Journey to Universal Health Coverage (Orient BlackSwan, 2015).

Morin JF, 'Tripping up TRIPS debates IP and health in bilateral agreements' (2006) 1(1-2) International Journal of Intellectual Property Management 37.

Mukherjee JS et al, 'Antiretroviral Therapy in Resource-Poor Settings: Decreasing Barriers to Access and Promoting Adherence' (2006) 43(1) Journal of Acquired Immune Deficiency Syndromes 123.

Mullin TF, 'AIDS, Anthrax, and Compulsory Licensing: Has the United States Learned Anything? A Comment on Recent Decisions on the International Intellectual Property Rights of Pharmaceutical Patents' (2002) 9 ILSA J Int'I \& Comp L 185

Munos B, 'Lessons from 60 years of pharmaceutical innovation' (2009) 8 Nature Reviews in Drug Discovery 959.

Musungu SF, Villanueva S, Blasetti R, 'Utilizing TRIPS Flexibilities for Public Health Protection Through SouthSouth Regional Frameworks', South Centre, April 2004.

Nicol D, Owoeye O, 'Using TRIPS flexibilities to facilitate access to medicines' (2013) 91 Bulletin of the World Health Organization 533.

Nolan M, 'Challenges to the Credibility of the Investor-State Arbitration System' (2016) 5 American Universities Business Law Review 429.

Nunn AS, 'Evolution of Antiretroviral Drug Costs in Brazil in the Context of Free and Universal Access to AIDS Treatment' (2007) 4(11) PLoS Medicine 1804.

Oliveira MA et al, 'Has the implementation of the TRIPS Agreement in Latin America and the Caribbean produced intellectual property legislation that favours public health?' (2004) 82(11) Bulletin of the World Health Organization 815. 
Oluduro $\mathrm{O}$ and Durojaye $\mathrm{E}$, 'The Normative Framework on the Right to Health under International Human Rights Law' in Ebenezer Durojaye (ed), Litigating the Right to Health in Africa: Challenges and Prospects (Routledge, 2016).

Outterson K, 'Pharmaceutical Arbitrage: Balancing Access and Innovation in International Prescription Drug Markets' (2005) 5(1) Yale Journal of Health Policy, Law, and Ethics 193.

Papovich JS, 'NAFTA's Provisions Regarding Intellectual Property--Are They Working as Intended--A U.S. Perspective' (1997) 23(32) Canada-United States Law Journal 253.

Perehudoff SK, Laing RO, Hogerzeil HV, 'Access to essential medicines in national constitutions' (2010) 88 Bulletin of the World Health Organization 800.

Perry G, 'Data Exclusivity-A Major Threat to Access to Affordable Medicines' (2002) Business Briefing: Pharmagenerics, 16.

Piergentili P, 'Monopoly and public health in the medication market: The case of sofosbuvir' (2017) 13(3) Journal of Generic Medicines 131.

Pogge T, 'The Health Impact Fund: Better Pharmaceutical Innovations at Much Lower Prices' in Pogge T, Rimmer M, Rubenstein K, Incentives for Global Health: Patent Law and Access to Essential Medicines (Cambridge University Press, 2010).

Puig S, 'The Internationalization of Tobacco Tactics' (2018) 28 Duke Journal of Comparative \& International Law 495.

Quick J et al, 'Twenty-five years of essential medicines' (2002) 80(11) Bulletin of the World Health Organization 913.

Raju KD, 'Compulsory v Voluntary Licensing: A Legitimate way to Enhance Access to Essential Medicines in Developing Countries' (2017) 22 Journal of Intellectual Property Rights 23.

Ramani SJ, Urias E, 'Access to Critical Medicines: When are compulsory licences effective in price negotiations?' (2015) 135 Social Science \& Medicine 75.

Ramani SJ, Urias E, 'When access to drugs meets catch-up: Insights from the use of CL threats to improve access to ARV drugs in Brazil' (2018) 47 Research Policy 1538.

Rathod SK, 'Compulsory licences on pharmaceutical patents in India: A short article' (2017) 13(3) Journal of Generic Medicines 108.

Reichman JH, Hasenzahl C, 'Non-Voluntary Licensing of Patented Inventions: Historical Perspective, Legal Framework under TRIPS, and an Overview of the Practice in Canada and the U.S.A.,' (2003) UNCTAD-ICTSD ISSue Paper No. 5.

Reidenberg JR, 'Trade, TRIPS and NAFTA' (1993) 4(1) Fordham Intellectual Property, Media and Entertainment Law Journal 283.

Reinisch A, 'The Role of Precedent in ICSID Arbitration' (2008) 2 Austrian Arbitration Yearbook 495.

Russo G, McPake B, 'Medicine prices in urban Mozambique: a public health and economic study of pharmaceutical markets and price determinants in low-income settings' (2010) 25 Health Policy and Planning 70.

Sagaon-Teyssier L et al, 'Affordability of adult HIV/AIDS treatment in developing countries: modelling price determinants for a better insight of the market functioning' (2016) 19 Journal of the International AIDS Society 1.

Saha S, 'Patent Law and TRIPS: Compulsory Licensing of Patents and Pharmaceuticals' (2009) 91 J Pat \& Trademark Off Soc'y 364. 
Santoro MA, 'Human Rights and Human Needs: Diverse Moral Principles Justifying Third World Access to Affordable HIV/AIDS Drugs' (2006) 31(4) North Carolina Journal of International Law and Commercial Regulation 923.

Scherer FM, 'A Note on Global Welfare in Pharmaceutical Patenting,' (2002) Federal Reserve Bank of Philadelphia Working Paper No. 03-11.

Schoen C et al, 'How Health Insurance Design Affects Access To Care And Costs, By Income, In Eleven Countries' (2010) 29(12) Health Affairs 2323.

Scopel CT, Chaves GC, 'Initiatives to challenge patent barriers and their relationship with the price of medicines procured by the Brazilian Unified National Health System' (2016) 32(11) Cad Saúde Publica 1.

Sell SK, 'TRIPS and the Access to Medicines Campaign' (2001) 20(3) Wisconsin International Law Journal 481.

Sell SK, 'The Quest for Global Governance in Intellectual Property and Public Health: Structural, Discursive, and Institutional Dimensions' (2004) 77 Temp L Rev 363.

Sell SK, 'Trips-plus free trade agreements and access to medicines' (2007) 28 Liverpool Law Review 41.

Sell SK, 'TRIPs Was Never Enough: Vertical Forum Shifting, FTAS, ACTA, and TPP' (2011) 18 Journal of Intellectual Property Law 447.

Serrano O, Burri M, 'Making use of TRIPS flexibilities: Implementation and diffusion of compulsory licensing regimes in Brazil and India' (2016) World Trade Institute, NCCR working paper 2016/1.

Shadlen KC, 'Exchanging Development for Market Access? Deep Integration and Industrial Policy under Multilateral and Regional-Bilateral Trade Agreements' (2005) 12(5) Review of International Political Economy 750.

Shaffer G, 'International Law and Global Public Goods in a Legal Pluralist World' (2012) 23(3) The European Journal of International Law 669.

Slade A, 'The Objectives and Principles of the WTO TRIPS Agreement: A Detailed Anatomy' (2016) 53(3) Osgoode Hall Law Journal 948.

Stack AJ, 'TRIPS, Patent Exhaustion and Parallel Imports' (2005) 1(4) Journal of World Intellectual Property 657. Stavropoulou C, Valletti T, 'Compulsory licensing and access to drugs' (2015) 16 European Journal of Health Economics 83.

Stirner B, Thangaraj H, 'Learning from practice: compulsory licensing cases and access to medicines' (2013) 2(2) Pharmaceutical Patent Analyst 195.

Sun H, 'The Road to Doha and Beyond: Some Reflections on the TRIPS Agreement and Public Health' (2004) 151 European Journal of International Law 123.

Sussex J, Towse A, Devlin N, 'Operationalizing Value-Based Pricing of Medicines' (2013) PharmacoEconomics 1.

Tang KL, Ghali WA, Manns BJ, 'Addressing cost-related barriers to prescription drug use in Canada' (2014) 186(4) Canadian Medical Association Journal 276.

Tediosi F et al, 'Access to medicines and out of pocket payments for primary care: Evidence from family medicine users in rural Tajikistan' (2008) 8 BMC Health Services Research.

Teixeira PR, Vitória MA, Barcarolo J, 'The Brazilian Experience in Providing Universal Access to Antiretroviral Therapy' in Jean-Paul Moatti et al (eds), Economics of AIDS and access to HIV-AIDS care in developing countries: issues and challenges (ANRS, 2003).

Tietje C, Baetens F, 'The Impact of Investor-State-Dispute Settlement (ISDS) in the Transatlantic Trade and Investment Partnership' (2014) MINBUZA-2014.78850. 
Torres MA, 'The Human Right to Health, National Courts, and Access to HIV/AIDS Treatment: A Case Study from Venezuela' (2002) 3(1) Chicago Journal of International Law 105.

Valletti TM, Szymanski S, 'Parallel Trade, International Exhaustion and Intellectual Property Rights: A Welfare Analysis' (2006) 54(4) Journal of Industrial Economics 49.

Vanderelst D, Speybroek N, 'Quantifying the Lack of Scientific Interest in Neglected Tropical Diseases' (2010) 4(1) PLoS Neglected Tropical Diseases, 1.

Velásquez G, 'Indonesia Government Granted 7 Compulsory Licences to promote Acces to HIV related medicines' (2012) 19(3) Vitae 1.

Villa S, Compagni A, Reich MR, 'Orphan drug legislation: lessons for neglected tropical diseases' (2009) 24 International Journal of Health Planning and Management 27.

Vogel RJ, 'Pharmaceutical Patents and Price Controls' (2002) 24(7) Clinical Therapeutics 1204, 1205.

Wade $\mathrm{RH}$, 'What strategies are viable for developing countries today? the World Trade Organization and the shrinking of 'Development Space' (2003) 10(4) Review of International Political Economy 621.

Waning B et al, 'Global strategies to reduce the price of antiretroviral medicines: evidence from transactional databases' (2009) 87 Bulletin of the World Health Organization 520.

Weissman R, 'Long, Strange Trips: The Pharmaceutical Industry Drive to Harmonize Global Intellectual Property Rules, and the Remaining WTO Legal Alternatives Available to Third World Countries' (1996) 17(4) University of Pennsylvania Journal of International Law 1069.

Wellhausen RL, 'Recent Trends in Investor-State Dispute Settlement' (2016) Journal of International Dispute Settlement 1.

Wibulpolprasert S et al, 'Government use licenses in Thailand: The power of evidence, civil movement and political leadership' (2011) 7(32) Globalization and Health.

Yamabhai I et al, 'Government use licenses in Thailand: an assessment of the health and economic impacts' (2011) 7(28) Globalization and Health.

Yamey G, 'The world's most neglected diseases: Ignored by the pharmaceutical industry and by public-private partnerships' (2002) 325 BMJ 176.

Yamin AE, 'The Right to Health Under International Law and Its Relevance to the United States' (2005) 95(7) Am J Public Health 1156.

Zhou S, 'Challenging the Use of Special 301 against Measures Promoting Access to Medicines: Options Under the WTO Agreements' (2016) 19 Journal of International Economic Law 51.

\section{Official Publications and Reports}

Amin T, 'Voluntary licensing practices in the pharmaceutical sector: An acceptable solution to improving access to affordable medicines?' (2007) Oxfam

Access to Medicine Foundation, Methodology for the 2018 Access to Medicine Index (September 22, 2017).

Angus Reid Report, Prescription drug access and affordability an issue for nearly a quarter of all Canadian households (Angus Reid Institute, July 2015).

Baker D, Jayadev A, Stiglitz JE, 'Innovation, Intellectual Property, and Development: A better set of approaches for the 21st century.' AccessIBSA (July 2017).

Commission of Inquiry on the Pharmaceutical Industry, Report of The Commission of Inquiry on the Pharmaceutical Industry (1985). 
Costa Chaves C, Britto Gaspar W, Fogaça Vieira M, 'Mercosur-EU Free Trade Agreement: Impact analysis of TRIPS-plus measures proposed by the EU on public purchases and domestic production of HIV and Hepatitis C medicines in Brazil' (2017) ENSP Fiocruz.

Department of Disease Control (Thailand), The Department of Disease Control Notification, titled 'Compulsory License for Patented Medicines and Medical Devices (November 29, 2006).

Department of Disease Control (Thailand), The Department of Disease Control Notification, titled 'Compulsory License for Patented Medicines and Medical Devices: Lopinavir/Ritonavir (January 24, 2007).

Department of Industrial Policy and Promotion (India), Intellectual Property Rights Regime in India - An Overview (January 24, 2018).

European Commission, EU Proposal on Chapter on Intellectual Property Rights (November 2016).

Fogaça Vieira M, Costa Chaves G, The Patent Paradox in Brazil - implications for purchases of medicines by the public health system, Access IBSA (March 2018).

International Federation of Pharmaceutical Manufacturers \& Associations, Export Manufacturing Exemption During SPC/PTR Extended Patent Term: Global Position, Policy Position (September 19, 2016$).$

International Federation of Pharmaceutical Manufacturers \& Associations, The Pharmaceutical Industry and Global Health: Facts and Figures 2017 (February 2017).

International Federation of Pharmaceutical Manufacturers and Associations, IFPMA Statement at WHA 71 on agenda item 11.5 Addressing the global shortage of, and access to, medicines and vaccines (May 23, 2018).

Joint UN Programme on HIV/AIDS, Towards Universal Access: Scaling up priority HIV/AIDS interventions in the health sector (World Health Organisation, 2008).

Jones Day, 'Treaty Protection for Global Patents: A Response to a Growing Problem for Multinational Pharmaceutical Companies' (October 2012).

Khanna R et al, Letter to the Department of Health and Human Services Secretary Alex Azar, February 15, 2018.

Kieny MP (Assistant Director-General, Health Systems and Innovation, World Health Organization), Letter to Alejandro Gaviria Uribe (Minister of Health and Social Protection, Colombia), May 25, 2016.

Liebermann JI et al, Letter to USTR Susan F Schwab, March 20, 2007.

Love J, Letter to Ambassador Robert Lighthizer, Knowledge Ecology International, March 14, 2018.

Médecins sans Frontières, Oxfam Canada, Canadian HIV-AIDS Legal Network, Interagency Coalition on AIDS and Development, Canadian Council for International Cooperation, and Canadian Treatment Action Council, An Open Letter to All Members of Parliament (25 October 2001).

Brazil Ministry of Health (Brazil), Ministry of Health announces compulsory licensing of Nelvinavir patent: official note, Ministry of Health, August 22, 2001.

Ministry of Health and Social Protection (Colombia), Resolution 2475/16 (June 14, 2016).

National Pharmaceutical Pricing Authority, Order S.O. 1039(E) (April 1, 2017).

Office of the High Commissioner for Human Rights, CESCR General comment No. 3: The Nature of States Parties' Obligations, Fifth Session of the Committee on Economic, Social and Cultural Rights (December 14, 1990).

Office of the High Commissioner for Human Rights, CESCR General Comment No. 14: The Right to the Highest Attainable Standard of Health (Art. 12), Twenty-Second Session of the Committee on Economic, Social and Cultural Rights (August 11, 2000).

Office of the United States Trade Secretary, 1999 Special 301 Report (April 1999).

Office of the United States Trade Representative, 2001 Special 301 Report (May 2001). 
Office of the United States Trade Representative, 2007 Special 301 Report (April 2007).

Office of the United States Trade Representative, 2007 Special 301 Report (April 2008).

Office of the United States Trade Representative, 2013 Special 301 Report (May 2013).

Office of the United States Trade Representative, 2017 Special 301 Report (April 2017).

Office of the United States Trade Representative, 2018 Special 301 Report (April 2018).

Outterson K, Nonrival access to pharmaceutical knowledge, January $3^{\text {rd }}, 2005$, Submission to the WHO Commission on Intellectual Property Rights, Innovation \& Public Health.

PhRMA, 'Pharmaceutical Research and Manufacturers of America (PhRMA) Special 301 Submission 2017'.

Rahman F, Thirumanyi S, 'Making sense of the WHO international viral hepatitis targets - strategising for concerted action' in Fifa Rahman (ed), At the edge of a miracle: the hepatitis C virus (HCV) in Malaysia (2017) Malaysian AIDS Council.

Scherer FM, 'The Size Distribution of Profits from Innovation' (1998) Annales D’Économie et de Statistique. No 49/50.

Tasioulas J, The Minimum Core of the Human Right to Health (2017) World Bank.

UNCTAD, IIA Issues Note No.2 Reform of investor-state dispute settlement: in search of a roadmap (June 2013).

United Nations Committee on Economic, Social and Cultural Rights, Substantive issues arising in the implementation of the International Covenant on Economic, Social and Cultural Rights, E/C.12/2000/4 (11 August 2000).

United Nations General Assembly, Right of everyone to the enjoyment of the highest attainable standard of physical and mental health, A/71/304 (August 5, 2016).

United Nations High-Level Panel on Access to Medicines, Report of the United Nations Secretary General's High-Level Panel on Access to Medicines (United Nations, September 2016).

United States House of Representatives, Trade Agreements and Access to Medications under the Bush Administration, Committee on Government Reform - Minority Staff Special Investigations Division, prepared for Rep. Henry A. Waxman (June 2005).

United States International Trade Commission, Economic Impact of Trade Agreements Implemented Under Trade Authorities Procedures, 2016 Report (June 2016).

World Health Organization, Health in 2015: from MDGs, Millennium Development Goals to SDGs, Sustainable Development Goals (2015).

World Intellectual Property Organization, Exceptions and Limitations to Patent Rights: Exhaustion of Patent Rights, Document SCP/21/7 (October 6, 2014).

World Trade Organization 2018, Mainstreaming trade to attain the Sustainable Development Goals (ITC/UNCTAD/WTO, 2018).

\section{News Articles and Press Releases}

Bajaj V, Pollack A, 'India Orders Bayer to License a Patented Drug' New York Times, March 12, 2012.

Baker BK, 'Don't be afraid of compulsory licenses despite US threats: Special 301 Reports 1998-2017 - listing concerns but taking little action', InfoJustice February 20, 2018.

Beasley D, 'Pfizer hikes U.S. prices for over 100 drugs on January 1' Reuters, January 9, 2016.

Julia Belluz, 'How the Trans-Pacific Partnership could drive up the cost of medicine worldwide', Vox, October 5 , 2015. 
Brazilian Ministry of Health Press Release, Brasil decreta licenciamento compulsório do Efavirenz, May 4, 2007. Brennan Z, 'Malaysia Issues Compulsory License for Gilead Hepatitis C Drug', Regulatory Focus, September 15, 2017.

Colin Packham C, 'Final version of Trans-Pacific trade deal released, rules pushed by U.S. on ice', Reuters, February 21, 2018.

Crow D, Ben-Zion I, 'Teva plans 'risky' price rise on US medicines' Financial Times, December 17, 2017.

Dennis B, 'Prescription drug prices jumped more than 10 percent in 2015, analysis finds' The Washington Post, January 11, 2016.

DNDi Press Release, 'New affordable hepatitis C combination treatment shows 97\% cure rate', April 12, 2018.

European Commission Press Release, Ecuador joins EU-Colombia/Peru trade agreement, November 11, 2016.

Harmon A, Pear R, 'A nation challenged: the treatment; Canada overrides patent for Cipro to treat Anthrax' New York Times, October 19, 2001.

Inside U.S. Trade, 'USTR Signals Support for Longer Data Protection for Biologics in TPP', Inside U.S. Trade, 27 May, 2011.

Khor M, 'Action at last on Hepatitis C?', The Star, September 11, 2017.

Kulkarni K, Foy H, 'Analysis: India cancer ruling opens door for cheaper drugs' Reuters, March 13, 2012

Love J, 'Merck, USTR ask Thailand to Reconsider Compulsory License on AIDS Drug' Huffington Post, December $18,2006$.

Love J, 'Senator Lieberman and Four Others Rap Thailand Compulsory Licenses on Non-AIDS Drugs' Huffington Post, April 2, 2007.

Maneerungsee W, Arunmas P, ‘Drug dispute could lead to trade trouble’ Bangkok Post, April 30, 2007.

McNeil DG, 'India Alters Law on Drug Patents' New York Times, March 24, 2005.

Markandya S, 'Timeline of Trade Disputes involving Thailand and access to medicines' KEI Online, July $23,2001$.

McGregor J, 'TPP deal 'in best interests' of Canadian economy, Stephen Harper says' CBC Canada October 5, 2015.

Pharmaceutical Research and Manufacturers of America, PhRMA Applauds USTR Action Against Argentina and Brazil, Press Release May 1, 2000.

Rahman F, 'Malaysia Inclusion In Gilead Voluntary Licence - A Product Of Compulsory Licence Pressure', Intellectual Property Watch, August 24, 2017.

Rampton R, Vey JB, 'G7 agrees to fight protectionism as Trump threatens allies on trade' Reuters, June 9, 2018. Ramsey L, 'We just experienced the largest rise in drug costs in 24 years' Business Insider, October 18, 2016. Rautray S, 'Nexavar Licence Case: SC dismisses Bayer's appeal against HC decision' India Times, December 13, 2014.

Reuters Staff, 'India defends right to issue drug 'compulsory licenses" Reuters, March 23, 2016.

Reuters Staff, 'Germany's Merkel: EU must compromise to get trade deal with Mercosur' Reuters, June 8, 2017.

Robbins R, 'Gilead hikes price of HIV therapies, other drugs by up to 10 percent' STAT News, July 1, 2016.

Matt Peterson, 'A Glimpse of a Canadian-Led International Order', The Atlantic, January 24, 2018.

Siddiqui Z, 'India defends right to issue drug 'compulsory licenses" Reuters, March 23, 2016. 
Silverman E, 'US pressures Colombia over plan to sidestep patent for a Novartis drug' STAT News, May 11, 2016.

Smith D, 'Trump withdraws from Trans-Pacific Partnership amid flurry of orders', The Guardian, January 23, 2017.

Thomas Z, Swift T, 'Who is Martin Shkreli - 'the most hated man in America'?' BBC News, August 4, 2017.

The Economist, 'Patent problems pending' The Economist, October $25^{\text {th }}, 2001$.

Tribble Kaiser SJ, 'Louisiana proposes tapping a century-old patent law to cut hepatitis C drug prices' Washington Post, May 2, 2017.

Truveris Press Release, 'Prescription Drug Prices Continue to Climb, Soaring 8.77\% in Latest Truveris NDI Report' Truveris, May 10, 2017.

World Intellectual Property Organization Press Release, 'WIPO, WHO and WTO Directors General Pledge Further Cooperation on Innovation and Public Health' WIPO, February 27, 2018.

\section{Online Resources}

Electronic Frontier Foundation, 'Trans-Pacific Partnership Agreement', Electronic Frontier Foundation, $<$ https://www.eff.org/issues/tpp > accessed 18/06/2018.

European Commission, 'Report from the XXXth round of negotiations of the Trade Part of the Association Agreement between the European Union and Mercosur', November 27, 2017 EC Directorate General Trade $<$ http://trade.ec.europa.eu/doclib/docs/2017/november/tradoc 156408.pdf > accessed 12/12/2017.

Global Polio Eradication Initiative, History of Polio, <http://polioeradication.org/polio-today/history-of-polio/> accessed 26/05/2018.

Jewell C, Gilead Targets Elimination of Hepatitis C, World Intell Prop Org Magazine (February 2015) <http://www.wipo.int/wipo magazine/en/2015/01/article 0001.html> accessed 25/03/2018.

Gilead Sciences, License Agreement between Gilead and Licensee app. 1 (Sept. 15, 2014), 1, available at https://www.gilead.com/ /media/files/pdfs/other/2014 original hcv licensing agreement.pdf?la=en accessed 11/04/2018.

Medicines Patent Pool, 'Our Work' <https://medicinespatentpool.org/what-we-do/our-work/> accessed $16 / 06 / 2018$.

Sustainable Development Goal (SDG) 3, 'Ensure healthy lives and promote wellbeing for all at all ages' $<$ https://sustainabledevelopment.un.org/sdg3 > accessed 27/06/2018.

World Bank, 'FAQs: Global Poverty Line Update' September 30, 2015 <http://www.worldbank.org/en/topic/poverty/brief/global-poverty-line-faq> accessed 27/06/2018.

World Bank, 'WDI 2017 Maps' <https://data.worldbank.org/products/wdi-maps> accessed 19/06/2018.

World Intellectual Property Organization, 'International Exhaustion and Parallel Importation' $<$ http://www.wipo.int/sme/en/ip business/export/international exhaustion.htm> accessed 12/02/2018.

World Trade Organization, Compulsory licensing of pharmaceuticals and TRIPS

$<$ https://www.wto.org/english/tratop e/trips e/public health faq e.htm > accessed 13/06/2018.

World Trade Organization, The Doha Declaration Explained,

<https://www.wto.org/english/tratop e/dda_e/dohaexplained e.htm> accessed January 16, 2017.

World Trade Organization, Intellectual Property Council debates access to medicines, November 8-9, 2016

<https://www.wto.org/english/news e/news16 e/trip 08nov16 e.htm> accessed 16/06/2018. 
World Trade Organization, Responding to least developed countries' special needs in intellectual property, <https://www.wto.org/english/tratop e/trips e/ldc e.htm> accessed January 16, 2017. 